$$
\begin{gathered}
\text { UnB - UNIVERSIDADE DE BRASÍLIA } \\
\text { FGA - FACULDADE GAMA } \\
\text { PROGRAMA DE PÓS-GRADUAÇÃO EM ENGENHARIA } \\
\text { BIOMÉDICA }
\end{gathered}
$$

MÓDULO PARA MEDIÇÃO E CONTROLE DA TEMPERATURA NO ESÔFAGO DURANTE O PROCEDIMENTO DE ABLAÇÃO CARDÍACA

SYLVIA DE SOUSA FARIA

ORIENTADOR: Dr. ADSON FERREIRA DA ROCHA CO-ORIENTADORA: Dra. SUÉLIA DE S. R. FLEURY ROSA

DISSERTAÇÃO DE MESTRADO EM ENGENHARIA BIOMÉDICA

BRASÍLIA/DF: JANEIRO - 2018

UnB - UNIVERSIDADE DE BRASÍLIA 


\section{UNIVERSIDADE DE BRASÍLIA \\ FACULIDADE UNB GAMA \\ ENGENHARIA BIOMÉDICA}

\section{"MÓDULO PARA MEDIÇÃO E CONTROLE DA TEMPERATURA NO ESÔFAGO DURANTE O PROCEDIMENTO DE ABLAÇÃO CARDÍACA"}

\section{SYLVIA DE SOUSA FARIA}

DISSERTAÇÃO DE MESTRADO SUBMETIDA À FACULDADE UNB GAMA DA UNIVERSIDADE DE BRASÍLIA, COMO PARTE DOS REQUISITOS NECESSÁRIOS PARA A OBTENÇÃO DO TÍTULO DE MESTRE EM ENGENHARIA BIOMÉDICA.

APROVADA POR:

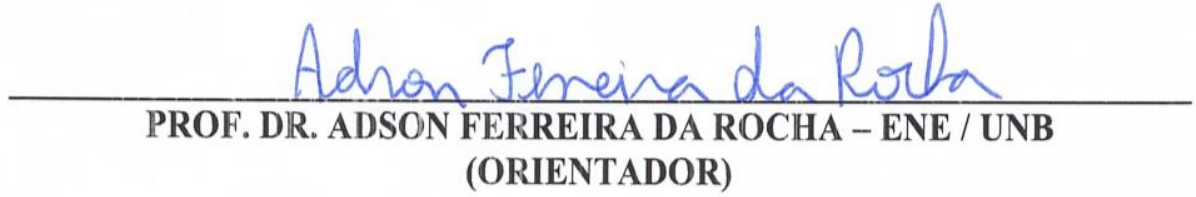

PROFA. DRA. SUÉLIA DE SIQUEIRA RODRIGUES FLEURY ROSA - FGA / UNB (COORIENTADORA)

Pistians Aacaues Miong

PROF. DR. CRISTIANO JACQUES MIOSSO ROORIGUES MENDES - FGA / UNB (EXAMINADOR INTERNO)

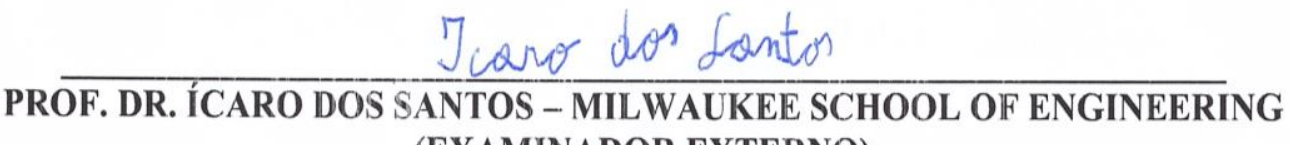
(EXAMINADOR EXTERNO) 


\section{FICHA CATALOGRÁFICA}

\section{Sylvia de Sousa Faria}

Módulo para medição e controle da temperatura no esôfago durante o procedimento de ablação cardíaca, [Distrito Federal] 2018.

No.p. 68, 210 x 297 mm (FGA/UnB Gama, Mestre, Engenharia Biomédica, 2018). Dissertação de Mestrado - Universidade de Brasília. Faculdade Gama. Programa de PósGraduação em Engenharia Biomédica.

1. Fístula átrio-esofágica 2. Ablação Cardíaca

3. Resfriamento 4. Peltier

I. FGA UnB Gama/ UnB.

\section{REFERÊNCIA BIBLIOGRÁFICA}

FARIA, S. S. (2018). Módulo para medição e controle da temperatura no esôfago durante o procedimento de ablação cardíaca por radiofrequência. Dissertação de Mestrado em Engenharia Biomédica, Publicação 079A/2018, Programa de Pós-Graduação em Engenharia Biomédica, Faculdade Gama, Universidade de Brasília, Brasília, DF, no.p. 68.

\section{CESSÃO DE DIREITOS}

AUTOR: Sylvia de Sousa Faria

TÍTULO: Módulo para medição e controle da temperatura no esôfago durante o procedimento de ablação cardíaca

GRAU: Mestre

ANO: 2018

É concedida à Universidade de Brasília permissão para reproduzir cópias desta dissertação de mestrado e para emprestar ou vender tais cópias somente para propósitos acadêmicos e científicos. $\mathrm{O}$ autor reserva outros direitos de publicação e nenhuma parte desta dissertação de mestrado pode ser reproduzida sem a autorização por escrito do autor.

2018

FGA/UnB, St. Leste Projeção A - Gama Leste.

CEP 72444-240, Gama, DF - Brasil. 


\section{DEDICATÓRIA}

Para todos que me ajudaram nas horas mais insólitas, com amor.

Pinky: "Cérebro, o que vamos fazer esta noite?". Cérebro: "O que fazemos todas as noites, Pinky... Tentar conquistar o mundo!!!"”.

(Pinky and the Brain, 1995, Steven Spielberg.) 


\section{AGRADECIMENTOS}

Agradeço a minha família por me apoiar na decisão de realizar o mestrado, por cuidar da minha saúde física e mental, por ouvir todas as minhas indecisões, reclamações e angústias, por me manter com os pés no chão e por me receberem sempre com alegria mesmo nos dias mais difíceis. Mãe, Lays e Amora, com vocês pude aprender e crescer durante esse processo.

Também sou muito grata por ter trabalhado com dois professores e educadores excepcionais que aceitaram tentar conquistar o mundo comigo, ouviram meus questionamentos e me direcionaram para a execução do meu plano. Professor Adson, eu agradeço cada conselho, cada puxão de orelha, cada incentivo que me foi dado. Professora Suélia, eu agradeço pelo apoio emocional, pelas oportunidades e por sempre estar disposta a me ouvir e ensinar.

Agradeço à UnB por ter me proporcionado um mestrado com boas aulas, boa estrutura de aula e bons livros. Também agradeço o programa PPGEB, que me acolheu e fez do mestrado uma experiência positiva. Em especial, agradeço à secretária Denise pelo serviço prestado, pela educação e pela eficiência sempre demonstradas. Durante o mestrado recebi bolsa da FAP-DF (Fundação de Apoio a Pesquisa do Distrito Federal) e sou muito grata pelo incentivo financeiro.

Agradeço também a ajuda que recebi de meus colegas de laboratório. Em especial agradeço ao Danilo, que me ajudou tirar uma ideia do papel e a construir os moldes, ao Dilson, pelas horas incansáveis em trabalhar comigo para que eu tivesse melhor desempenho no layout do projeto, ao Pedro Inazawa, pela ajuda com o software do Arduino, ao Paulo, pela ajuda com o primeiro design da placa, e ao Guilherme e ao Bruno, por terem programado o equipamento Sofia para que eu realizasse a ablação cardíaca.

Agradeço aos laboratórios que apoiaram o desenvolvimento do meu projeto: BioEngLab, LabTVDigital, LaB e LEI. Sem a contribuição de espaço e equipamentos não seria possível alcançar os resultados que obtive.

Por fim, agradeço à minha banca examinadora do meu exame de qualificação, Professores Cristiano e Fabiano, por terem me dado bons conselhos e sugestões para a melhoria do meu trabalho. E agradeço ao Professor Ícaro pela consultoria de métodos que resultaram em um projeto bem construído. 
RESUMO

\title{
MÓDULO PARA MEDIÇÃO E CONTROLE DA TEMPERATURA NO ESÔFAGO DURANTE O PROCEDIMENTO DE ABLAÇÃO CARDÍACA
}

\author{
Autora: Sylvia de Sousa Faria \\ Orientador: Prof. Dr. Adson Ferreira da Rocha \\ Co-orientadora: Profa. Dra. Suélia de Siqueira Rodrigues Fleury Rosa \\ Programa de Pós-Graduação em Engenharia Biomédica \\ Brasília, Janeiro de 2018. \\ Palavras-chaves: fistula átrio-esofágica, ablação cardíaca, látex, resfriamento, peltier. \\ diferenças finitas.
}

A técnica mais utilizada atualmente para o tratamento da Fibrilação Atrial (FA) é a ablação cardíaca com cateter em radiofrequência (ACRF). Um dos possíveis efeitos indesejados que podem ocorrer após esse procedimento é a formação de fístula átrio-esofágica (FAE), que ocorre quando há perfuração por aquecimento da parede do átrio esquerdo, levando, em alguns casos, à formação do que pode vir a se tornar um tubo comunicante entre o átrio e o esôfago. Esse tubo pode vir a causar grave sangramento seguido por morte do paciente. Neste trabalho, foi proposta a arquitetura de um módulo esofágico que permite $\mathrm{o}$ monitoramento da temperatura, bem como o resfriamento da parede esofágica durante o ACRF. Termistores embutidos no módulo esofágico permitem a medição da temperatura, e dispositivos Peltier embutidos permitem o resfriamento da parede esofágica. Uma simulação numérica do processo de ablação foi desenvolvida para permitir uma avaliação preliminar da eficácia do módulo. A simulação utilizou o método das diferenças finitas em duas dimensões, com base na equação de biotransferência de calor de Pennes. Os resultados dessa simulação sugerem que o uso do dispositivo Peltier pode permitir a criação de uma barreira térmica (condição de contorno favorável ao aquecimento) que gera uma distribuição de temperatura que pode reduzir a formação de FAE. Para se testar o método de resfriamento proposto, foi desenvolvido um sistema físico simulado para o processo de ablação, utilizando um gel de ágar-ágar para simular o tecido biológico. O sistema também utilizou um eletrodo de ablação comercial que foi adaptado a um gerador de RF; utilizou também termistores e os respectivos circuitos de condicionamento para permitir a medida do campo de temperatura gerado. Para a realização de uma avaliação preliminar do uso do dispositivo Peltier, foi desenvolvido um tubo que permitiu convecção do lado quente do dispositivo, com o resfriamento do outro lado. O experimento desenvolvido demonstrou que o campo de temperatura gerado apresenta temperaturas de até $70^{\circ} \mathrm{C}$ em regiões próximas ao eletrodo, e que as temperaturas caem de forma efetiva à medida que o calor propagado avança em direção ao dispositivo Peltier. Em posições correspondentes à região ocupada pela parede do esôfago, observaram-se temperaturas iguais ou inferiores a $36^{\circ} \mathrm{C}$. Esses resultados sugerem que o método proposto tem bom potencial para ser efetivo na geração de um perfil mais adequado de temperatura. Primeiras versões do protótipo do módulo foram construídas usando Látex, mas os sistemas de monitoração de temperatura e de resfriamento não foram ainda embarcados no módulo. Propõe-se, como continuação deste trabalho, a continuação do desenvolvimento do módulo, e a posterior realização de testes do sistema incluindo teste em cobaias e testes clínicos. 
ABSTRACT

\title{
MODULE FOR MEASUREMENT AND TEMPERATURE CONTROL OF ESOPHAGUS DURING THE HEART ABLATION PROCEDURE
}

\author{
Author: Sylvia de Sousa Faria \\ Supervisor: Dr. Adson Ferreira da Rocha \\ Co-supervisor: Dra. Suélia de Siqueira Rodrigues Fleury Rosa \\ Post-Graduation Program in Biomedical Engineering \\ Brasília, January of 2018.
}

Key-words: atrial-esophageal fistula, cardiac ablation, latex, cooling, peltier, finite difference method.

The most commonly used technique for the treatment of Atrial Fibrillation (AF) is cardiac ablation with a radiofrequency catheter (ACRF). One of the possible undesirable effects that may occur after this procedure is the formation of an atrial-esophageal fistula (AEF), which occurs when there is perforation of the wall of the left atrium, caused by heating, leading, in some cases, to the formation of what may become a communicating tube between the atrium and the esophagus. This tube can cause severe bleeding followed by the death of the patient. In this work, we proposed the architecture of an esophageal module that allows the monitoring of temperature as well as cooling of the esophageal wall during the ACRF. Thermistors embedded in the esophageal module allow for the measurement of temperature, and embedded Peltier devices allow for cooling the esophageal wall. A numerical simulation of the ablation process was developed to allow a preliminary evaluation of the effectiveness of the module. The simulation used the finite difference method in two dimensions, based on the Penne's bioheat transfer biotransference equation. The results of this simulation suggest that the use of the Peltier device can allow the creation of a thermal barrier that generates a temperature distribution that may reduce AEF. To test the proposed method, we developed a mock system for the ablation process using an agar-agar gel to simulate the biological tissue. The system also used a commercial ablation electrode, adapted to an RF generator; we also used thermistors and the respective conditioning circuits to allow the measurement of the generated temperature field. For a preliminary evaluation of the use of the Peltier device, we developed an acrylic tube that allowed for convection of the hot side of the device, and the cooling of the cold face. The results demonstrated that the generated temperature field has temperatures up to $70^{\circ} \mathrm{C}$ in regions near the electrode and that temperatures fall effectively as the propagated heat advances towards the Peltier device. In positions corresponding to the area occupied by the esophagus wall, temperatures equal to or lower than $36^{\circ} \mathrm{C}$ were observed. These results suggest that the proposed method has good potential to be useful in generating an adequate temperature profile. First versions of the module prototype were constructed using Latex, but we have not embedded the temperature measurement and cooling systems in the module. We proposed, as future work, the continuation of the development of the cooling system, and its subsequent testing. 


\section{SUMÁRIO}

1 INTRODUÇÃ

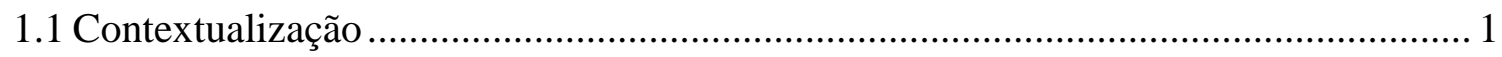

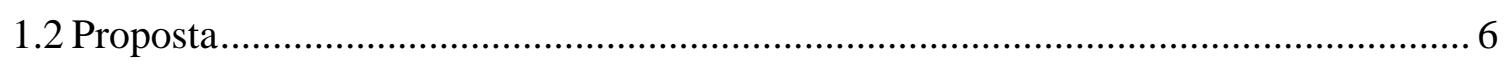

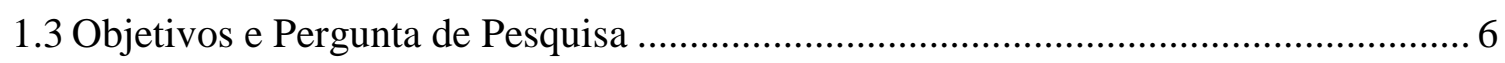

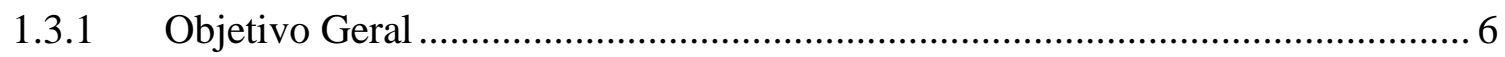

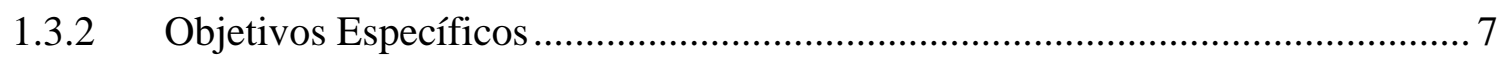

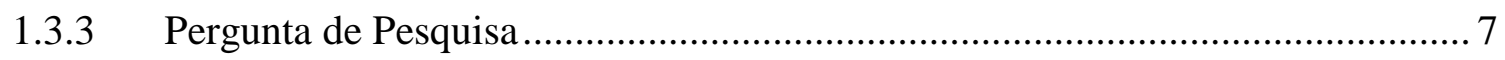

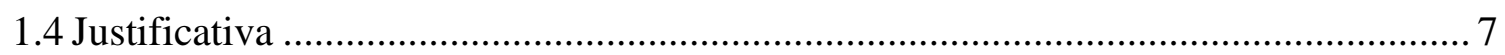

2 FUNDAMENTAÇÃO TEÓRICA .........................................................................9

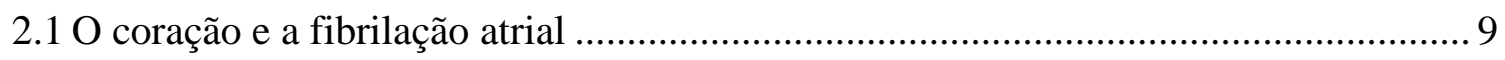

2.2 Ablação cardíaca com cateter em radiofrequência................................................... 11

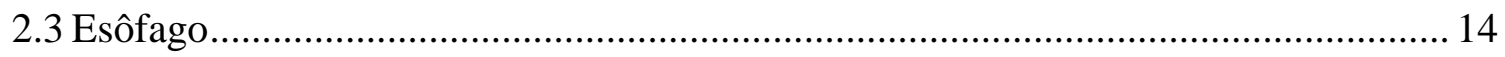

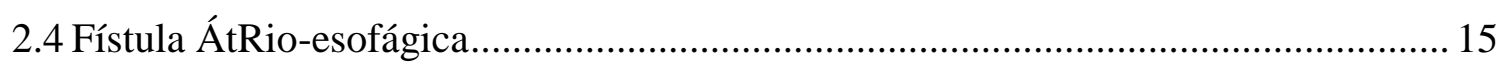

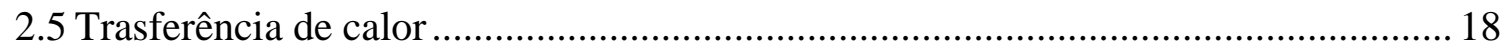

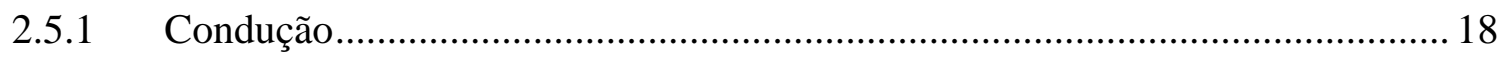

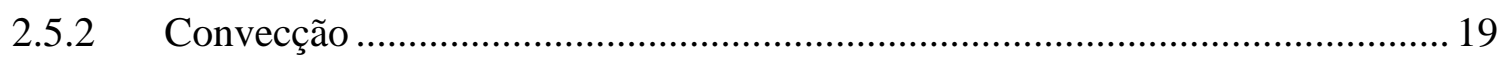

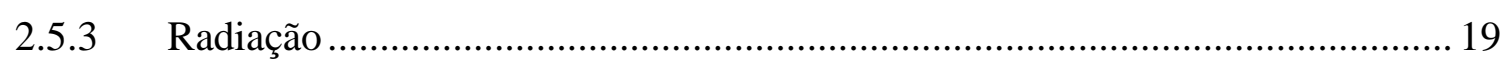

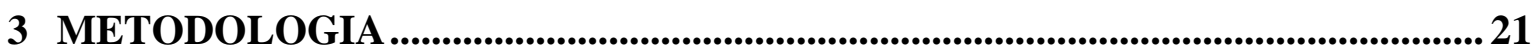

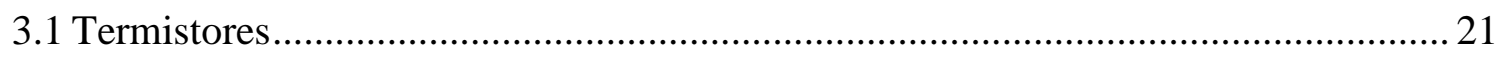

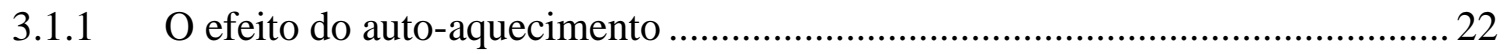

3.1.2 Circuito para aquisição de dados da temperatura............................................. 23

3.1.3 Captação da temperatura e tensão ............................................................... 25

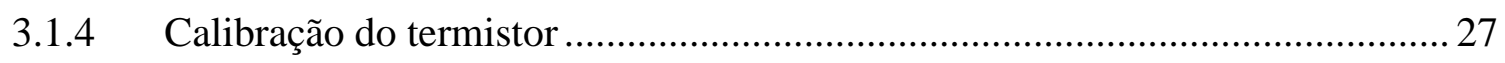

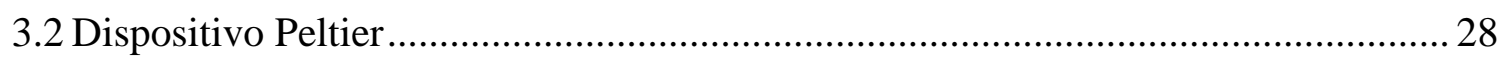

3.2.1 Determinação das temperaturas de trabalho................................................... 29

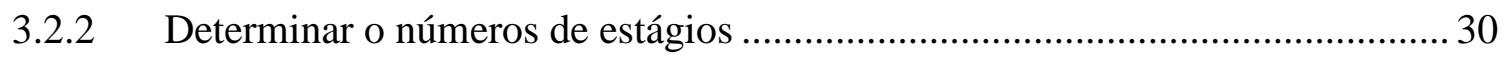

3.2.3 Especificações do modelo escolhido para o projeto......................................... 30

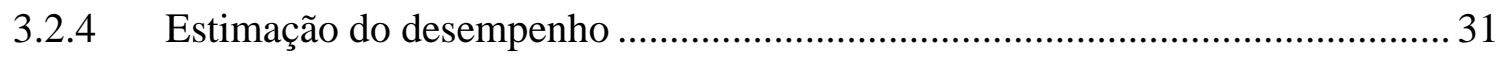

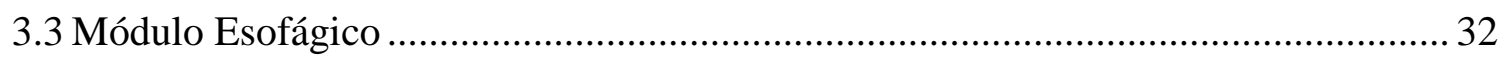

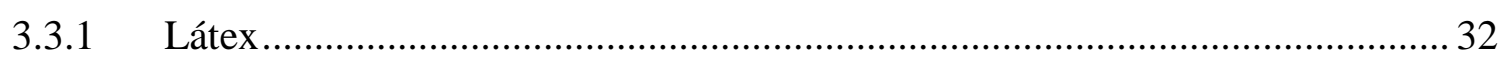

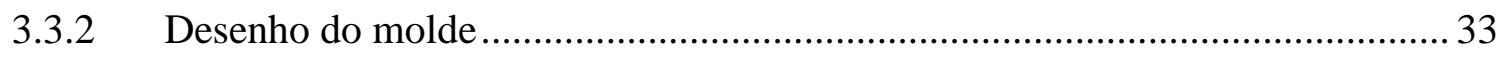




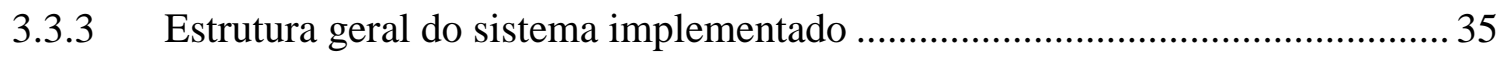

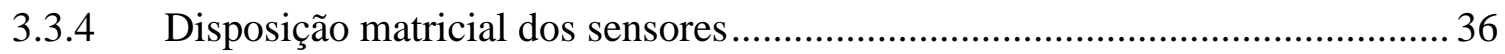

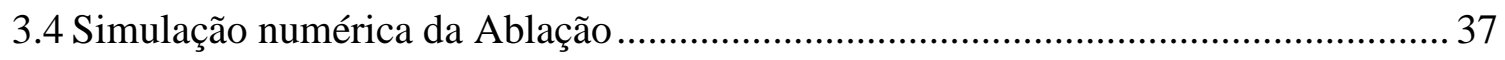

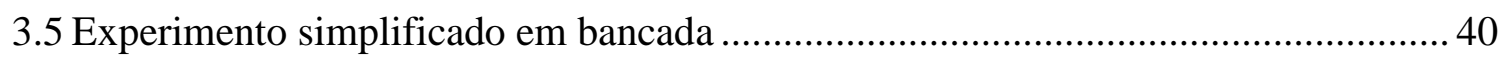

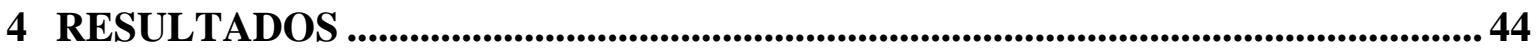

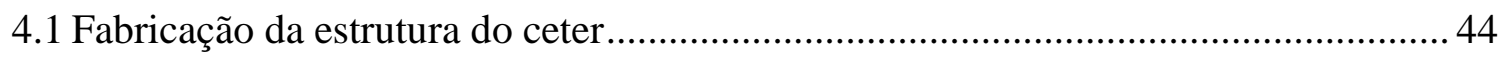

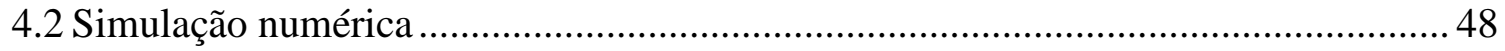

4.3 Implementação da placa do circuito........................................................................ 50

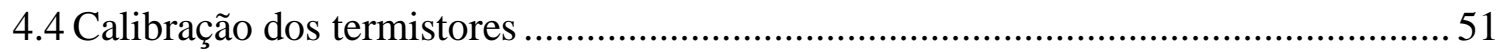

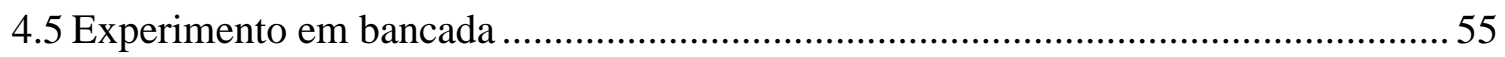

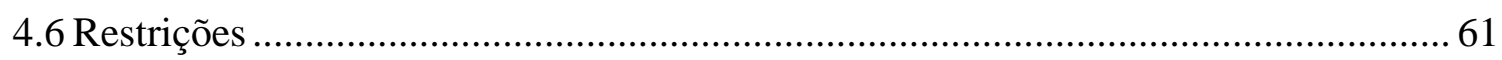

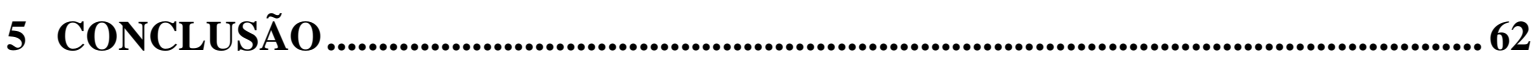

REFERÊNCIAS BIBLIOGRÁFICAS _...........................................................63

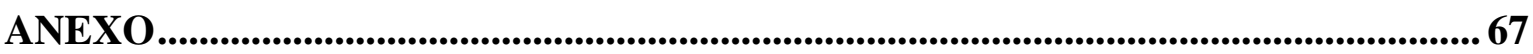

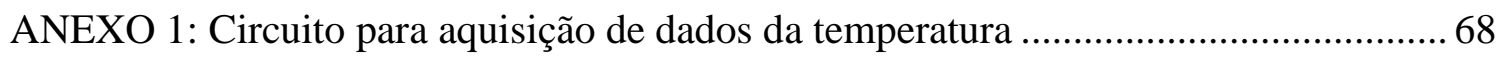




\section{LISTA DE TABELAS}

Tabela 1: - Descrição dos componentes utilizados na implementação da placa de leitura da

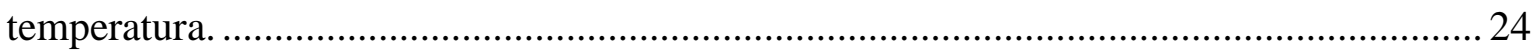

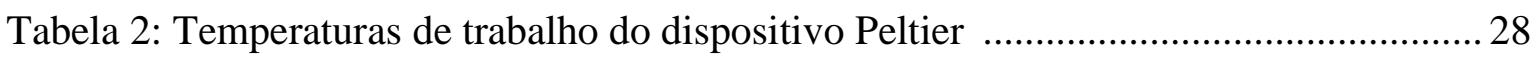

Tabela 3: Número de estágios do Peltier em relação a variação da temperatura .................29

Tabela 4: Especificações do dispositivo Peltier para o projeto................................................30

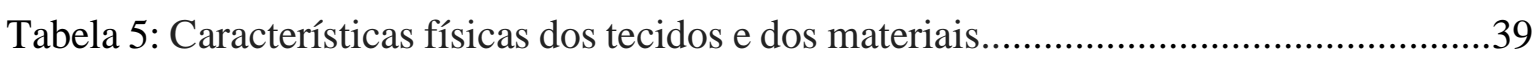

Tabela 6: Dados obtidos na calibração dos termistores.......................................................52

Tabela 7: Coeficientes dos polinômios gerados para cada termistor ................................. 53

Tabela 8: Erro RMS obtido por meio das medidas da calibração e do polinômio gerado na interpolação 56 


\section{LISTA DE FIGURAS}

Figura 1: Imagem de ressonância magnética que mostra a distribuição física dos tecidos do átrio esquerdo, esôfago e pulmão

Figura 2: Imagem de um esôfago sem fístula átrio-esofágica (A) e imagem do esôfago lesionado com $1 \mathrm{~cm}$ de fístula na parede anterior mostrando sangramento (B). 04

Figura 3: Estruturas que compõem o sistema de condução do coração e a direita estão representados os potenciais de ação..

Figura 4: Eletrocardiograma de paciente com FA; as ondas observadas são o complexo QRS e as ondas $\mathrm{T}$ ventriculares.

Figura 5: Fotografia que mostra a ACRF, com uso do eletrodo unipolar, no endocárdio do

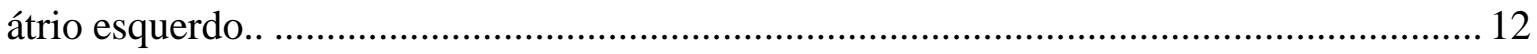

Figura 6: Esquema representando a aplicação da RF.

Figura 7: Imagens de tomografia computadorizada do tórax que mostra a relação anatômica entre o AE e o esôfago. A: corte axial. B: corte saginal..

Figura 8: Imagem de Endoscopia digestiva alta. A: Coágulo sanguíneo no esôfago. B: Ulceração no esôfago médio.

Figura 9: Localização aproximada das fístulas atrioesofágicas descritas na visão posteroanterior do átrio esquerdo. As FAE associadas à ablação RF estão distribuídas de

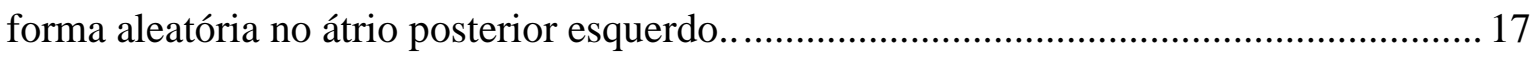

Figura 10: Termistores utilizados no projeto com fios isolados........................................ 20

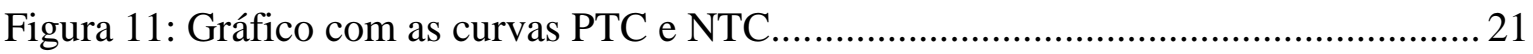

Figura 12: Circuito para captação de dados que será implementado no módulo esofágico e representa a etapa de captação da temperatura.

Figura 13: Gráfico da curva ideal para a relação tensão de saída do INA 118 com a variação de temperatura......

Figura 14: Gráfico da curva ideal para a relação da resistência no termistor com a temperatura em Kelvin....

Figura 15: Fluxograma com a rotina do software criado para a captação e armazenamento da temperatura e tensão. .26

Figura 16: Fluxograma da rotina de trabalho para a realização da calibração dos termistores.

Figura 17: Esquemático do efeito Peltier com fonte quente e fria, e a corrente gerada...... 28

Figura 18: Módulo Peltier CP60133 da empresa CUIINC................................................. 29

Figura 19: Gráfico de desempenho do módulo Peltier fornecido pelo fabricante................ 30

Figura 20: Moldes para a confecção do CETER. A: molde 1 com chanfros frontais. B: molde 2 com a parede lisa 
Figura 21: Vista frontal (A), lateral esquerda (B) e traseira (C) com cotas para a confecção

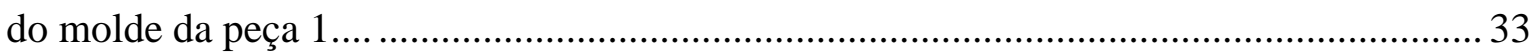

Figura 22: Vista frontal (A), lateral esquerda (B) e traseira (C) com cotas para a confecção

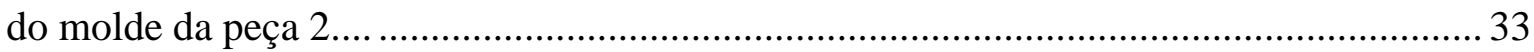

Figura 23: Simulação em 3D da confecção do molde sem sensoriamento. A: vista isométrica. B: visualização da peça 1. C: visualização da peça 2 ..................................................... 34

Figura 24: Simulação em 3D da confecção do molde com sensoriamento. A: vista isométrica. B: visualização da peça 1 . C: visualização da peça 2 .

Figura 25: Esquema da entrada e saída de água e da acomodação da fiação dos componentes. B: Corte na peça para visualização da parede interna do CETER e da localização dos furos

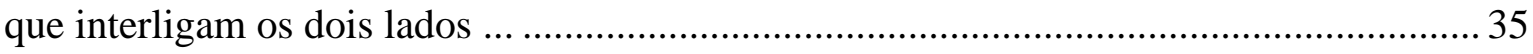

Figura 26: Disposição matricial dos sensores no CETER. ................................................ 36

Figura 27: - Representação 2D do modelo utilizado na simulação da ACRF ................... 37

Figura 28: Cateter de ablação modelo SAFIRE TX ……..................................................... 39

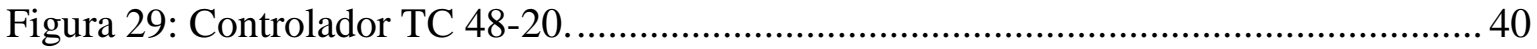

Figura 30: Termistor de referência para o controlador TC 48-20. .................................. 40

Figura 31: Esquema com detalhamento do posicionamento dos elementos necessário para o experimento simplificado com barreira de térmica e simulação da ACRF ....................... 41

Figura 32: Esquemático do experimento com distancias equidistantes entre os termistores e com o posicionamento da ponta do eletrodo .................................................................. 41

Figura 33: - Modelo 3D da disposição em bancada do experimento .................................. 42

Figura 34: Modelo 3D da disposição dos elementos para a simulação em bancada .......... 42

Figura 35: Molde de poliacetal das peças 1 e 2, da esquerda para a direita, que formam a estrutura do CETER. Com cabos para o manuseio das peças

Figura 36: Fluxograma para fabricação da estrutura do CETER com a descrição da rotina de desenvolvimento. 45

Figura 37: Látex utilizado e a formação de nata durante o descanso do látex. A: látex bi centrifugado e pré-vulcanizado da marca DU LÁTEX. B: Nata de látex se formando e bolhas. 45

Figura 38: A: banho de látex no molde. B: processo de secagem dos moldes após banho de látex. .46

Figura 39: A: estufa utilizada na fabricação da estrutura de látex. B: parte interna da estufa

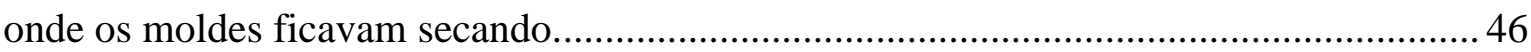

Figura 40: Implementação das peças do molde do CETER em látex..................................47

Figura 41: Versão parcial da implementação do CETER com os scalps ............................. 47

Figura 42: Esquemático da simulação numérica ............................................................ 48 
Figura 43: Gráfico da simulação numérica 2D com a condição de contorno inferior em $0^{\circ} \mathrm{C}$ $(273 \mathrm{~K})$

Figura 44: Gráfico da simulação numérica $2 \mathrm{D}$ com a condição de contorno inferior em $37^{\circ} \mathrm{C}$ $(310 \mathrm{~K})$

Figura 45: Implementação da PCB do circuito para leitura das tensões nos termistores .... 50

Figura 46: Placa final PCB do circuito para leitura das tensões nos termistores ................ 50

Figura 47: Calibração dos termistores ............................................................................. 51

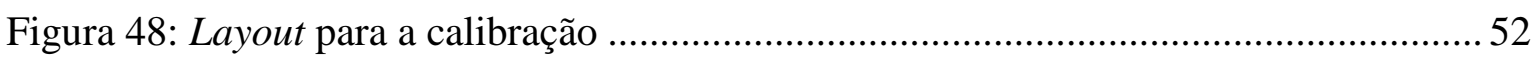

Figura 49: Gráfico dos dados obtidos na calibração dos termistores .................................. 53

Figura 50: Gráfico dos polinômios de interpolação obtidos para cada termistor ................. 54

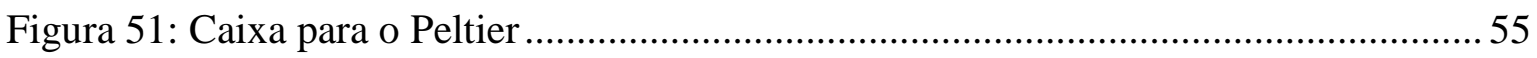

Figura 52: Primeiro teste com a caixa do Peltier, a bomba de água e o controlador............ 55

Figura 53: Segundo teste com a caixa do Peltier, a bomba de água e o controlador............ 56

Figura 54: Fixação dos termistores com distancia total de $6 \mathrm{~mm}$....................................... 57

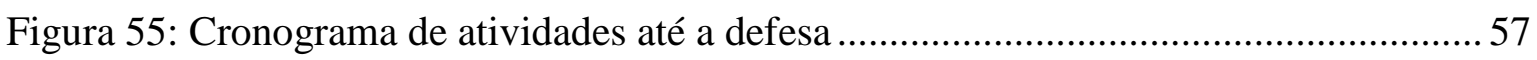

Figura 56: Implementação dos termistores com o eletrodo de ablação e a caixa do Peltier58

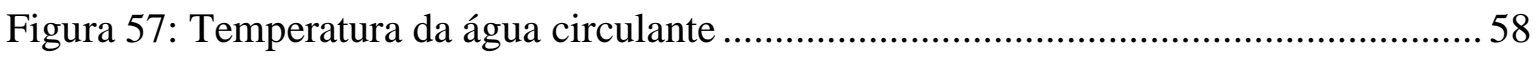

Figura 58: Imersão da caixa com os sensores no gel agar-agar......................................... 58

Figura 59: Parte do layout do experimento com o SOFIA, gel agar-agar e a caixa com os

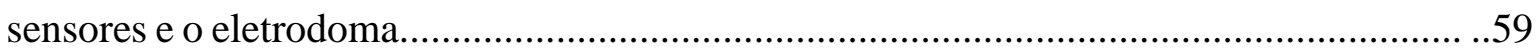

Figura 60:Parte do layout com o computador, fonte, controlador, Arduino e placa ........... 59

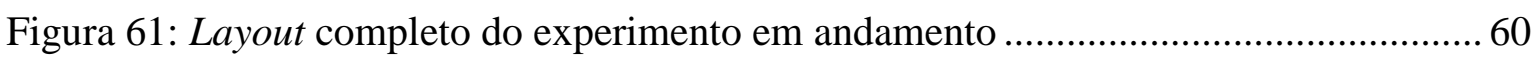

Figura 62: Gráfico do resultado do experimento em bancada. Term1 é o termistor mais próximo do Peltier e term4 o mais próximo do ablador. 60 


\section{LISTA DE NOMENCLATURAS E ABREVIAÇÕES}

AA - ablação atrial

AC - ablação por cateter

ACRF - ablação cardíaca com cateter em radiofrequência

$\mathrm{AE}$ - átrio esquerdo

$\mathrm{AV}$ - atrioventricular

AVC - acidente vascular cerebral

AVP - ablação por veias pulmonares

BioEngLab - Laboratório Engenharia e Biomaterial

bpm - batimentos por minuto

$\mathrm{BN}$ - borracha natural

CETER - controlador esofágico de temperatura e resfriamento

ECG - eletrocardiograma

FA - fibrilação atrial

FAE - fístula átrio-esofágica

FEM - método de elementos finitos

IBGE - Instituto Brasileiro de Geografia e Estatística

LaB - Laboratório de Engenharia Biomédica

ME - módulo esofágico

$\mathrm{RF}$ - Radiofrequência

$\mathrm{SA}$ - sinoatrial

UnB - Universidade de Brasília

$\mathrm{VP}$ - veias pulmonares

VPIE - veia pulmonar inferior esquerda

VPSE - veia pulmonar superior esquerda

VPID - veia pulmonar inferior direita

VPSD - veia pulmonar superior direita 


\section{INTRODUÇÃO}

\subsection{CONTEXTUALIZAÇÃO}

A Fibrilação Atrial (FA) cardíaca é a arritmia sustentada mais frequente na prática clínica [1]. É um problema de saúde pública que afeta a qualidade de vida do indivíduo devido às complicações na saúde do mesmo, e impacta o sistema de saúde, já que o tratamento hospitalar é caro. A FA está associada a problemas que geram elevado risco de morte, como a insuficiência cardíaca e eventos tromboembólicos [2].

Por ser uma doença mais comum em pessoas com mais de 50 anos, e pelo fato da expectativa de vida estar crescendo, a FA é uma doença que deve apresentar aumento de incidência ao longo dos próximos anos [3]. Segundo o estudo de Framingham [4], desde 1948 são coletados dados sobre a incidência de doenças cardíacas nos Estados Unidos, e os dados mostram que $0.4 \%$ da população geral tem FA [5] e essa porcentagem chega a cerca de $2 \%$ da população acima de 60 anos [5]. É uma doença que está diretamente relacionada à idade. Uma simulação embasada no estudo sugere que o número de pessoas com FA cresce 2.5 vezes com o envelhecimento da população americana [4]. Assim, em 2050, 5.7 milhões de pessoas deverão ter a doença [5]. O estudo hoje está na terceira geração de participantes.

O mecanismo da FA ocorre na massa muscular atrial e é independente do movimento ventricular - os ventrículos e os átrios são separados por tecido fibroso [2]. O motivo de ocorrência da FA é o aumento do volume atrial. Este ocorre por problemas valvares cardíacos que impedem que os átrios se esvaziem totalmente, enviando todo o sangue remanescente aos ventrículos, gerando hipertrofia da parede atrial [6]. Outra possível causa da FA é a insuficiência ventricular, que pode causar acúmulo de sangue nos átrios [6]. Com a alteração no funcionamento dos átrios, a atividade elétrica no coração fica desorganizada e rápida, podendo ocorrer recirculação da propagação do potencial de ação cardíaco. Essa anomalia pode causar o aumento da frequência cardíaca para até cerca de 400 batimentos por minuto (bmp) [1].

Na última década, os tratamentos mais comuns para a FA foram a ablação por meio das veias pulmonares e a ablação por cateter (AC) [1]. A ablação via veias pulmonares (VP) tinha como objetivo identificar as fibras musculares com comportamento anômalo nas VPs e em seguida desconectá-las do átrio esquerdo (AE) em pontos específicos. A AC vem se desenvolvendo e se consolidando como método terapêutico em virtude de sua segurança e eficácia. Outra possibilidade é o tratamento farmacológico, que além de caro, apresenta efeitos colaterais e questões de segurança [1].

As primeiras intervenções cirúrgicas para controlar a FA ocorreram em 1982 [3]. A técnica usava choque de desfibriladores, com corrente contínua, por meio da ablação com cateter para isolar a junção atrioventricular [7]. Essa técnica era eficaz para corrigir os problemas associados à contração atrial, mas era necessário o uso posterior de um marcapasso para corrigir a frequência cardíaca. 
Em 1991, a técnica de AC tinha como objetivo reproduzir o procedimento cirúrgico de Maze, ou labirinto. O procedimento consistia em fazer a secção, sutura e crioablação visando corrigir todas as consequências FA [7]. Apesar da tentativa de corrigir os batimentos irregulares e permitir o sincronismo atrioventricular, a técnica não conseguia evitar as consequências da ablação, como o tromboembolismo (a presença de trombos nas veias) e a fístula átrio-esofágica [1]. Em 1993 foram testadas novas técnicas como o autotransplante cardíaco como opção para substituir o procedimento de Maze. No entanto, essa técnica aumentava a chance de ocorrência de complicações no pós-operatório [7].

Em 1998, a ablação por veias pulmonares (AVP) surgiu como uma possibilidade de controlar a FA [1]. A ideia era fazer o isolamento das veias pulmonares. Isso poderia ser efetivo, pois o movimento irregular atrial pode ocorrer devido a presença de focos deflagradores dentro das veias pulmonares [8]. Esses focos geram atividade elétrica de alta frequência, que conduz para o movimento irregular dos átrios, surgindo assim a FA. Mas a técnica acabou gerando remodelamento elétrico nos átrios e perpetuando as arritmias [1], [8].

Pacientes com FA persistente têm um substrato atrial anormal devido à ocorrência da alteração no perfil elétrico atrial causado pelo tempo [8]. Nesses casos, a ablação linear e a ablação por eletrogramas fragmentados são as mais indicadas. A primeira promove a criação de linhas de bloqueio na parte superior do átrio esquerdo, no istmo mitral e no átrio direito [1]. Com esse procedimento, é possível evitar o flutter atrial - tipo de arritmia em que os átrios geram um circuito elétrico anormal [8]. A segunda técnica usa alta frequência para controlar a atividade do átrio esquerdo [1]. O desenvolvimento de novas técnicas promoveu o tratamento da FA por meio da AC.

A técnica mais utilizada hoje, primeiramente relatada em 2004 [1], é a ablação cardíaca com cateter em radiofrequência (ACRF). Com o sucesso do método de Maze, foram feitos novos testes que levaram à descoberta de que o procedimento de se gerar lesões lineares por radiofrequência teria como consequência a reindução da FA [7]. A ACRF é realizada com a introdução de um cateter pelo interior da veia de acesso comum com o objetivo de chegar ao coração, chegando ao átrio direito e ao átrio esquerdo posteriormente. O médico posiciona o cateter na posição correta com o auxílio de um fio guia e de um aparelho de raios-X.

O cateter é utilizado para gerar calor por meio de correntes elétricas com frequência na faixa de radiofrequência (RF) [1]. Com o efeito Joule gerado, mais por condução do que por radiação, a região de foco é aquecida. As temperaturas alcançadas estão entre os $60^{\circ} \mathrm{C}$ e $90^{\circ} \mathrm{C}$, mas em temperaturas superiores a $50{ }^{\circ} \mathrm{C}$ o tecido é carbonizado [9]. A potência liberada está entre 20 e $60 \mathrm{~W}$ e o tempo de aplicação é de cerca de 900 segundos, com a frequência variando entre 460 e $550 \mathrm{kHz}$ [9]. Apesar da melhora no quadro de FA, a ablação por cateter é um procedimento complexo e pode gerar complicações.

Entre variações causadas pela ACRF estão os acidentes vasculares cerebrais, o tamponamento cardíaco e a formação de fístula átrio-esofágica [1]. As fístulas átrioesofágicas são potencialmente fatais. Os acidentes vasculares cerebrais (AVCs) são as lesões causadas nos vasos sanguíneos cerebrais quando a pressão cerebral chega a valores muito 
altos [2]. Os AVCs podem levar a quadros de demência, cegueira e outros distúrbios graves [2]. O tamponamento cardíaco é o aumento da pressão intracardíaca devido ao acúmulo de líquido ou gás na parede do pericárdio [10].

Segundo Oliveira [1], a fístula átrio-esofágica (FAE) é uma complicação, geralmente fatal, da ACRF e é responsável por 18\% dos casos de morte após a ablação. O estudo afirma também que o desenvolvimento da FAE é a segunda causa mais frequente de morte em procedimentos de ACRF. Entre os pacientes com FAE, o índice de mortalidade varia entre $83 \%$ a $100 \%$ dos casos [1], [11]. Estudos recentes usando endoscopia de vigilância após ACRF para fibrilação atrial relatam vários graus de dano da mucosa esofágica em aproximadamente 15\% dos pacientes após a ACRF [1], [11], [12]. Embora a utilização de várias medidas preventivas tenha diminuído o risco de doença grave por lesão esofágica, esse risco não foi eliminado.

A FAE ocorre quando há perfuração da parede do átrio esquerdo, que é adjacente à parede anterior do esôfago [9], Figura 1. Isso ocorre porque durante o processo de ACRF podem ocorrer lesões graves no átrio e no esôfago. Anatomicamente, o esôfago desce a parede do mediastino posterior a partir do mediastino superior, passa por uma região posterior e à direita da aorta e posterior ao pericárdio e ao átrio esquerdo [2].

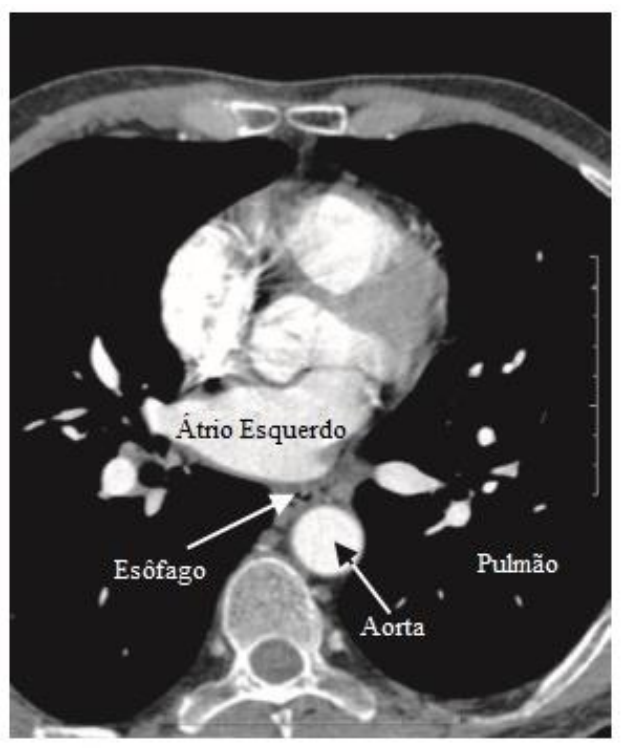

Figura 1 - Imagem de ressonância magnética que mostra a distribuição física dos tecidos do átrio esquerdo, esôfago e pulmão. (Modificado de Berjano [13])

Dessa forma, uma lesão causada no $\mathrm{AE}$ - com a necrose dos tecidos - pode lesionar a parede do esôfago unindo esses dois órgãos e criando a fístula. Uma grave hemorragia interna vai ocorrer com o sangue desviado diretamente do coração, causando a morte do paciente. A Figura 2 mostra imagens de endoscopia e compara um esôfago sem lesão com um esôfago lesionado com uma FAE de $1 \mathrm{~cm}$ e com sangramento. 

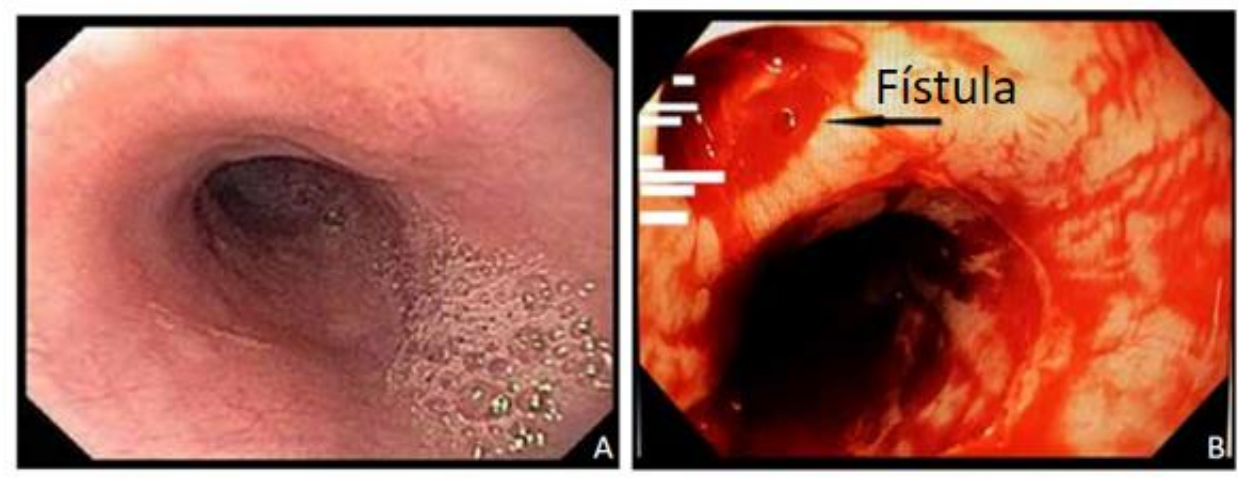

Figura 2 - Imagem de um esôfago sem fístula átrio-esofágica (A) e imagem do esôfago lesionado com fístula de $1 \mathrm{~cm}$ na parede anterior com sangramento (B). (Modificado de Khan et. al. [14])

As especificações clínicas do paciente com FAE não são precisas. Os pacientes apresentam febre, disfagia, sangramento gastrointestinal, sepse, acidentes vasculares etc. [14]. Dessa maneira, a FAE pode ser confundida com outras doenças que apresentam sintomas semelhantes. Para obter o diagnóstico preciso são realizados exames de imagem, como a endoscopia, e o resultado é determinado pelo local exato da lesão e, se diagnosticado tardiamente, o paciente é levado a óbito. A mortalidade dos pacientes com FAE é de $20 \%-$ para os pacientes que foram diagnosticados e tratados - e pode duplicar com o diagnóstico feito após 24 horas [9].

Com o objetivo de evitar o surgimento da fístula átrio-esofágica algumas estratégias podem ser adotadas, tais como: (i) limitar a energia durante a aplicação de radiofrequência; (ii) o uso de ablação por resfriamento em vez de aquecimento, por meio do processo de crioablação. O primeiro método é atualmente a forma mais comumente usada, e o segundo ainda está em estudo.

Em Oliveira [1], o método testado foi o de limitar a energia empiricamente durante o processo de ACRF na parede posterior do átrio esquerdo. O método foi eficaz como medida de prevenção de lesões esofágicas e periesofágicas após a ACRF. Os resultados preliminares do uso da crioablação, apresentados por Bahnson [15], sugerem que a forma de transmissão de calor é a mesma que em ACRF, e assim é possível que os dois métodos tenham limitações similares. No entanto, não foram encontrados na literatura trabalhos que provam que a crioablação previne lesões.

Lim et al. [16] apresentam um estudo de caso com um novo eletrodo de ablação. Em vez de utilizar um eletrodo com RF, o cateter usa um eletrodo que fornece baixas temperaturas (na faixa entre $-59^{\circ} \mathrm{C}$ e $-61^{\circ} \mathrm{C}$ ). O Cryoballon (Medtronic, Inc.), já em sua segunda geração, tem a capacidade de criar linhas continuas, um resfriamento uniforme e uma melhor oclusão nas veias pulmonares. Os resultados dos primeiros testes mostraram que a crioablação não forma tecido fibroso na camada muscular do esôfago. 
Bahnson [15] reconhece que monitorizar o aquecimento por RF no tecido cardíaco ou no esôfago tem limitações; devido a esse fato, o conhecimento sobre como se obter lesões esofágicas com características desejadas é empírico. A crioablação é um método alternativo para o tratamento de FA endocárdica e também para cirurgias de arritmia. Não é uma ablação isenta de riscos e pode apresentar lesões transmurais. Porém, relatos na literatura apresentam testes em que o procedimento permitiu a preservação da arquitetura celular e evitou a formação de fístulas evidentes, diferentemente da ACRF, que apresenta necrose do tecido transmural e formação de úlceras.

O estudo de caso de Khan et al. [14] levantou diversos fatores que causam a FAE durante o processo de ACRF. Esses fatores são: lesão térmica no esôfago; lesão enzimática; infecção de organismos externos no cateter; e dismotilidade esofágica após anestesia geral. Além disso, a anestesia geral deixa ausente o mecanismo de resfriamento fisiológico do esôfago, que resulta da deglutição, e o órgão fica mais vulnerável a lesões térmicas.

Khan et al. [14] reforçou a importância do diagnóstico imediato em lesões no esôfago. As intervenções cirúrgicas precoces podem diminuir o índice da morbidade e mortalidade. Camilleri et al. [17], usando um banco de processamento de dados com registros médicos, verificou que dos 5380 pacientes que fizeram ACRF 40 pacientes possuíam lesões no esôfago. Esse estudo concluiu que não existe um método padronizado para o tratamento e diagnóstico dos pacientes.

Alves [9] propôs um modelo matemático usando o método de elementos finitos para relacionar a temperatura do eletrodo de ablação na parede do átrio esquerdo com a temperatura dentro do esôfago. A ideia de simular a ACRF considerando a variação das estruturas de acordo com a temperatura - densidade, condutividade e perfusão - foi eficiente, mas não levou em conta a perfusão sanguínea. Um complemento poderia ser o uso de métodos probabilísticos para delimitar a área de ablação e analisar isoladamente outras formas de controle do eletrodo considerando todas as variáveis possíveis.

Cummings [18] avaliou a temperatura do tecido esofágico durante a ablação no átrio esquerdo em cães. $\mathrm{O}$ estudo feito constatou que a temperatura luminal do esôfago tem um aquecimento mais lento do que o tecido externo do esôfago. Considerando que leva aproximadamente 25 segundos para que a temperatura máxima do tecido alcance $80^{\circ} \mathrm{C}$, usando o cateter irrigado aberto, o estudo conclui que uma boa estratégia para evitar a fistula seja reduzir o tempo para 20 segundos.

Alguns biomateriais têm sido testados na tentativa de criação de novas técnicas. Um exemplo disso é o uso de látex em dispositivos. O látex natural é um biomaterial que apresenta propriedades convenientes, como elasticidade, suavidade, resistência, impermeabilidade e hipoalergenicidade [19]. Assim, moldes para a confecção de aparelhos médicos são utilizados amplamente e com baixo risco à saúde [20].

Richter [21] fez uma revisão integrativa que avalia o uso de biomembranas de látex (Hevea Brasiliensis) para realização da cicatrização de tecidos. Este estudo mostra que o látex possui propriedades cicatrizante e angiogênica, apresentando baixo custo de obtenção. 
As biomembranas possuem adaptabilidade, elasticidade, impermeabilidade e possibilidade de sutura. Também se destacam a ausência de toxidade e efeito antimicrobiano [21].

A necessidade de se modelar um módulo para o esôfago surgiu da pesquisa de Alves [9]. Nessa pesquisa foi utilizado um cateter comercial com $4 \mathrm{~mm}$ de diâmetro. A implementação dos sensores necessários foi complexa devido ao tamanho do cateter. Contudo, Rodrigues [19] implementou um módulo esofágico - módulo CFE® - que consiste em um módulo de látex com formato de balão cilíndrico para o tratamento da obesidade. Posteriormente, Paula [20] utilizou o módulo CFE® para fazer uma análise fisiológica do esôfago. Essas duas pesquisas corroboram a eficiência em criar um módulo esofágico com o látex.

\subsection{PROPOSTA}

Neste trabalho, propõe-se desenvolver um módulo esofágico que resfria o interior do esôfago, com o propósito de se evitar o aquecimento de regiões próximas ao esôfago, e testar se este resfriamento poderá ou não evitar o surgimento de fístula átrio-esofágica em decorrência do processo de ablação cardíaca por RF. Além disso, o trabalho tem como objetivo a elaboração de um modelo matemático computacional por meio de diferenças finitas da distribuição de temperatura no esôfago e do processo de resfriamento nesse órgão, para investigar se há correlação entre processo de resfriamento e a prevenção de lesões esofágicas e fístulas.

Com a motivação de melhorar a captação dos sensores no módulo esofágico, esses sensores serão posicionados na parede do eletrodo em formato matricial, que é adequado para o posicionamento dos termistores e dispositivos Peltier. O material utilizado para a fabricação do módulo esofágico é o látex da borracha natural (Hevea brasiliensis), por suas propriedades de biocompatibilidade.

Com os desenvolvimentos descritos, pretende-se analisar questões como as limitações do modelo, a propagação do calor entre o átrio e o esôfago, e os métodos para se evitar lesões.

\subsection{OBJETIVOS E PERGUNTAS DE PESQUISA}

\subsubsection{OBJETIVO GERAL}

O objetivo deste trabalho é implementar um módulo esofágico que seja capaz de resfriar, monitorar e controlar a temperatura no esôfago durante o procedimento de ablação cardíaca com cateter em radiofrequência. 


\subsubsection{OBJETIVOS ESPECÍFICOS}

Para realização do trabalho será necessário cumprir as seguintes etapas:

- implementar circuito de leitura da temperatura com termistores;

- calibrar os sensores de temperatura;

- implementar um circuito de resfriamento com o dispositivo Peltier;

- utilizar controlador de tensão para o circuito de resfriamento;

- testar em bancada a funcionalidade dos circuitos;

- programar o software de linearização da curva de temperatura;

- desenhar o módulo esofágico;

- fazer o molde para o módulo;

- implementar o módulo utilizando o látex;

- simular a ablação cardíaca numericamente usado o método de diferenças finitas;

- simular em bancada a ablação cardíaca com a tecnologia de resfriamento criada.

O trabalho não visa o desenvolvimento e teste completo do módulo, e, sim, o seu desenvolvimento parcial. O teste em bancada tem como objetivo mapear a temperatura entre átrio e esôfago. Pretende-se continuar o desenvolvimento em um posterior curso de doutoramento.

\subsubsection{PERGUNTA DE PESQUISA}

Qual é o diferencial numérico associado a monitorização da temperatura e o resfriamento do esôfago, por meio de condições de contorno favoráveis, que permitem gerar uma melhor distribuição de temperatura (evitando o aquecimento excessivo das regiões próximas à parede esofágica) durante a ACRF?

\subsection{JUSTIFICATIVA}

Apesar de ser uma consequência rara do procedimento de ablação com cateter, a fístula átrio-esofágica e as lesões na parede do esôfago são complicações graves que podem levar os pacientes a óbito. As lesões causadas no esôfago podem trazer complicações futuras como gastrites, refluxos e a disfunção vagal - que indica que houve uma lesão mais extensa no tecido. Dessa forma, evitar que essas lesões aconteçam traz um impacto forte na longevidade desse paciente.

Os tratamentos farmacológicos para problemas no coração, visando controlar a fibrilação atrial, bem como os tratamentos - posteriores à ablação - para as lesões no esôfago, são dispendiosos, causam perda da qualidade de vida e abalam a vida em sociedade desse paciente doente. Quando as lesões são mais graves e levam à necessidade de novas internações e cirurgias, a saúde pública é prejudicada com esses altos gastos, que poderiam ser evitados se técnicas mais eficazes fossem desenvolvidas. 
Portanto, o trabalho, ao obter dados que possam auxiliar no desenvolvimento de um sistema que possibilite a prevenção de lesões no esôfago, com foco em evitar a fístula átrioesofágica, pode auxiliar na busca de possíveis soluções para problemas que impactam a vida em sociedade. Esses pacientes terão uma melhor qualidade de vida, não farão usos de drogas desnecessárias e não irão onerar tanto a saúde pública com mais gastos. 


\section{FUNDAMENTAÇÃO TEÓRICA}

\subsection{O CORAÇÃO E A FIBRILAÇÃO ATRIAL}

O coração é um órgão composto de tecido muscular, que bombeia o sangue de forma a possibilitar a irrigação dos demais órgãos do corpo humano. Podemos considerar que o coração é dividido em dois lados: o coração direito e o esquerdo [2]. Cada lado possui um átrio e um ventrículo. No coração direito, o sangue é direcionado para o ventrículo direito e este o bombeia para a artéria pulmonar [22]. O ventrículo esquerdo bombeia o sangue para os órgãos periféricos.

Os batimentos cardíacos acontecem de forma ordenada [22]. Primeiro, ocorre a contração dos átrios (sístole atrial) e em seguida a contração dos ventrículos (sístole ventricular). O relaxamento e o enchimento dos átrios e ventrículos ocorre na diástole. A origem do batimento cardíaco acontece em um sistema de condução especializado e se espalha ao longo de todo o miocárdio.

Na Figura 3 pode-se ver as estruturas que compõem o sistema de condução do batimento: o nódulo sinoatrial (SA); as vias internodais; o nódulo atrioventricular (AV); o feixe de His e suas ramificações; e o sistema de Purkinje [22]. No lado direito da Figura 3 são mostrados os potenciais de ação que ocorrem nos tecidos musculares do coração e dos nódulos SA e AV. Esses potenciais são responsáveis pela geração do sinal eletrofisiológico denominado eletrocardiograma (ECG), e estão plotados em função do tempo, mas com diferentes pontos de zero na escala vertical [22].

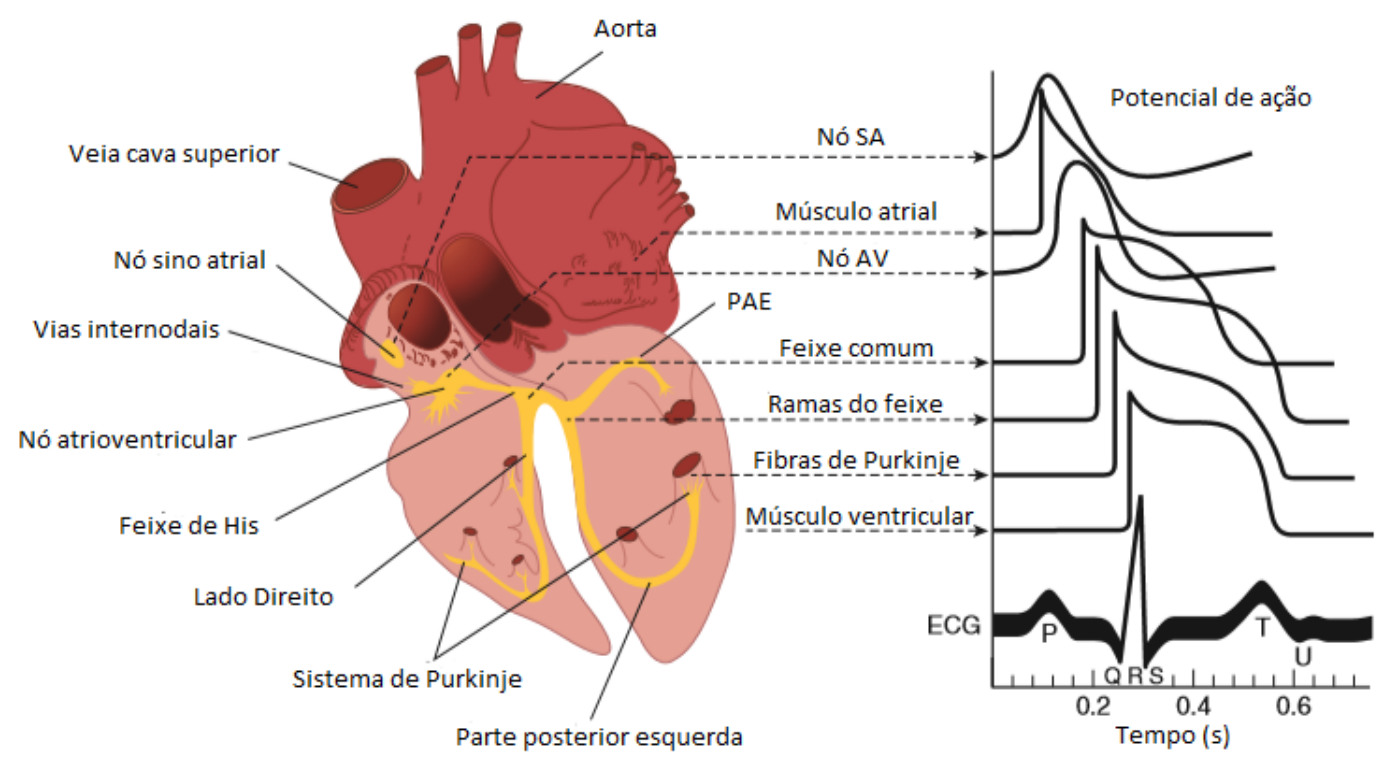

Figura 3 - Estruturas que compõem o sistema de condução do coração. No lado direito da figura estão representados os potenciais de ação. (Modificado de Barret et al. [22]) 
O nódulo SA tem a função de emitir potenciais de ação, controlando o ritmo do batimento cardíaco. Com a despolarização, tem-se o prolongamento dessas descargas espontâneas para outras regiões [2], [8]. O nódulo SA é comumente denominado marcapasso cardíaco, pois controla a frequência do coração. Impulsos gerados no nódulo SA se propagam pelo átrio, chegando ao nó $\mathrm{AV}$, onde sofrem um atraso de 0,1 segundo, e passam através deste, passando então pelo feixe de His e pelas fibras de Purkinje [22], chegando, por fim, às paredes dos ventrículos e gerando sua contração.

O músculo atrial, o músculo ventricular, e as fibras excitatórias e condutoras formam a estrutura responsável pela geração do ritmo cardíaco [22]. Os músculos atrial e ventricular apresentam algumas semelhanças com o músculo esquelético, mas possuem maior elasticidade e apresentam capacidade de contração rítmica e independente [8].

As fibras excitatórias não possuem muitas fibras contráteis e, por isso, são mais rígidas e têm pouca contratilidade [8]. Porém, essas fibras transportam descargas elétricas rítmicas pelo coração, em forma de potencial de ação, auxiliando a condução desse potencial ao longo do coração. Como visto, é o sistema excitatório - ou sistema de condução - que controla os batimentos rítmicos [2].

O mau funcionamento do coração geralmente tem início com a alteração no ritmo normal do marcapasso, com bloqueios da propagação do impulso ou com geração espontânea de estímulos indevidos [2]. Alguns tipos mais preocupantes de mau funcionamento ocorrem não em decorrência de anormalidade no músculo cardíaco, mas como resultado de anormalidade no ritmo cardíaco. Por exemplo, quando ocorre a fibrilação atrial, os batimentos dos átrios não são coordenados com os batimentos dos ventrículos, os átrios passam a não funcionar como bombas que auxiliam o enchimento dos ventrículos [2], [22].

O mecanismo da FA ocorre somente na massa muscular atrial [2]. A FA tem como causas principais o aumento do volume atrial e a insuficiência cardíaca. O primeiro acontece quando lesões valvares impedem que os átrios se esvaziem adequadamente, não conseguindo enviar a quantidade ideal de sangue aos ventrículos [8]. A insuficiência cardíaca acontece quando as paredes atriais estão dilatadas, impedindo a correta condução elétrica no átrio [2], [8].

A razão pela qual os átrios não bombeiam sangue durante a FA é a geração ou a condução incorreta das ondas de polarização no átrio, que alteram o funcionamento regular do coração. Pequenas ondas contráteis distintas propagam-se ao mesmo tempo e em diferentes direções pelo músculo cardíaco [22]. Os impulsos reentrantes na fibrilação não são simplesmente impulsos únicos que se propagam em círculos. Sendo assim, os átrios passam a não funcionar efetivamente como bombas que auxiliam ao enchimento dos ventrículos ao final da diástole.

Mesmo com a ocorrência da FA, o sangue pode fluir passivamente dos átrios e para os ventrículos. Porém, nesse caso ocorre a diminuição da eficiência do bombeamento ventricular em $20 \%$ a $30 \%$ [2]. A FA pode ser paroxística - quando a fibrilação acontece 
abruptamente e sem repetição - ou crônica [22]. A FA pode ter diversas origens. Por exemplo, a ocorrência da FA pode ter origem genética, ou ser adquirida em função do histórico clínico do paciente. A pessoa pode viver meses com FA, embora com redução da eficiência do bombeamento global do coração.

A Figura 4 mostra o eletrocardiograma (ECG) durante a fibrilação atrial. Muitas ondas pequenas de despolarização se propagam em todas as direções pelos átrios durante a fibrilação atrial [2], [22]. Como as ondas são fracas, quase se neutralizam eletricamente de maneira completa, e muitas delas têm polaridade contrária em algum momento. Logo, no eletrocardiograma não é possível, em todos os casos, observar as ondas $\mathrm{P}$ dos átrios, ou é possível apenas ver um registro ondulado fino de voltagem muito baixa com alta frequência [2]. Nessa patologia, os complexos QRS-T são normais, a menos que exista alguma patologia dos ventrículos, mas seu ritmo é irregular [2].

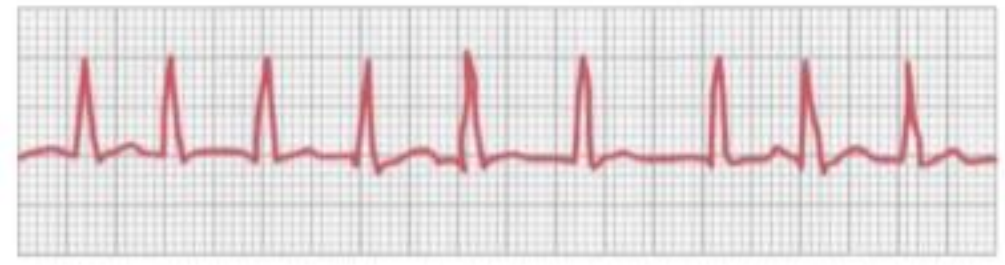

Figura 4 - Eletrocardiograma de paciente com FA; as ondas observadas são o complexo QRS e as ondas T ventriculares. (Reproduzido de Hall et al. [2])

Durante a FA, o batimento cardíaco nos átrios acontece de forma rápida, cerca de 300 a 500 batimentos/min, de maneira irregular e desordenada. Como o nó AV despolariza em intervalos regulares, os ventrículos batem em um ritmo irregular, quase sempre entre 80 e 160 batimentos/min [22]. Consequentemente, as ondas excitatórias irregulares - que são geradas a partir do ritmo cardíaco anormal - causam a FA.

Muitos fármacos são utilizados no tratamento de arritmias para se obter a diminuição da velocidade de condução do miocádio e do sistema excitatório [22]. Medicamentos podem deprimir as atividades etópicas e reduzir a discrepância entre as vias normais para que não haja re-entrada de sangue nos átrios [1]. Entretanto, em alguns pacientes o efeito dos fármacos pode ser pró-arrítmico em vez de antiarrítmico; ou pode causar outras arritmias. Por conseguinte, os remédios estão sendo cada vez mais substituídos por ablação percutânea para corrigir a arritmia [23].

\subsection{ABLAÇÃO CARDÍACA COM CATETER EM RADIOFREQUÊNCIA}

A ablação é a destruição do tecido por meios térmicos. Por isso, são utilizados princípios físicos com intuito de aquecer ou resfriar o tecido, com as seguintes técnicas: 
radiofrequência (RF), corrente elétrica, micro-ondas, laser, ultrassom e resfriamento criogênico [9]. A ablação tem várias aplicações na medicina e pode ser usada para controlar a fibrilação atrial, câncer em diversos órgãos (pulmão, fígado, rim, próstata e etc.), hemorragias e arritmias cardíacas [2].

O sistema de RF geralmente, utilizado é constituído por um gerador de potencial elétrico alternado e por um eletrodo unipolar em forma de caneta. O sistema pode ser irrigado por meio de uma bomba de infusão contínua, com solução salina fisiológica $(0.9 \%)$ para resfriar a ponta do eletrodo, que entra em contato com o miocárdio atrial, com o objetivo de reduzir o risco de lesão aos tecidos atriais e esofágicos, Figura 5.

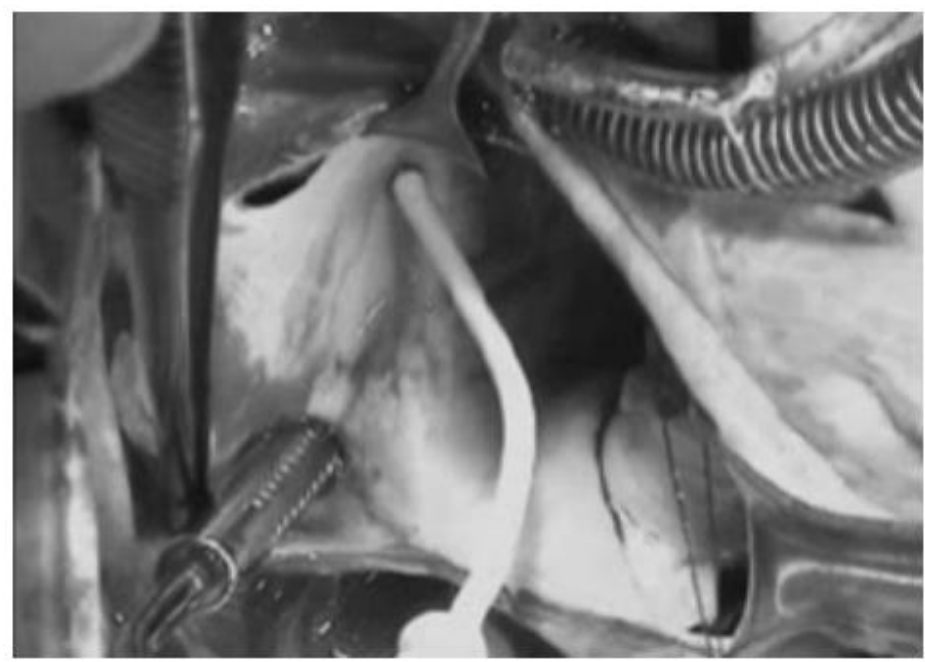

Figura 5 - Fotografia que mostra a ACRF, com uso do eletrodo unipolar, no endocárdio do átrio esquerdo. (Reproduzido de Alberto et al.[12])

O conceito de radiofrequência é usado para designar uma faixa de frequências do espectro eletromagnético [24]. Este espectro é determinado pelas frequências radiações que são emitidas. A frequência usada na ablação é de cerca de $450 \mathrm{kHz}$, que está na faixa denominada radiofrequência.

O gerador de energia opera na faixa entre 20 e $40 \mathrm{~W}$, com impedância de até 500 Ohms [12]. O aquecimento surge quando a energia dissipada por uma corrente elétrica flui por um condutor, o átrio, por exemplo, e é convertida, por efeito Joule, em energia térmica. À frequência utilizada, de cerca de $450 \mathrm{kHz}$, é gerada corrente no tecido biológico, causando aquecimento por fricção molecular, sem estimular reação neuromuscular e eletrólise sendo suficientemente baixa para confinar a transmissão energética nos tecidos sem produzir radiação excessiva [12], [23], [25]. Mesmo estando na faixa de radiofrequência, a corrente nessa frequência gera apenas corrente elétrica, gerando uma quantidade muito pequena de onda eletromagnética propagante. 
Primeiramente, uma cânula passa pela aorta ascendente e pelas veias cavas superior e inferior para que seja estabelecida uma forma de circulação extracorpórea, mantendo o paciente com $32{ }^{\circ} \mathrm{C}$. Ainda com o coração batendo, a aorta é pinçada. A partir desse momento, a ACRF começa. Nesse processo, é realizada a ressecção do apêndice atrial direito, seguida por duas incisões na parede lateral do átrio direito, uma longitudinal em direção à veia cava inferior e outra transversal.

A aplicação da RF acontece externamente, no epicárdio do átrio direito, estendendose ao local de canulação da veia cava superior até o da veia cava inferior. O próximo passo é a aplicação da RF no endocárdio do átrio direito, partindo-se da base da ressecção do apêndice atrial direito até a borda superior da válvula tricúspide. A atriotomia lateral esquerda é realizada com a exposição do interior do átrio esquerdo, seguida pela ressecção do apêndice atrial esquerdo. Ocorre então a aplicação da RF no endocárdio do átrio esquerdo, iniciando-se a partir do local de ressecção do apêndice atrial esquerdo até o orifício da veia pulmonar superior esquerda.

A Figura 6 apresenta uma representação esquemática para a aplicação de RF nas linhas $\mathrm{f}, \mathrm{g}, \mathrm{i}, \mathrm{j}$ e k. Na linha f, a aplicação é no interior do AE - ao redor dos orifícios das veias pulmonares esquerdas. Na linha g, é aplicada ao redor dos orifícios das veias pulmonares superior e inferior direita. Na linha i, acontece a união das veias pulmonares direitas às esquerdas entre o orifício da veia pulmonar superior esquerda e a base do AE. De forma longitudinal, a aplicação é entre as veias pulmonares direitas e esquerdas, linha j, e entre o orifício da veia pulmonar inferior esquerda e a borda do anel da valva mitral - linha $\mathrm{k}$.

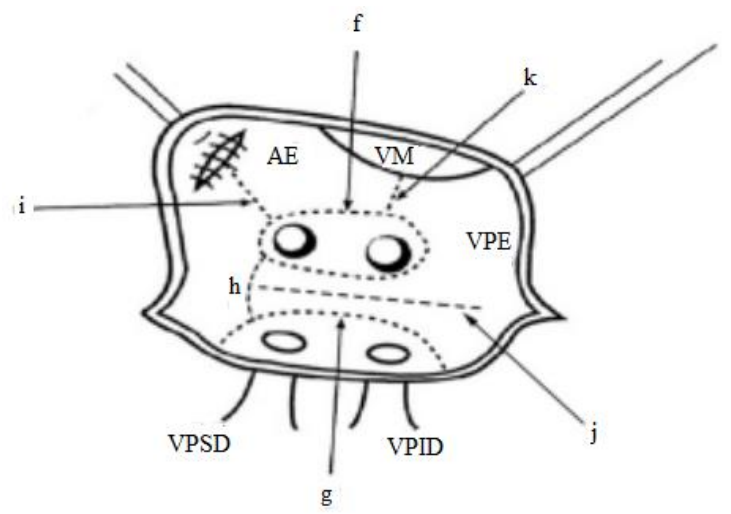

Figura 6 - Esquema representando os locais de aplicação da RF. As direções indicadas na figura correspondem as direções em que é feita a ACRF. (Modificado de Alberto et al.[12])

A eficácia da ACRF para a FA varia conforme as características clínicas da arritmia e a extensão da cardiopatia. As maiores evidências de benefício e os resultados positivos são obtidos em pacientes jovens com FA persistente sintomática sem cardiopatia estrutural [26]. Nesse perfil de pacientes, a intervenção proporciona melhora significativa da sintomatologia 
e da qualidade de vida. Porém, faltam dados que comprovem o benefício do procedimento nos pacientes muito idosos, com FA persistente de longa duração [1], [26].

Alves [9] e Quallich et al. [23], por exemplo, fizeram a simulação da ACRF por meio de métodos computacionais. A simulação da ablação por RF considera a aplicação no átrio esquerdo (AE), na altura das vértebras T8-T9, na qual existe estreitamento entre o AE e o esôfago. O objetivo é obter a distribuição de temperatura na área de ablação. Essa é uma técnica que vem sendo usada desde 1990 e gera interesse, sobretudo, em relação às consequências do tratamento.

Entretanto, a ACRF não é curativa. As recorrências da FA são comuns, ocorrendo devido à reconexão das veias pulmonares ou à progressão do substrato atrial [26]. Nesses casos, um novo procedimento de ablação pode ser necessário. Após a ACRF, todos os pacientes devem ter um acompanhamento médico de 2 a 3 meses [27]. Após esse período, os pacientes com baixo risco de fenômenos tromboembólicos e sem lesões são liberados. Consequentemente, a forma de se evitar lesões com ACRF é empírico e não é livre de riscos [15].

\subsection{ESÔFAGO}

A função principal do esôfago é conduzir o alimento da faringe até o estômago e as características de seus movimentos são fundamentais para a execução dessa função. São dois movimentos específicos: peristaltismo primário e secundário [2]. O esôfago é um tubo fibromuscular achatado. Ele começa no mediastino superior, entre a traqueia e coluna vertebral, e possui cerca de $25 \mathrm{~cm}$ a partir da sua origem [22].

O movimento peristáltico primário é a continuação da onda peristáltica que começa na faringe. Essa onda percorre a faringe até o estômago. Quando as ondas primárias não conseguem levar o alimento ingerido até o estômago, surgem os movimentos peristálticos secundários que resultam na distensão do esôfago [22]. O estímulo do movimento secundário é proveniente do sistema nervoso, sendo transmitido por fibras vagais que começam na faringe [2].

A musculatura do esôfago pode ser dividida em três partes: o músculo é estriado no terço superior do esôfago. Dessa forma, os movimentos peristálticos são controlados pelas fibras nervosas motoras dos músculos esqueléticos dos nervos glossofaríngeo e vago [19]. Nos dois terços inferiores, o músculo é liso e essa porção é controlada pelo nervo vago. Mesmo quando os ramos do nervo vago são cortados, o plexo nervoso gera ondas secundárias [6]. Assim, a alimentação por meio de sonda é possível.

Inicialmente, o esôfago se inclina para o lado esquerdo e é movido pelo arco da aorta para o plano mediano oposto da raiz esquerda dos pulmões [6]. No mediastino superior, o esôfago se localiza próximo ao arco da aorta. O esôfago se estende ao mediastino superior, passando por região posterior e à direita do arco da aorta, posterior ao pericárdio e ao AE. 
Nesse ponto, tem-se a menor distância entre o AE e o esôfago. A Figura 7 mostra o contato direto do esôfago com as porções média e inferior do AE, essas são imagens feitas pelo exame de tomografia computadorizada [1].
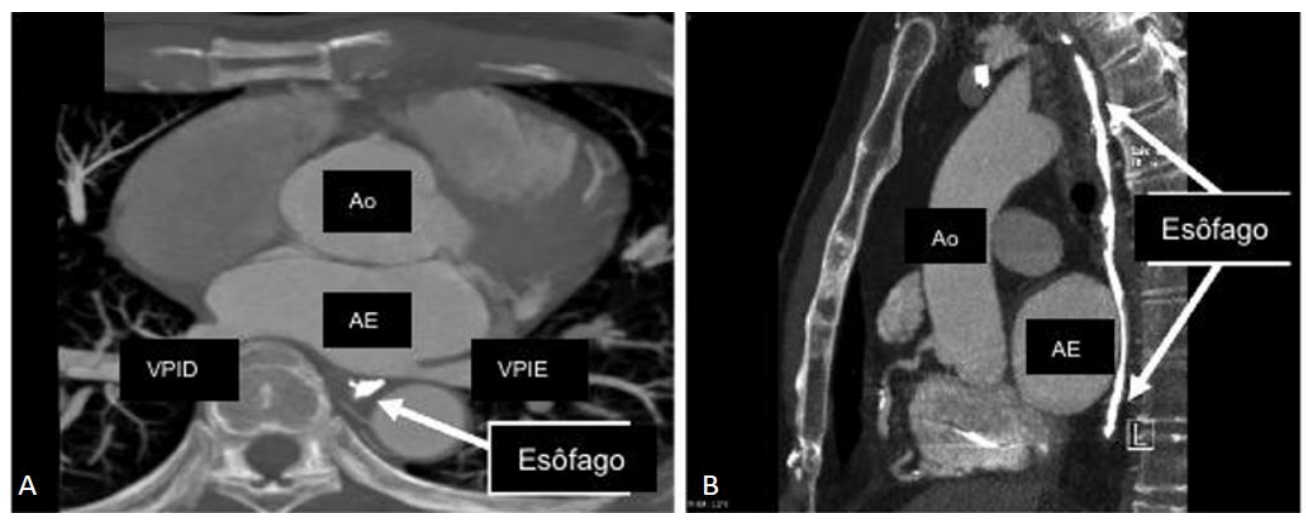

Figura 7 - Imagens de tomografia computadorizada do tórax que mostra a relação anatômica entre o AE e o esôfago. A: corte axial. B: corte sagital. (Modificado de Oliveira

O AE, a aorta e o esôfago estão alinhados. A aorta pressiona o esôfago contra a parede do AE [6]. Estando em posição abaixo do arco da aorta, o esôfago novamente inclina-se para a esquerda à medida que se aproxima e passa através do hiato esofágico - abertura existente no diafragma - e está situado no diafragma na altura da vértebra T10, anterior à aorta [9]. O esôfago, então, constitui o relacionamento posterior primário da base do coração.

As lesões térmicas propagadas para o esôfago e o risco de desenvolvimento da FAE são proporcionais à área de superfície de contato entre o esôfago e o AE. Um problema a ser considerado é a localização espacial do esôfago que está localizado próximo às veias pulmonares superior e inferior esquerdas e na linha média entre as veias direitas e esquerdas [27].

\subsection{FÍSTULA ÁTRIO-ESOFÁGICA}

A FAE ocorre quando há necrose do tecido devido às temperaturas acima de $50{ }^{\circ} \mathrm{C}$ no eletrodo de ablação durante a ACRF [9]. A lesão começa na parede do AE e se estende até o esôfago. O diagnóstico tem que ser precoce, mesmo com a dificuldade de se identificar tal lesão. Os exames de imagem, como a endoscopia, auxiliam nesse diagnóstico. Após a descoberta da FAE, o método mais indicado é a reparação cirúrgica imediata.

Inicialmente, o diagnóstico da FAE, após a ACRF, era feito até o quinto dia do pósoperatório [1]. Os pacientes podem apresentar algumas consequências da FAE, entre elas o 
déficit neurológico por embolia aérea, o sangramento gastrointestinal e o choque séptico [2], o que pode levar a óbito. O diagnóstico é difícil, pois os sintomas apresentados nos exames gerais podem estar associados também a outras doenças. Os sintomas são disfagia, odinofagia, isquemia miocárdica ou neurológica, febre, bacteremia, funguemia, melena ou queixas sem especificações [1].

O esôfago está em contato direto com o AE. Contudo, podem acontecer variações na anatomia que podem definir a extensão das lesões. Essas alterações incluem a ausência de gordura na área periesofágica, graus de espessamento das paredes esofágicas e atriais, e a relação espacial desses. A camada protetora de gordura, que não existe em cerca de $2 \%$ da população [1], é descontínua. O espessamento da parede do esôfago varia entre 1.9 a $5.3 \mathrm{~mm}$ e a parede do átrio varia entre 1.3 a $3.1 \mathrm{~mm}$ [27]. Então, a separação total mínima é de 5.5 $\mathrm{mm}$. O comprimento entre o esôfago e o AE foi de $58 \pm 14 \mathrm{~mm}$ e a largura $13 \pm 6 \mathrm{~mm}$ [27].

Katz-Agranov [11] apresentou um estudo de caso em que um paciente desenvolveu a FAE durante a ACRF. O indivíduo tinha 75 anos, fez a ACRF para controlar a FA, e apresentou sintomas somente 7 dias após o procedimento. A ACRF durou cerca de 57 minutos, com potência de $50 \mathrm{~W}$ e incluiu isolamento completo da veia pulmonar, uma linha do istmo mitral e ablação da parede posterior do AE. O paciente retornou aos médicos com dores abdominais, disfagia e odinofagia seguida de hematemesis (perda de hemoglobina). Foi realizada uma endoscopia digestiva alta (ou esofagogastroduodenoscopia) e os médicos observaram a formação de um coágulo ao longo da parede esofágica, ilustrada na Figura 8. Ao retirar este coágulo, os médicos encontraram uma ulceração de $2 \mathrm{~cm}$. O paciente foi a óbito.

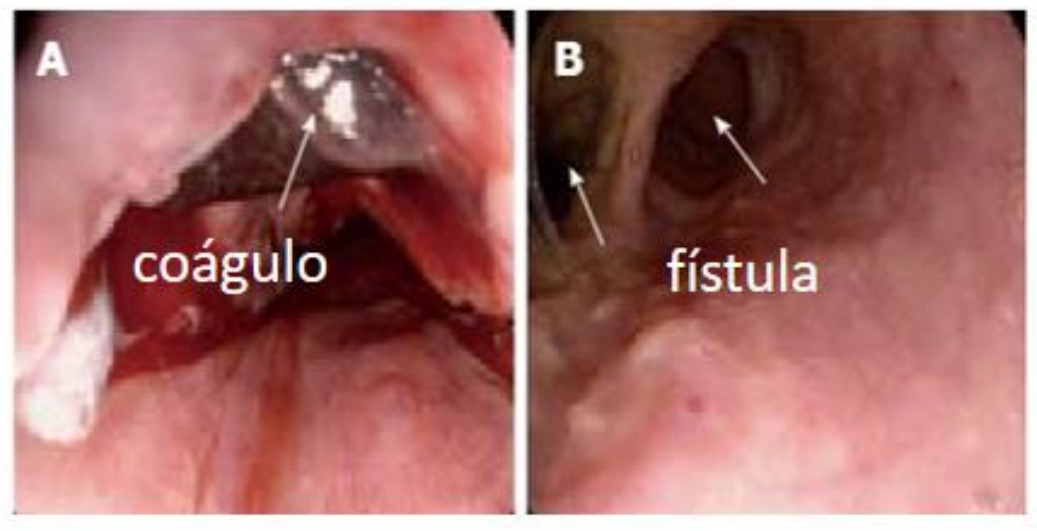

Figura 8 - Imagem de Endoscopia digestiva alta. A: Coágulo sanguíneo que se estende ao longo do esôfago. B: Ulceração no esôfago médio de $2 \mathrm{~cm}$. (Modificado de Katz-Agranov [11])

As lesões esofágicas ocorrem majoritariamente por condução térmica durante a aplicação de RF [9]. O mecanismo fisiopatológico indica que essas lesões estão presentes na 
microvascularização da parede esofágica e necrose isquêmica da camada mucosa do esôfago [1]. Alguns sintomas podem ser relacionados com a FAE, entre eles a presença de refluxo gastroesofágico, lesões transmurais excessiva na parede do AE, lesões do nervo periesofágico, casos de espasmos agudos e distúrbio na motilidade gástrica [14].

John et al. [28] fizeram um estudo sobre a distribuição das FAE no AE. No estudo foram analisados 10 pacientes com FAE. O resultado foi que as lesões são aleatórias, sem especificação de um lugar exato no átrio, o que é ilustrado na Figura 9. Nesse estudo, a veia pulmonar inferior esquerda (VPIE), a veia pulmonar superior esquerda (VPSE), a veia pulmonar inferior direita (VPID) e veia pulmonar superior direita (VPSD) foram lesionadas durante o processo de ACRF. Sendo a VPSE a mais grave, pois com a necrose da região não passaram as cargas elétricas nessas linhas do átrio.

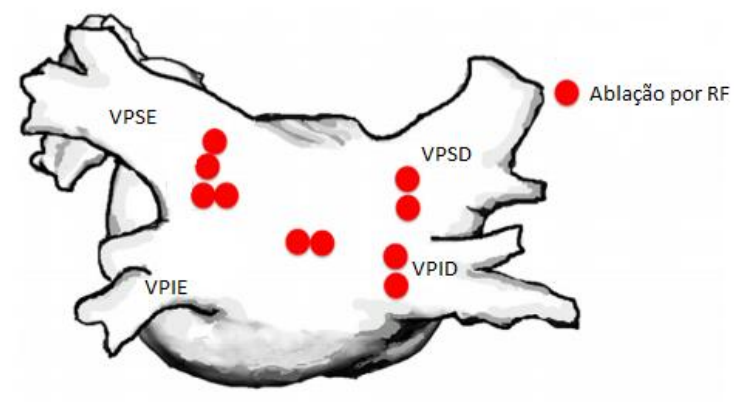

Figura 9 - Localização aproximada das fístulas atrioesofágicas descritas na visão posteroanterior do átrio esquerdo. As FAE associadas à ablação RF estão distribuídas de forma aleatória no átrio posterior esquerdo. (Modificado de John et al. [28])

As estratégias de proteção esofágica vão desde o exame regular de endoscopia à monitorização da temperatura esofágica durante a ACRF. Redfearn et al. [29] mostrou que o aquecimento do lúmen esofágico ocorreu com lesões no $\mathrm{AE}$ a $1 \mathrm{~cm}$ do esôfago. Demonstrou-se também que lesões geradas por RF no AE geram microbolhas no ecocardiograma intracardíaco em temperaturas mais altas no esôfago [1], [29]. Outra estratégia é limitar a energia de radiofrequência na parede posterior do AE [14].

Para o tratamento da FAE são indicados a cirurgia de reparação e o stent esofágico [30]. Embora o stent esofágico seja associado a $100 \%$ de mortalidade que, com uma cirurgia primária de reparo, cai para 40\% [31]. O stent é um dispositivo feito de metal ou plástico que pode ser colocado no esôfago ao longo da lesão - nesse caso, ele se auto expande em forma de um tubo protegendo a parede do esôfago [30].

As cirurgias reparadoras podem ser a esternotomia padrão, a atriotomia esquerda, incisão supra umbilical e a toracotomia direita para reparação da circulação [30], [31]. Velotta et al. [31] relata que o uso de retalhos intercostais e retalhos de pericárdio bovino, 
para fazer reparo no esôfago e no átrio, respectivamente, são possíveis soluções para a cura da FAE causada pela ACRF.

\subsection{TRASFERÊNCIA DE CALOR}

O fenômeno de transporte do calor consiste basicamente no transporte de energia térmica que se dá pela diferença de temperatura entre esses corpos [32]. Essa diferença de temperatura (gradiente de temperatura) atua como a força motriz do sistema, pois na área da física que trata da transferência de calor, essa transferência ocorre sem que seja exercido o elemento trabalho (diferentemente do caso da termodinâmica) [33]. A transferência de calor é classificada de três formas diferentes: condução, convecção e radiação (irradiação).

\subsubsection{CONDUÇÃO}

A condução térmica é uma forma de transferência de calor que pode ocorrer entre sólidos, líquidos e gases, onde a energia é passada de partícula para partícula, átomos para átomos, moléculas para moléculas adjacentes dentro de uma mesma substância ou entre substâncias que estão em contato físico direto [9], [33].

O fluxo de energia é dado pelo gradiente de temperatura (variação de temperatura) em nível microscópico. Ocorre sempre pela transferência de calor pelas partículas, átomos e moléculas que possuem maior energia cinética e interagem colidindo com seus vizinhos, que possuem menor quantidade de energia, transferindo a eles parte dessa energia cinética.

Com duas superfícies isoladas e as outras mantidas a diferentes temperaturas, $T_{1}>T_{2}$, acontecerá transferência de calor entre as superfícies por condução. De acordo com a lei de Fourier, equação 1, o fluxo térmico local no sólido é um vetor perpendicular, em qualquer ponto, às linhas de temperatura constantes (isotermas) [33]. A equação de Fourier possui o sinal negativo em decorrência da segunda lei da termodinâmica, onde a relação é negativa visto que o gradiente de temperatura estabelece que o fluxo de transferência de energia ocorre das regiões de temperaturas mais elevadas para as regiões de temperaturas menos elevadas [9]. A equação de Fourier é

$$
q^{\prime \prime}=-\mathrm{k}\left(\boldsymbol{i} \frac{\partial T}{\partial x}+\boldsymbol{j} \frac{\partial T}{\partial y}+\boldsymbol{k} \frac{\partial T}{\partial z}\right)
$$

onde $q^{\prime \prime}$ é o fluxo térmico na direção x, y, z; k é a condutividade; e $\frac{\partial T}{\partial x}, \frac{\partial T}{\partial y}$ e $\frac{\partial T}{\partial z}$ são as taxas de variação da temperatura nas direções $\mathrm{x}, \mathrm{y}$ e $\mathrm{z}$, respectivamente. $\mathrm{I}$, j e k são vetores de comprimento 1 nas direções $\mathrm{x}, \mathrm{y}$, e $\mathrm{z}$, respectivamente. 
A capacidade de transmitir calor, que diversos tipos de substâncias possuem, varia conforme as propriedades térmicas destas. Sendo que os sólidos são melhores condutores de calor que os líquidos, que por sua vez são melhores que os gases [34]. Como exemplo, a transferência de calor ocorre melhor entre os metais, pois estes são excelentes condutores de calor, enquanto o ar é um péssimo condutor de calor.

\subsubsection{CONVECÇÃO}

A convecção térmica é uma forma de transferência de calor que ocorre somente em líquidos e gases, em que o transporte é feito por meio de movimentações do próprio fluído. As movimentações ocorrem devido às diferenças de massa específica (densidades) presentes no fluído [33]. Ocorre em função da dependência da intensidade do fluido com a temperatura, ou seja, da dilatação térmica, e das regras de flutuabilidade (menos denso ascende; mais denso descende) [34].

Embora usualmente coloque-se em foco a ascensão horizontal do fluido, a convecção térmica caracteriza-se de fato por uma corrente fechada de matéria, que causa um aumento significativo de frio entre as regiões envolvidas se comparado ao calor entre elas esperado apenas pelo fenômeno de condução térmica [9], [32]. Fala-se em calor por convecção. Existem dois tipos de convecção: a natural (explicada acima) e a forçada, a qual utiliza aspiradores e bombas para fazer o deslocamento do fluído.

A convecção natural ocorre quando um sistema se torna instável e consequentemente inicia-se um processo de mistura pelo movimento de massa. Uma observação comum de convecção é da convecção térmica em um recipiente de água fervente, na qual a água quente e menos densa na camada do fundo evapora, em movimentos de baixo para cima, e a água fria e mais densa perto do topo do pote igualmente afunda.

Na convecção de calor forçada, a transferência de calor é devida ao movimento no fluido que resulta de muitas forças externas, tais como (por exemplo) um ventilador ou bomba. Assim, um forno de convecção funciona por convecção forçada, como um ventilador que circula rapidamente ar quente força calor em alimento mais rápido do que seria natural acontecer, devido ao simples aquecimento sem o ventilador. Aquecimento aerodinâmico é uma forma de convecção forçada. Sistemas comuns de radiador de calor por fluido, e também de aquecimento e resfriamento de partes do corpo por circulação do sangue, são outros exemplos familiares de convecção forçada [9], [33], [34].

\subsubsection{RADIAÇÃO}

A radiação ou irradiação é uma forma de transferência de calor que ocorre através da propagação, na velocidade da luz, de ondas eletromagnéticas [33]. Para que ocorra a radiação não é necessária a existência de matéria no meio de propagação, podendo esta ser o único tipo de transmissão de calor que pode ocorrer em um espaço vazio (a vácuo).

Todos os tipos de corpos emitem e absorvem a radiação eletromagnética [33], [34]. Quando um corpo aquece ele transfere calor na forma de radiação, como por exemplo, o Sol 
que aquece a Terra. Um corpo em equilíbrio térmico com sua vizinhança emite e absorve a radiação em uma mesma taxa.

Ondas de rádio e televisão, ondas de raios $\mathrm{X}$ e ondas de infravermelho são alguns exemplos de ondas eletromagnéticas, cujas diferenças entre elas são a sua frequência e seu comprimento de onda. 


\section{METODOLOGIA}

\subsection{TERMISTORES}

A origem dos termistores começou com estudos de Michael Faraday (França), em 1883, que registrou pela primeira vez - e noticiou - o acentuado decréscimo da resistividade elétrica do sulfeto de prata em função do aumento da temperatura [35]. Mas, foi a partir dos trabalhos práticos realizados em 1930 por Samuel Ruben (USA), fundador da Duracell, que a indústria de componentes eletroeletrônicos deu início a produção comercial dos atuais termistores. Esses são fabricados em vários tamanhos e formas, além da tecnologia empregada para melhor exatidão, estabilidade e resolução [36].

Os termistores, Figura 10, são um tipo de componente cuja resistência se altera com a variação da temperatura - como o nome sugere, termistor vem da junção das palavras temperatura e resistor. Existem dois tipos de termistor: o PTC (Positive Temperature Coefficient) e o NTC (Negative Temperature Coefficient). Eles possuem esses nomes por conta da variação da resistência. O PTC apresenta uma variação da resistência positiva quando a temperatura é alterada e o NTC apresenta uma variação negativa da resistência para a mesma variação [35].

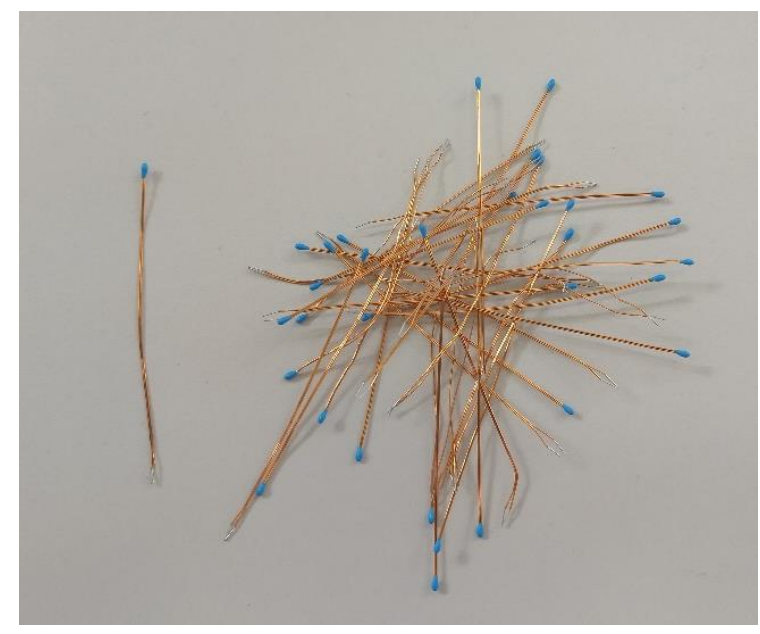

Figura 10 - Termistores utilizados no projeto: com fios isolados, resistência de $100 \mathrm{k} \Omega$ e 1 mm de espessura.

A fabricação dos termistores é feita com uma pequena quantidade de pasta semicondutora sobre fios de liga de platina. Essas unidades são revestidas com um epóxi para a proteção e a estabilização [36]. A mudança na temperatura do corpo do termistor, por conta da natureza do material utilizado, gera uma grande mudança na resistência medida. Muitos termistores do tipo NTC são construídos com discos prensados ou fundidos de material semicondutor, tais como óxidos metálicos [37]. 
O termistor funciona com base no fato de que a temperatura aumenta o número de elétrons livres na estrutura. E, portanto, aumenta a condutividade do material e diminui a resistência. Assim, a corrente aumenta. O NTC, como sensor para a temperatura, apresenta um problema em sua calibração - isto é, estabelecer a relação entre a resistência elétrica e a temperatura [35]. Essa relação não é linear e pode ser vista com uma função exponencial decrescente.

A resposta dos termistores NTC e PTC pode ser observada na Figura 11, que ilustra o comportamento da resistência em função da temperatura e o alto grau de não-linearidade dos termistores [37]. Os fabricantes disponibilizam vários tipos de termistores, com diferentes curvas de resposta, temperaturas máximas e mínimas de operação e outras características, de modo que seu funcionamento seja adequado a determinadas aplicações [35].

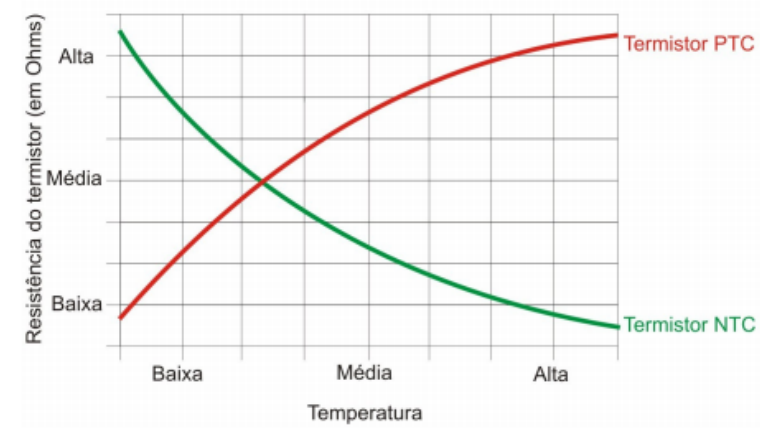

Figura 11 - Gráfico ilustrando exemplo de curvas dos termistores PTC e NTC.

(Reproduzido de Pastko [35])

Os termistores têm muitas aplicações na ciência, na indústria e nas atividades comerciais e domésticas. São empregados como sensores, no controle e na proteção térmica de motores e nos eletrodomésticos, por exemplo. Também são utilizados em instrumentos de pesquisa científica, como sensores térmicos no monitoramento e acionamentos em automóveis e aviões, e em dispositivos de equipamentos para as telecomunicações [38]. Como são dispositivos pequenos e muito sensíveis, são destaque na utilização em aparelhagens médico-hospitalares e dos processos vinculados à indústria farmacêutica, incluindo algumas aplicações para medições no campo da biologia.

\subsubsection{O EFEITO DO AUTO-AQUECIMENTO}

Quando uma corrente passa pelo termistor, a temperatura tende a aumentar neste componente. Afinal, um termistor é uma resistência e as resistências dissipam energia elétrica na forma de calor [39]. Caso esse termistor seja utilizado para medir a temperatura desse meio, um erro significante pode ocorrer se uma adequada correção não for aplicada. 
O calor gerado pelo termistor pode influir na medição da temperatura acarretando erros de medição, por outro lado, este efeito é usado em alguns equipamentos como, por exemplo, equipamento de medição do fluxo de ar ou ainda em temporizadores usando relês com termistores em série que disparam após certo tempo ligado.

A equação da potência dissipada, eq. 2, no termistor é dada por:

$$
P_{E}=\mathrm{I} \text {.V }
$$

Quando uma corrente passa pelo termistor, essa energia é transformada em calor e a temperatura do termistor é alterada. A equação que descreve a alteração da temperatura no termistor, eq. 3 , é a equação geral de Newton:

$$
P_{T}=\mathrm{K}\left(T_{(R)}-T_{0}\right)
$$

onde $T_{(R)}$ é a temperatura do termistor em função da sua resistência, $T_{0}$ é temperatura ao redor do termistor e $\mathrm{K}$ é o fator de dissipação do termistor. $\mathrm{K}$ é expresso normalmente em $\mathrm{mW} /{ }^{\circ} \mathrm{C}$. No ponto de equilíbrio as duas equações devem ser iguais.

A corrente através do termistor depende do circuito em que ele está ligado. Por exemplo, se o termistor está sendo alimentado por uma fonte de tensão fixa, a corrente pode ser determinada pela lei de $\mathrm{Ohm}$. Nesse caso, você pode resolver a equação para o equilíbrio a uma temperatura ambiente $T_{0}$, resultando na equação 4:

$$
T_{0}=T_{(R)}-\frac{V^{2}}{K \cdot R}
$$

\subsubsection{CIRCUITO PARA AQUISIÇÃO DE DADOS DA TEMPERATURA}

O diagrama esquemático do circuito implementado para a medida da temperatura está apresentado na Figura 12. A Figura está ampliada no Anexo 1. As tensões de alimentação do circuito são de $5 \mathrm{~V},-5 \mathrm{~V}$, e a conexão dessas tensões de alimentação ao circuito partir é feita através de um conector, pois a fonte de alimentação é externa ao circuito. A primeira parte do circuito consiste em um divisor de tensão, que converte a variação não-linear de resistência na temperatura, com uma variação não-linear da tensão com a temperatura. Para completar o circuito, foi anexado ao um segundo divisor de tensão, 
em que os resistores têm a mesma resistência que o termistor à temperatura de $25^{\circ} \mathrm{C}$. Com a adição deste, forma-se uma ponte de Wheatstone.

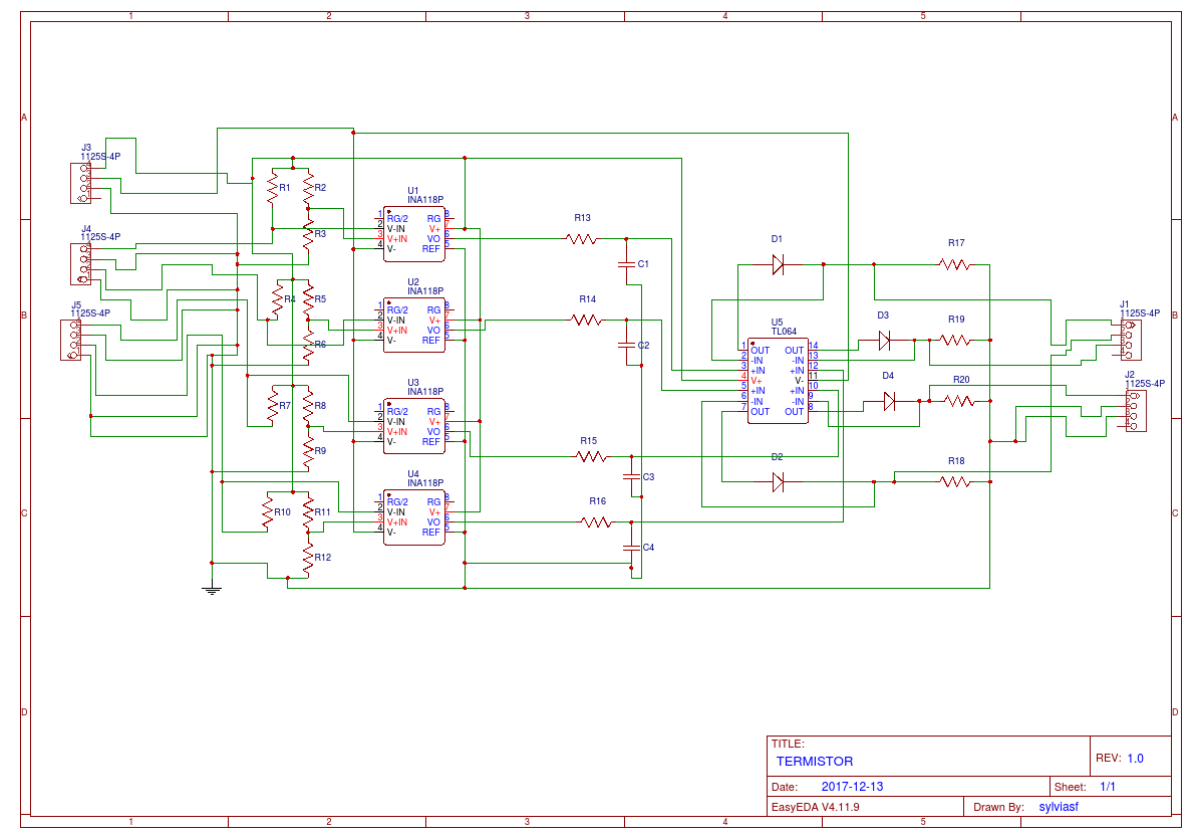

Figura 12 - Circuito para captação de dados que será implementado no módulo esofágico e representa a etapa de captação da temperatura.

Os divisores de tensão da ponte de Wheatstone são conectados às entradas inversora e não-inversora do amplificador operacional de instrumentação INA118. Na Figura 12, pode-se observar que o termistor também é conectado ao circuito com a utilização de conector externo. Isso acontece porque a ideia é captar a temperatura em um local não tão próximo ao circuito - com duas estações de trabalho: uma contém o circuito, microcontrolador e computador, e a outra é a estação em que os sensores serão colocados.

O ganho do circuito é um, não foi adicionado nenhum ganho além do que é entregue pelo INA. A saída do INA é filtrada com um filtro passa baixa, para diminuir ruídos e interferência. Em seguida, é utilizado um buffer (seguidor de tensão) com o amplificador TL064.

A saída do buffer passa, ainda, por um limitador de tensão, que é usado para evitar que, por acidente, apareça uma tensão excessivamente alta na entrada do conversor analógico/digital (conversor $\mathrm{A} / \mathrm{D}$ ). $\mathrm{O}$ microcontrolador é conectado à placa através de um conector externo. Os componentes e suas descrições estão mostrados na Tabela 1, os valores utilizados têm como referência a modelagem do projeto. O circuito foi implementado no aplicativo EasyEDA - é um programa online que permite a implementação do circuito e da placa PCB, além, de dar a opção mandar fazer a placa e entregar no Brasil por um custo mais baixo. 
Tabela 1 - Descrição dos componentes utilizados na implementação da placa de leitura da temperatura.

\begin{tabular}{|c|c|}
\hline Componentes & Descrição \\
\hline R2, R3, R4, R6, R7, R10, R11 & $100 \mathrm{k} \Omega$ \\
\hline R1, R5, R8, R12 & $27 \mathrm{k} \Omega$ \\
\hline R13, R14, R15, R16 & $10 \mathrm{k} \Omega$ \\
\hline R17, R18, R19, R20 & $1 \mathrm{k} \Omega$ \\
\hline Termistor & $100 \mathrm{k} \Omega$ \\
\hline Capacitor & $1 \mathrm{nF}$ \\
\hline Diodo & BZX79C 6V8 \\
\hline
\end{tabular}

\subsubsection{CAPTAÇÃO DA TEMPERATURA E TENSÃO}

A curva ideal da relação tensão-temperatura foi simulada no software MATLAB, e está ilustrada na Figura 13. A tensão varia entre 0 e 5V, e as temperaturas escolhidas para a análise estão entre 0 e $70^{\circ} \mathrm{C}$. Pode-se observar a relação não-linear crescente entre a tensão e a temperatura, como esperado. O valor utilizado para o $\beta$ (Beta) da equação é 4190, esse valor é encontrado no datasheet do termistor.

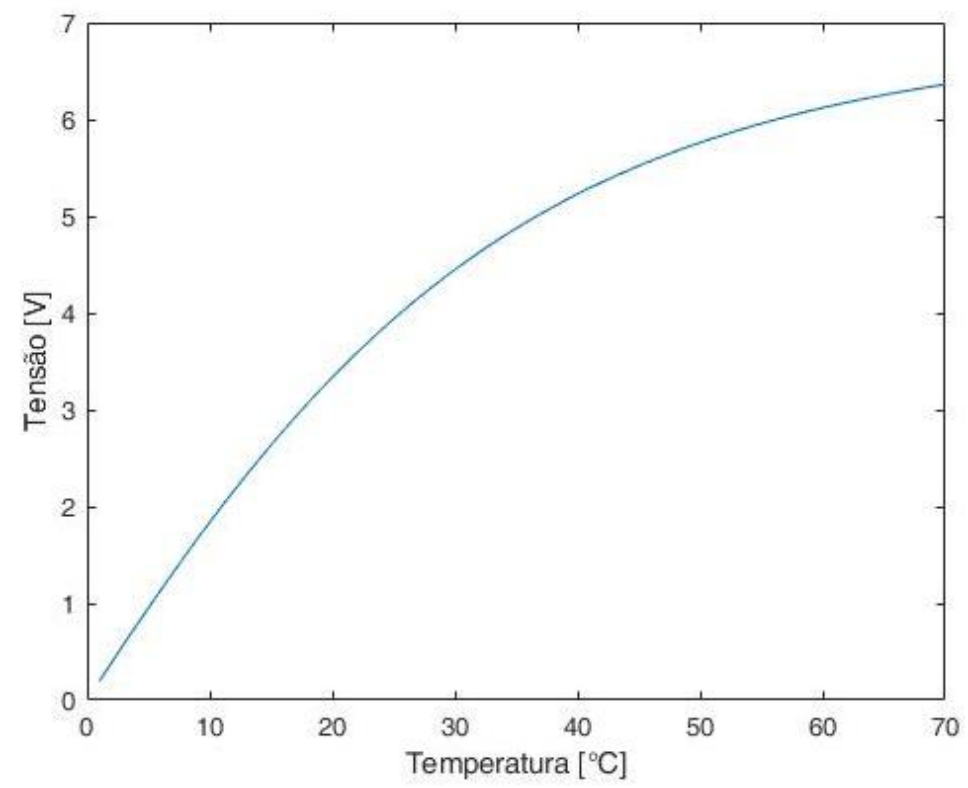

Figura 13 - Gráfico da curva ideal para a relação tensão de saída com a variação de temperatura. 
A relação entre a resistência no termistor e a temperatura é simulada na Figura 14. A reposta obtida é de um termistor NTC - quanto maior a temperatura, menor é a resistência. A temperatura mais baixa $\left(T_{0}\right)$ é $0^{\circ} \mathrm{C}$ - temperatura resfriada - e a resistência de referência $\left(R_{0}\right)$ é a do termistor, a essa temperatura, é de $100 \mathrm{k} \Omega$. Conforme a temperatura se aproxima de $70^{\circ} \mathrm{C}$, o termistor diminui sua resistência.

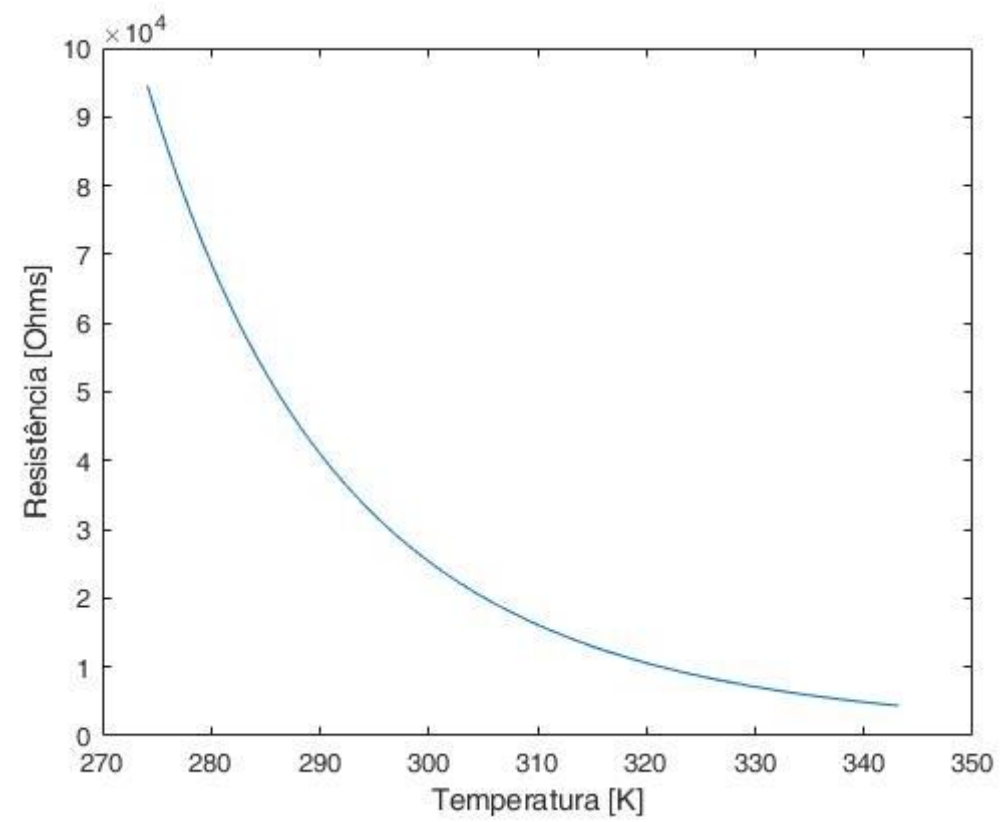

Figura 14 - Gráfico da curva ideal para a relação entre a resistência e a variação de temperatura.

A faixa de temperaturas escolhidas está dentro da faixa em que o projeto é modelado. A menor temperatura, $0^{\circ} \mathrm{C}$, representa o resfriamento máximo. A temperatura de $70^{\circ} \mathrm{C}$, típica em uma ACRF, seria o pior cenário, pois as células já estariam em processo de necrose e, assim, a perda de tecido é provável. A resistência, a tensão de saída e a temperatura são variáveis de interesse e, por isso, foi feito uma correlação entre elas para uma futura análise do desempenho do circuito proposto.

A captação desses dados é feita por meio do microcontrolador ATmega 2560 conhecido como Arduino UNO. A escolha do microcontrolador se deu pelo baixo custo e funcionalidade adequada para a captação desses sinais. A Figura 15 mostra o fluxograma com as atividades desempenhadas pelo software desenvolvido para captar a tensão no circuito. Essa tensão captada será convertida em temperatura, através de equações que serão obtidas na calibração dos termistores em outra parte do processo. Aqui vamos apenas registrar as tensões de saída do INA - lembrando, que esses valores serão utilizados em outras etapas. 


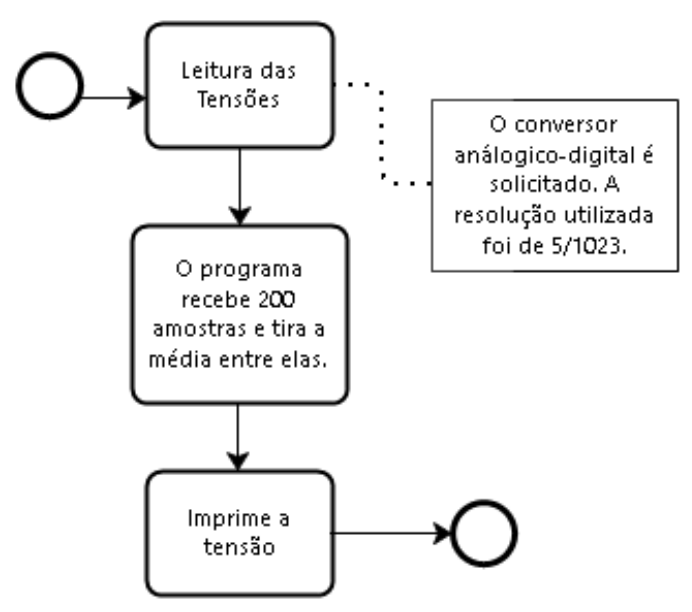

Figura 15 - Fluxograma com a rotina do software criado para a captação da tensão.

O programa é inicializado e começa o processo de leitura das portas analógicas setadas (escolhidas para a captação de dados - no projeto são utilizados quatro termistores). O conversor analógico-digital é solicitado, em uma resolução de 5/1023, e faz a conversão dos dados obtidos. Para uma medida mais precisa, são captadas duzentas amostras da tensão e é feita uma média desse valor. Esse valor é entregue com um atraso (delay) de 2000 milissegundos.

\subsubsection{CALIBRAÇÃO DO TERMISTOR}

O termistor é um sensor de alta sensibilidade, boa repetibilidade e exatidão, mas sensível a fatores físicos e químicos que podem interferir no seu desempenho e na sua curva de resposta, fazendo que haja uma variação relativamente alta na resposta de um termistor para outro [38]. Por isso, deve ser estabelecido e implementado um programa de verificação e de calibração que assegure a confiança nas medições. A periodicidade deve ser definida considerando a tolerância e grau de criticidade do processo, além de outros fatores.

O tempo de uso e alterações físico-químicas no semicondutor podem alterar a curva característica. Para calibrar termistores, pode-se empregar os métodos de pontos fixos ou calibração por comparação com outros termistores, termoresistência ou termômetro de líquido em vidro (TLV) [39].

A calibração por comparação é o método mais aplicado nas calibrações de termistores para aplicações convencionais [35]. Nesse processo, o termistor a ser calibrado tem suas medidas comparadas com um sensor de referência, seguindo procedimento validado. Esse sensor de referência pode ser um outro termistor com propriedades metrológicas comprovadas, porém, as comparações com uma termoresistência padrão em um meio térmico controlado é a forma mundialmente mais utilizada [39]. 
A ideia para fazer a calibração é ligar o circuito ao microcontrolador para receber os dados e processá-los - montar o circuito em bancada. Após esse passo, conecta-se o circuito com o sensor e utiliza-se o banho maria para variar as temperaturas. Essas são obtidas em intervalos até que todos os dados sejam medidos. Imersos em banho maria estão o termômetro de referência e o termistor - eles são colocados em um tubo de ensaio na mesma altura - de modo que, com tudo montado, o banho maria é ligado e as temperatura e tensões são captadas para análise posterior.

Dessa forma, os termistores estão calibrados com a captação e análise dos dados. Cada termistor tem a sua curva. No projeto serão utilizados quatro termistores para que seja obtida uma malha com suficiente eficácia. Cada termistor deve ser calibrado e depois de obtidas essas curvas, é necessário calibrar os quatro de uma só vez para não haver erros na calibração e captação dos dados. A Figura 16 mostra a rotina de trabalho utilizada para a calibração.

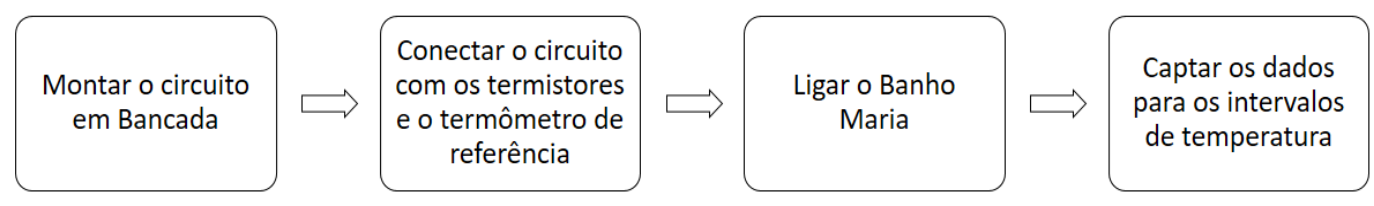

Figura 16 - Rotina de trabalho para a realização da calibração dos termistores.

\subsection{DISPOSITIVO PELTIER}

A partir do século XIX, os avanços na ciência dos materiais permitiram que os efeitos térmicos conhecidos se tornassem viáveis tecnologicamente. Um desses avanços foi a o uso do efeito Peltier para o desenvolvimento de dispositivo em estado sólido [40]. Consequentemente, a refrigeração baseada na expansão e compressão de fluidos deixou de ser a única opção para o resfriamento. Com técnicas modernas a indústria produz módulos termoelétricos capazes de produzir resfriamento ou aquecimento [34].

A forma mais prática de se utilizar o dispositivo Peltier (ou módulo Peltier, ou simplesmente Peltier) como refrigerador é fazer um arranjo de pequenos blocos em série. Esse arranjo faz com que os termoelementos irradiem calor em uma mesma direção, termicamente em paralelo. Os blocos são, geralmente, feitos de telureto de bismuto [40].

Os efeitos termoelétricos são aqueles em que a energia térmica e a elétrica são convertidas de uma forma para outra [34]. Existem dois efeitos de interesse: os efeitos Seebeck e o efeito Peltier. Thomas Seebeck decobriu esse efeito em 1821. Nele, uma tensão é criada quando dois metais são unidos formando uma junção e esta é aquecida [40]. Este o fenômeno é usado por engenheiros para fazer a medição exata da temperatura em termopares. 
No efeito Peltier, descoberto em 1834, ao contrário do que ocorre no efeito Seebeck, uma corrente passa pela junção dos metais, que formam o módulo Peltier, e essa junção ficará aquecida $\left(T_{Q}\right)$ ou refrigerada $\left(T_{F}\right)$, dependendo do sentido da corrente [40]. Na Figura 17 pode-se observar o caminho percorrido pela corrente, as junções entre o metal A e B e as fontes de temperaturas quente e fria.

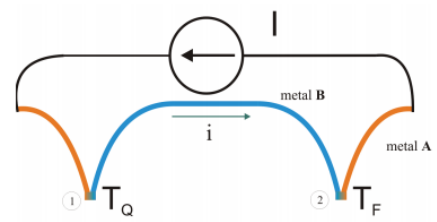

Figura 17 - Esquemático do efeito Peltier com fontes quente e fria, e a corrente gerada. (Reproduzido de Moura [40])

Nesta dissertação serão detalhadas as características elétricas e térmicas, assim como o dimensionamento do módulo Peltier para a aplicação em refrigeração de pequeno volume e com a refrigeração localizada - módulo esofágico. Para realizar o dimensionamento do sistema de refrigeração alguns passos foram desenvolvidos: (i) a definição das temperaturas de trabalho e da carga térmica; (ii) determinação do número de estágios, o desempenho e o modelo.

\subsubsection{DETERMINAÇÃO DAS TEMPERATURAS DE TRABALHO}

A escolha das temperaturas ajuda a definir o módulo Peltier, o dissipador de calor do módulo e calcular as cargas térmicas. A Tabela 2 mostra as temperaturas selecionadas para a execução do projeto. A temperatura ambiente é a mesma temperatura do corpo humano, que é em torno de $36^{\circ} \mathrm{C}$. A temperatura quente define o pior cenário, com $60^{\circ} \mathrm{C}$, o tecido já começará a ter lesões irreversíveis. Por fim, a temperatura fria é de $0{ }^{\circ} \mathrm{C}$ e corresponde à temperatura de trabalho do Peltier.

Tabela 2 - Temperaturas de trabalho do dispositivo Peltier.

\begin{tabular}{|c|c|l|}
\hline & Temperatura $\left[{ }^{\circ} \mathrm{C}\right]$ & \multicolumn{1}{c|}{ Observação } \\
\hline$T_{a m b}$ & 36 & Temperatura ambiente em que o dispositivo vai trabalhar \\
\hline$T_{Q}$ & 60 & Temperatura de trabalho na face quente \\
\hline$T_{F}$ & 0 & Temperatura de trabalho na face fria \\
\hline$\Delta \mathrm{T}$ & 60 & Os limites do módulo estão ligados a esta variável \\
\hline
\end{tabular}




\subsubsection{DETERMINAR O NÚMEROS DE ESTÁGIOS}

Os módulos estão disponíveis no mercado em vários tamanhos e podem ser utilizados de diferentes maneiras: individualmente ou agrupados eletricamente em série, paralelo ou série-paralelo. A partir da definição da temperatura, pode-se determinar o número de estágios do módulo necessários para que o $\Delta \mathrm{T}$ seja atingido. Cada estágio representa a temperatura máxima de trabalho.

Assim, em algumas aplicações é necessário usar mais de um estágio em série para a obtenção de um maior $\Delta \mathrm{T}$. A Tabela 3 mostra as temperaturas atingidas para cada número de estágios no módulo. Para este projeto, é utilizado um módulo de apenas um estágio, já que o $\Delta \mathrm{T}$ é $60{ }^{\circ} \mathrm{C}$. É possível observar que os outros estágios têm uma variação alta de temperatura que não se aplica à proposta do projeto.

Tabela 3 - Número de estágios do dispositivo Peltier em relação a variação da temperatura.

\begin{tabular}{|c|c|}
\hline Número de Estágios & $\Delta T_{\text {máx }}\left[{ }^{\circ} \mathrm{C}\right]$ \\
\hline 1 & 64 \\
\hline 2 & 84 \\
\hline 3 & 95 \\
\hline
\end{tabular}

\subsubsection{ESPECIFICAÇÕES DO MODELO ESCOLHIDO PARA O PROJETO}

No projeto será utilizado um Peltier pequeno, com dimensões que caibam em um cateter esofágico e que desempenha bem a função de resfriar a área desejada. O modelo escolhido, Figura 18, é o CP60133 da empresa CUIINC. Além de ser pequeno, as especificações estão dentro do que é esperado para o projeto, Tabela 4. Por exemplo, a variação da temperatura está dentro do que o projeto necessita e existe a garantia do fornecedor de que o Peltier funciona bem nessas faixas. As especificações foram retiradas do datasheet do dispositivo.

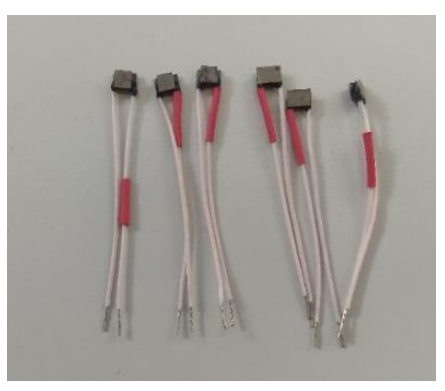

Figura 18 - Módulo Peltier CP60133 da empresa CUIINC. 
Tabela 4 - Especificações do dispositivo Peltier para o desenvolvimento do projeto.

\begin{tabular}{|c|c|c|}
\hline Especificações & $T_{Q}=27^{\circ} \mathrm{C}$ & $T_{Q}=50^{\circ} \mathrm{C}$ \\
\hline$V_{\text {máx }}[\mathrm{V}]$ & 3.8 & 3.8 \\
\hline$I_{\text {máx }}[\mathrm{A}]$ & 6 & 6 \\
\hline$Q_{\text {máx }}[\mathrm{W}]$ & 12.2 & 13.6 \\
\hline$\Delta T_{\text {máx }}\left[{ }^{\circ} \mathrm{C}\right]$ & 66 & 72 \\
\hline
\end{tabular}

\subsubsection{ESTIMAÇÃO DO DESEMPENHO}

Para estimar o desempenho utiliza-se as Tabelas 2 e 4 . Assim, a relação $\frac{\Delta T}{\Delta T_{\text {máx }}}$ é igual a 0,869 . No gráfico de desempenho fornecido pelo fabricante é possível traçar uma linha vertical para definir a relação $\frac{I}{I_{m a ́ x}}$. Esse procedimento foi executado e o valor obtido é 1 . Desta forma, a corrente de operação do módulo é 6 A. Outro dado é a voltagem máxima de operação que é 3,8 V e pode ser observada na Figura 19.

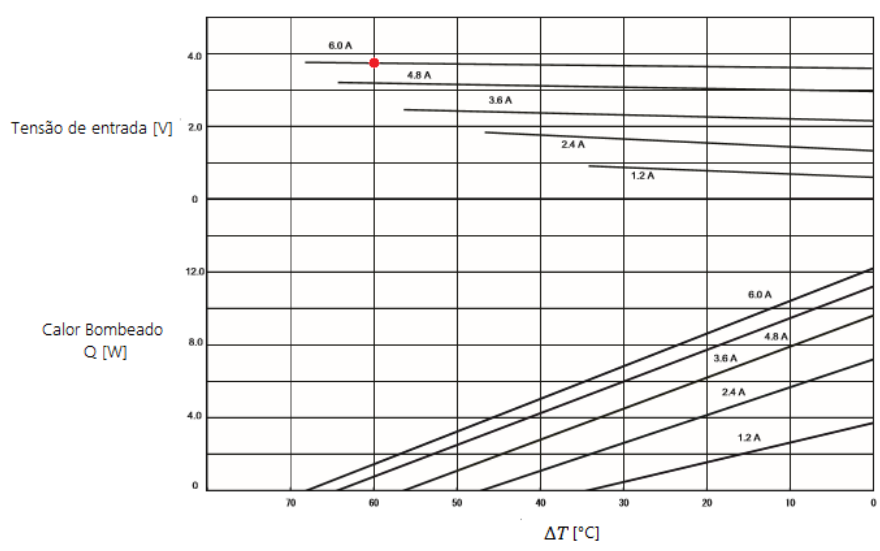

Figura 19 - Gráfico de desempenho do módulo Peltier fornecido pelo fabricante.

Conhecendo-se a corrente e o limite de tensão de operação, pode-se calcular a potência dissipada pelo módulo $\left(P_{\text {Peltier }}\right)$ multiplicando-se a corrente de operação pela tensão máxima de operação utilizando a eq.14.

$$
\begin{gathered}
P_{\text {Peltier }}=3,8 \times 6=22,8 \mathrm{~W} \\
Q_{\text {Dissip }}=\text { Carga térmica total }+P_{\text {Peltier }}
\end{gathered}
$$




\subsection{MÓDULO ESOFÁGICO}

O módulo esofágico é um controlador esofágico de temperatura e resfriamento (CETER). Para a sua construção, algumas etapas são necessárias: (i) desenhar o molde com a estrutura do módulo; (ii) confeccionar o molde com látex para que seja obtida a "carcaça" (estrutura) do CETER; (iii) alocar os sensores e os scalps por onde os fios e a água passam.

O molde possui duas peças, 1 e 2, uma chanfrada e outra lisa que juntas formam um cateter redondo e com a ponta abaulada. Já para a circulação de água, que faz a refrigeração junto com Peltier, dois scalps são alocados na estrutura final - e são explicados nos itens seguintes. O terceiro scalp está alocado de forma que toda a fiação do CETER passe por ele de forma isolada. A visualização do CETER em 3D com e sem sensoriamento está também apresentada na seção.

O molde das peças, bem como a alocação dos scalps e dos sensores, está descrito nos subitens desta seção. Primeiramente, uma breve explicação sobre o látex. Em seguida, o desenho do molde - das duas peças - que compõem a estrutura final. Também é apresentado uma visualização 3D do projeto completo e a forma como a matriz de sensores vai ser feita. Por fim, a logística de funcionamento é detalhada.

\subsubsection{LÁTEX}

O látex da borracha natural $(\mathrm{BN})$ é extraído da seringueira, como é popularmente conhecido - o nome científico é Hevea brasiliensis, e é a principal fonte de biomassa da BN no mundo. Segundo o Instituto Brasileiro de Geografia e Estatística (IBGE), o Brasil produz o equivalente a 1\% da produção mundial [41]. O Brasil tinha o monopólio de produção no início do século XX e hoje importa de outros países, pois não produz o suficiente para a demanda do mercado interno.

Em 1839, o empresário Charles Goodyear descobriu o processo de vulcanização do látex [41]. Esse processo consiste na adição de enxofre à BN, sob aquecimento e com uso de catalisadores [42]. Dessa forma, pontes de enxofre se formarão e aumentarão as propriedades da borracha proporcionando histerese e baixa formação de deformação permanente [41]. A histerese se refere à resposta de um sistema quando se faz solicitação externa.

Geralmente, é possível comprar o látex já com o processo de tratamento previsto de centrifugação, com as suspensões de enxofre e resina, com objetivo de o composto final possuir a elasticidade e a resistência necessárias [20]. A partir deste processo de preparo, o látex se torna um composto que vulcaniza em contato com a pele, tornando-se colante [41]. Para sua remoção, contudo, utiliza-se apenas água pura.

O látex apresenta uma viscosidade variável, pois consiste em uma dispersão de borracha em um soro aquoso que possui outras substâncias minerais e orgânicas, consequentemente sua densidade varia de 0,94 a 0,97 [41]. As propriedades do produto final 
são a elasticidade, flexibilidade, resistência à abrasão (desgaste), impermeabilidade, hipoalergenicidade, facilidade de adesão a tecidos e ao aço, e a resistência a produtos químicos [19].

A utilização do látex é ampla, com aplicações nas indústrias e como um biomaterial, por exemplo. Sendo, o biomaterial, a característica abordada na dissertação. Algumas pesquisas levaram a resultados positivos no uso de látex: a cicatrização da parede esofágica no caso de haver lesões [19]. Outra aplicação foi o uso de palmilhas de látex na indução de neoformação tecidual na cicatrização de úlceras no pé diabético [43].

Portanto, um biomaterial é qualquer substância sintética ou natural que pode ser utilizada como tratamento para substituir parte de um sistema vivo ou para funcionar em íntimo contato com um tecido vivo [20]. Essa área do conhecimento vem crescendo com o advento de novas tecnologias e as necessidades da ciência. O látex natural é um cicatrizante (uma defesa natural da planta), apresenta baixo custo, sem risco de transmissão de patógenos e de grande aplicabilidade clínico-social [43]. Por isso, o látex apresenta a principal característica de biomaterial - a biocompatibilidade, e será utilizado na fabricação do módulo esofágico.

\subsubsection{DESENHO DO MOLDE}

O desenho do molde do CETER leva em consideração algumas características importantes: o tamanho da área de cobertura - a extensão do esôfago que faz contato com o átrio esquerdo, o tamanho da expansão do órgão, os chanfros para encaixe dos sensores e fiação, e a ponta arredondada para melhor ergonomia. É um modelo inovador e inédito tanto na estrutura proposta, quanto na aplicação.

O material escolhido para o molde é o poliacetal e esse é modelado em um torno mecânico até chegar no produto final. A escolha do material do molde foi feita baseada no preço. E as medidas foram definidas através da correlação entre artigos levantados na Fundamentação Teórica e os objetivos deste trabalho.

A construção do CETER segue algumas etapas. A primeira etapa é a confecção do molde. O molde é formado por duas peças: a peça 1 - chanfrada, Figura 20-A; e a peça 2 lisa, Figura 20-B. A Figura 20 mostra uma imagem 3D, feita no software CATIA, de como as peças do molde ficaram. À princípio as peças são separadas, no entanto, para o produto final, as peças são coladas e formam a estrutura de um cateter. As duas peças foram construídas para se complementarem.

A Figura 21 apresenta a planta com cotas para a peça 1. Esta peça possui $150 \mathrm{~mm}$ de altura, $40 \mathrm{~mm}$ de diâmetro. Cada chanfro possui $8 \mathrm{~mm}$ de largura e $5 \mathrm{~mm}$ de profundidade que se estendem por $100 \mathrm{~mm}$. Os chanfros facilitam a acomodação dos sensores: peltier e termistor. Além de ter espaço para a fiação dos componentes. Para o projeto, houve a necessidade de três chanfros em apenas uma face. A cobertura de 125,6 mm é suficiente para cobrir a área de contato do esôfago com o átrio. 

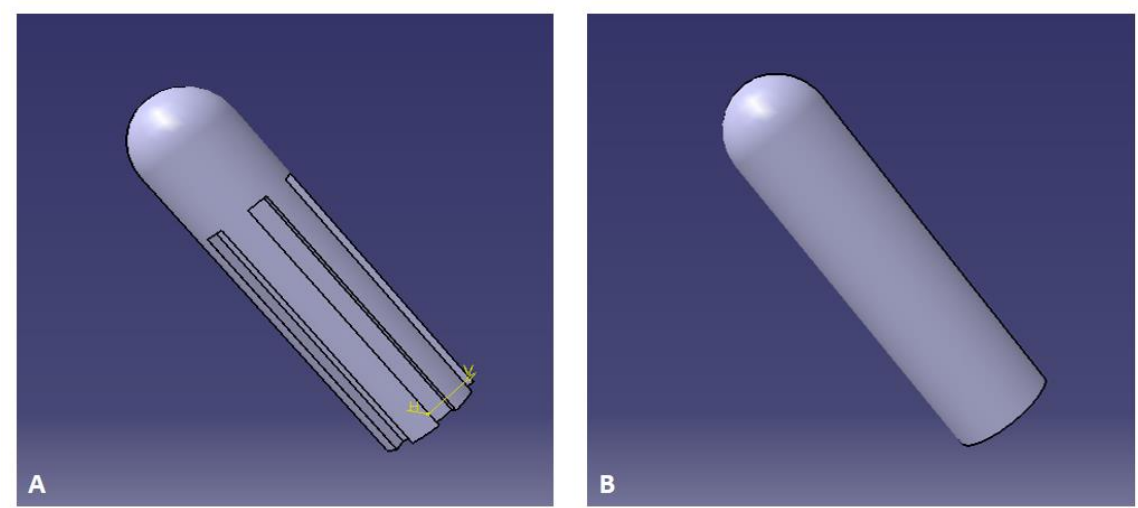

Figura 20 - Moldes para a confecção do CETER. A: molde 1 com chanfros frontais. B: molde 2 com a parede lisa.

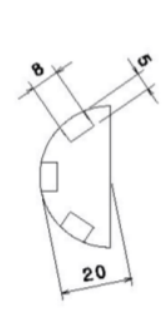

A

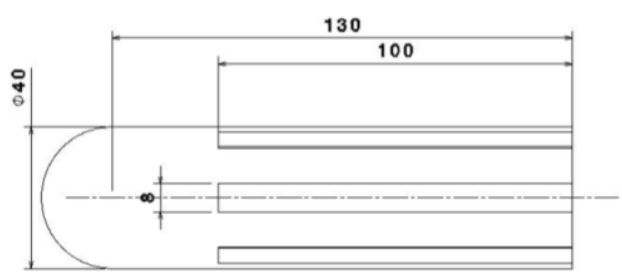

B

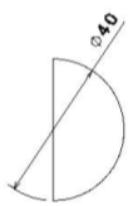

Figura 21 - Vista frontal (A), lateral esquerda (B) e traseira (C) com cotas em mm para a confecção do molde da peça 1 .

A segunda peça, Figura 20-B, não possui chanfros, pois no projeto não havia a necessidade de ter sensores ao longo de toda a parede do esôfago. Como vimos na Fundamentação Teórica, apenas uma porção do esôfago faz contato o átrio esquerdo e, portanto, tem risco de ser lesionada. Sendo assim, a peça pode ser lisa e igualmente funcional. Como na primeira peça, o comprimento é de $150 \mathrm{~mm}$ e o diâmetro de $40 \mathrm{~mm}-$ na Figura 22 estão as vistas e as cotas para a peça 2.

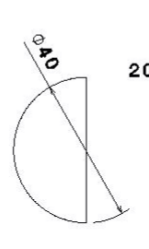

A

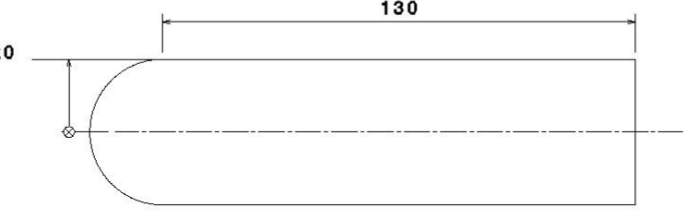

B

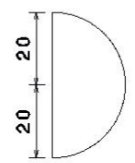

C

Figura 22 - Vista frontal (A), lateral esquerda (B) e traseira (C) com cotas em mm para a confecção do molde da peça 2. 
A Figura 23 mostra uma implementação preliminar do CETER - uma simulação 3D sem sensoriamento. Com esta simulação, já se pode observar que as duas peças formam uma só estrutura. E a localização dos scalps - um em cada peça, para fazer a água circular - e um diante do chanfro do meio - para a fiação dos sensores.
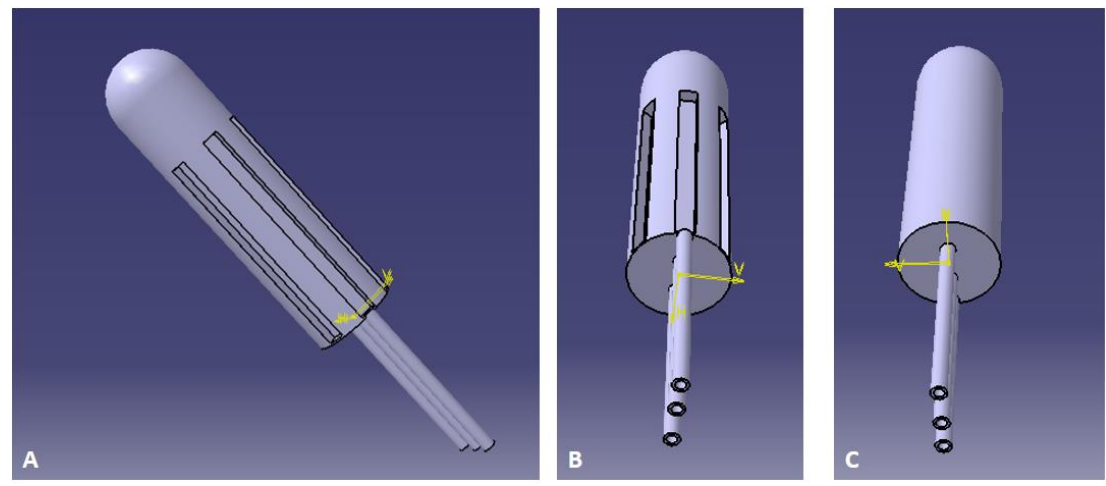

Figura 23 - Visualização em 3D da confecção do molde sem sensoriamento. A: vista isométrica. B: visualização da peça 1. C: visualização da peça 2.

\subsubsection{ESTRUTURA GERAL DO SISTEMA IMPLEMENTADO}

A construção do módulo esofágico parte da ideia de manter a temperatura do esôfago mais baixa do que a temperatura ambiente $\left(37^{\circ} \mathrm{C}\right.$, temperatura do corpo $)$ - por volta de $0^{\circ} \mathrm{C}$ - e, assim, criar uma barreira térmica com a intensão de evitar as lesões no órgão. Dessa forma, 9 Peltiers e 4 termistores formam o sensoriamento do CETER. Os termistores para o controle da temperatura no esôfago, durante a ACRF, e os Peltiers para refrigeração. A Figura 24 apresenta uma simulação 3D do CETER com sensoriamento - os sensores estão identificados na figura. Onde se lê barreira térmica pode-se considerar como condição de contorno favorável ao aquecimento excessivo.
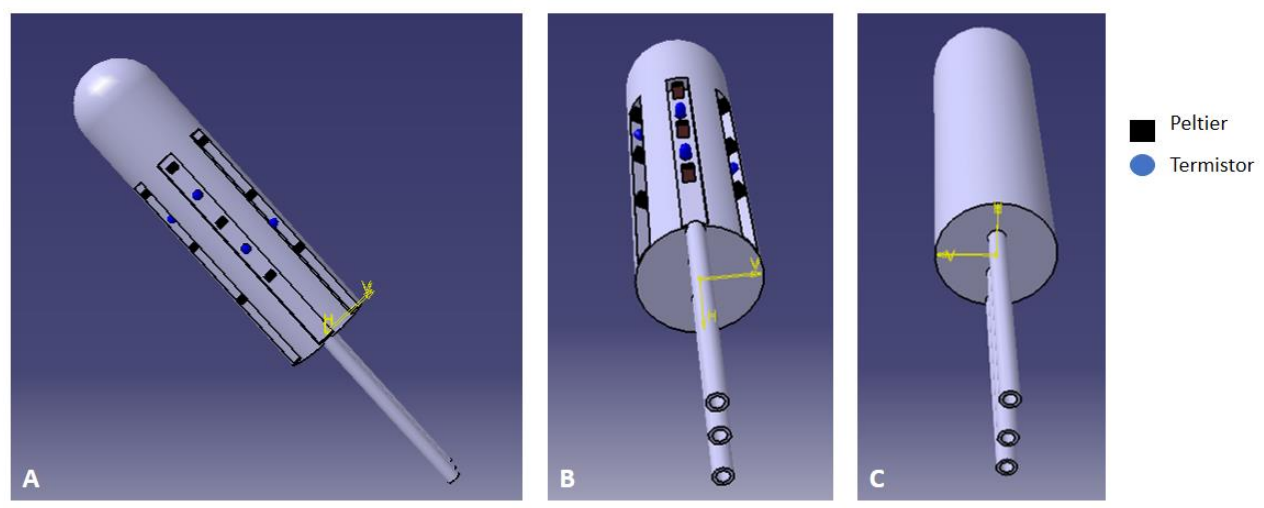

Figura 24 - Simulação em 3D da confecção do molde com sensoriamento. A: vista isométrica. B: visualização da peça 1 . C: visualização da peça 2. 
A Figura 25-A mostra esquema de irrigação do CETER. O scalp na peça 1, chanfrada, serve para bombear água gelada para o interior do módulo e resfriar a parte quente do Peltier. De acordo com o efeito de Peltier, o resfriamento e aquecimento ocorrem quando aplicamos uma diferença de potencial na célula de Peltier, que gera uma corrente elétrica responsável por gerar um gradiente de temperatura entre as faces. É por causa desse gradiente de temperatura entre as faces da célula, que ocorre o fluxo de calor, onde o resfriamento de Peltier fará o calor mover de um lado para o outro das faces.

Assim, o Peltier está isolado - parte quente para dentro do CETER e parte fria para fora do CETER. Para esse projeto a água será utilizada como dissipador, para poder dissipar o calor da face quente do Peltier. O corte transversal na estrutura, Figura 25-B, mostra que o CETER é "oco", pois por ele será feita a troca de calor utilizando a água. Também nessa imagem, podemos visualizar a parede interna do CETER e a localização dos furos que interligam os dois lados.

Ou seja, a água fria entra e promove a dissipação do calor na face quente do Peltier, e através de pequenos furos, na parede do meio do módulo, retorna para o recipiente pelo o outro lado do módulo, sem sensores. Essa água que sai é novamente refrigerada e bombeada para dentro módulo. Dessa forma, o CETER vai manter a temperatura de $0{ }^{\circ} \mathrm{C}$ na parede do esôfago.
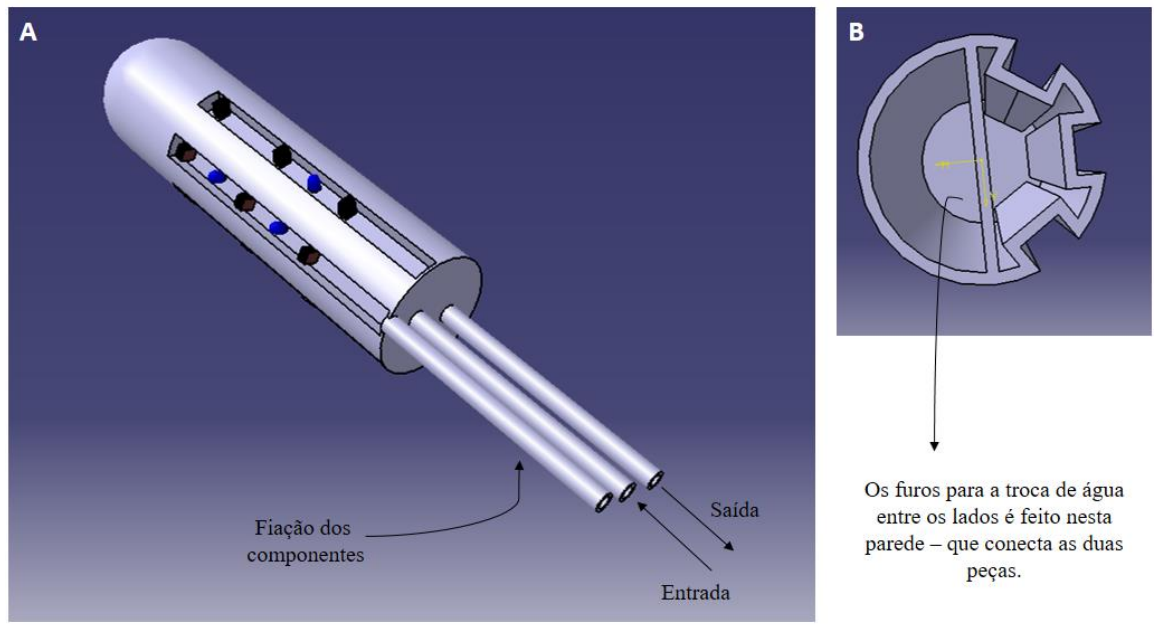

Figura 25 - A: Esquema da entrada e saída de água e da acomodação da fiação dos componentes. B: Corte na peça para visualização da parede interna do CETER e da localização dos furos que interligam os dois lados.

\subsubsection{DISPOSIÇÃO MATRICIAL DOS SENSORES}

Os termistores e os sensores Peltier estão dispostos em formato matricial, em que suas posições de linhas e colunas são equidistantes entre si, como ilustrado na Figura 26. Esse formato permite construir uma grade de temperatura - que possibilita a construção de 
um gráfico de gradiente das temperaturas internas no esôfago -, e definir a condição de contorno proporcionada pelo Peltier. A partir disso é possível captar os dados necessários para a pesquisa.

A forma matricial proporciona uma melhor disposição dos sensores e faz com que a barreira térmica fique clara. Onde se lê barreira térmica pode-se considerar como condição de contorno favorável ao aquecimento excessivo. $\mathrm{O}$ formato cilíndrico do esôfago também foi outra variável que favoreceu a escolha desse modelo. Assim, a forma que a matriz é fechada e possibilita a cobertura de toda a área necessária do tubo esofágico que faz contato com o AE. As temperaturas são captadas de forma planar-que é mais intuitiva ao usuário.

A altura é de $60 \mathrm{~mm}$, sendo $30 \mathrm{~mm}$ entre um Peltier e o outro, e de $15 \mathrm{~mm}$ entre o Peltier e o termistor. A largura, que é o comprimento da superfície da peça 1 do molde, é de 125,6 $\mathrm{mm}$. Além disso, os termistores tem $1 \mathrm{~mm}$ e o sensor Peltier tem $2 \mathrm{~mm}$ de largura, $4 \mathrm{~mm}$ de comprimento e $3 \mathrm{~mm}$ de profundidade. A porção torácica do esôfago que se relaciona com a aorta, átrio esquerdo e as veias pulmonares possui cerca de $40 \mathrm{~mm}$. Portanto, a matriz de sensores cobre toda a área de interesse do escopo do trabalho.
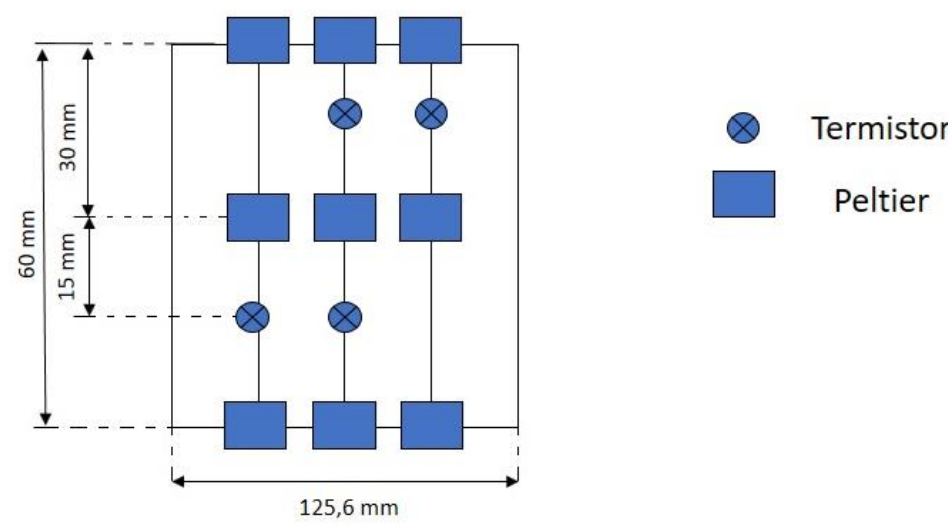

Figura 26 - Disposição matricial dos sensores no CETER.

\subsection{SIMULAÇÃO NUMÉRICA DA ABLAÇÃO}

Modelos computacionais são formas úteis para simular fenômenos físicos. A ideia desta parte da dissertação é simular a ablação cardíaca por RF utilizando o método de diferenças finitas. O objetivo é analisar a distribuição da temperatura no esôfago e responder as perguntas de pesquisa - a monitorização e o resfriamento do módulo esofágico geram uma melhor distribuição de temperatura com o uso do dispositivo Peltier?

O modelo será construído de forma análoga ao trabalho publicado por Berjano [9], que utilizou a equação de Pennes para simular os efeitos da ablação no esôfago. Com sua pesquisa, Berjano conseguiu monitorizar a área que faz contato com o esôfago e o átrio esquerdo e criar parâmetros para os equipamentos cirúrgicos [32]. 
Em um estudo feito por Berjano [44], em 2017, os resultados de uma simulação matemática mostraram que quanto menor a duração do pulso de RF (mantendo a energia constante), maior a profundidade da lesão durante a fase de resfriamento. Por exemplo, após um pulso de 10 segundos, a profundidade da lesão cresceu de 2,05 mm, no final do pulso para 2,39 mm (17\%), enquanto que, após um pulso de RF ultra-curto de apenas 1 segundo, o crescimento extra foi de $37 \%$ (de 2,22 a 3,05 mm).

Enquanto a redução do tempo de pulso produziu lesões mais profundas, o aumento associado da tensão aplicada causou superaquecimento no tecido. No entanto, uma vez que a profundidade da lesão aumentou durante o período de resfriamento, os valores baixos da taxa de transferência aplicada podem ser aplicados nas últimas transposições para obter danos semelhantes aos de maior duração, evitando o superaquecimento [44], [45].

O modelo teórico leva em consideração três elementos: o eletrodo para ACRF, a parede do átrio esquerdo, a gordura e a parede do esôfago, Figura 27-A. O domínio computacional utilizado na simulação inclui a parede e o tecido conjuntivo (gordura e a parede do esôfago). Duas condições diferentes de contorno foram simuladas. A primeira, Figura 27-B, propôs o resfriamento em $0^{\circ} \mathrm{C}$ na parede do esôfago. E para fazer uma comparação entre a distribuição de temperatura, a segunda - Figura 27-C, utilizou a parede do esôfago com $37^{\circ} \mathrm{C}$ (a temperatura média do corpo). O fluxo sanguíneo não foi considerado.

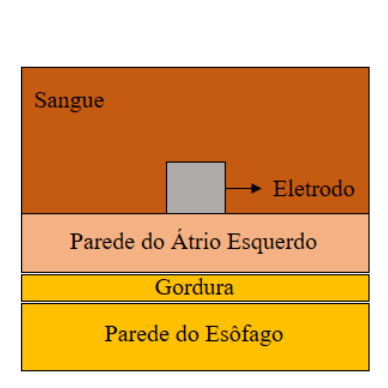

A

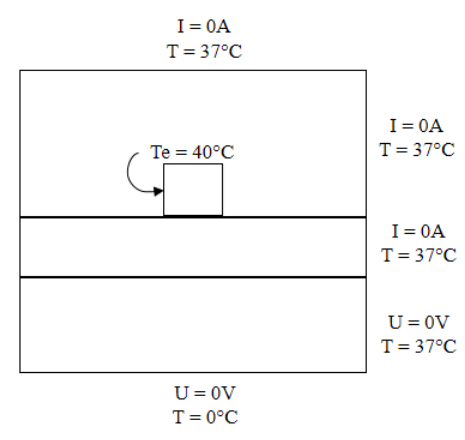

B

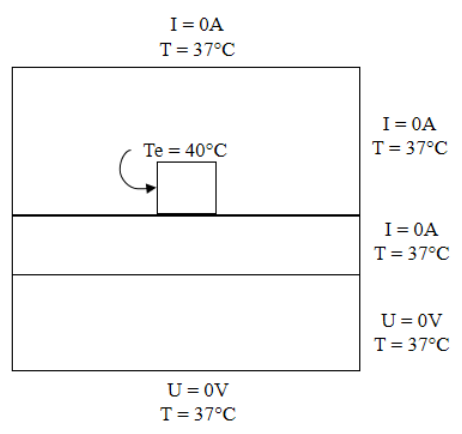

C

Figura 27 - Representação 2D do modelo geométrico utilizado na simulação da ACRF.

$\mathrm{O}$ eletrodo dispersivo (tensão em zero volts, $\mathrm{U}=0 \mathrm{~V}$ ) está nos limites do tecido conjuntivo dos dados do eletrodo ativo. Essas fronteiras representam uma superfície que coincide e uma distância suficiente aproximadamente com a área de um eletrodo dispersivo padrão. A distribuição da temperatura dentro do tecido foi obtida por meio da resolução da equação do bio-aquecimento.

A equação de bio-transferência de calor de Pennes [46] fornece as distribuições de temperatura adequadas aplicadas nos órgãos em estudo. De acordo com o modelo de Pennes, 
a troca total de energia pelo sangue corrente é proporcional ao fluxo de calor volumétrico e à diferença de temperatura entre o sangue e o tecido [13], [44], [45]. A expressão bidimensional da equação de bio-aquecimento de Pennes em um meio com propriedade de material uniforme é dada por

$$
\rho \mathrm{C} \frac{\partial T}{\partial t}=\mathrm{k}\left(\frac{\partial^{2} T}{\partial x^{2}}+\frac{\partial^{2} T}{\partial y}\right)+Q_{m}+Q_{r}(\mathrm{x}, \mathrm{y}, \mathrm{z}, \mathrm{t})
$$

onde T é a temperatura em ${ }^{\circ} \mathrm{C}, \rho$ é a densidade $\mathrm{kg} / \mathrm{m}^{3}, \mathrm{C}$ é o calor específico do tecido $\mathrm{J} /\left(\mathrm{kg}^{\circ} \mathrm{C}\right)$, k é a condutividade térmica $\mathrm{W} /\left(\mathrm{m}^{\circ} \mathrm{C}\right), Q_{m}$ é a taxa metabólica de geração de calor $\mathrm{W} / \mathrm{m}^{3}$, e $Q_{r}$ são as fontes regionais de calor $\mathrm{W} / \mathrm{m}^{3}$. A equação 16 é uma versão simplificada e não leva em consideração a perfusão sanguínea.

Como a ACRF acontece com o eletrodo diretamente no tecido atrial, a perfusão não será considerada. Bem como, outras fontes regionais de calor. Assim, a equação implementada na simulação é

$$
\rho \mathrm{C} \frac{\partial T}{\partial t}=\mathrm{k}\left(\frac{\partial^{2} T}{\partial x^{2}}+\frac{\partial^{2} T}{\partial y}\right)+Q_{m}
$$

As variáveis independentes do modelo são a temperatura (T) e a tensão (V). Ao se tentar aproximar o comportamento do corpo humano com relação às variações de temperatura, e seu reflexo em outros sistemas, podemos chegar a uma grande variação da perfusão e da condutividade elétrica quando a temperatura se eleva. Isso acontece porque o corpo humano possui basicamente água e as alterações nos metais e sais das células podem causar essas variações.

Se a temperatura na ponta do cateter de ablação aumentar rapidamente, as células ao redor desse cateter começam a sofrer um processo de necrose (temperaturas acima de $50^{\circ} \mathrm{C}$ ). Passam a não transmitir calor e a bloquear a corrente, porque a resistividade $\left(\frac{1}{\sigma}\right)$ da célula tende ao infinito e a condutividade $(\sigma)$ tende a zero. Se isso ocorrer, o aumento de temperatura não alcança a maior área possível, atingindo uma área concentrada e causando lesões. A Tabela 5 mostra as características físicas dos tecidos e dos materiais.

A perfusão não vai ser simulada, pela simplicidade do modelo bidimensional simulado na dissertação. Para trabalhos futuros, seria interessante trabalhar com a inclusão desses dados e avaliar o impacto da perfusão sanguínea no átrio durante a ablação cardíaca com a utilização da equação de Pennes. Neste trabalho, por decisão da autora, não será simulado unicamente pela simplificação proposta inicialmente. Outras considerações ficarão para trabalhos futuros. 
Tabela 5 - Características físicas dos tecidos e dos materiais.

\begin{tabular}{|c|c|c|c|c|c|c|}
\hline Estrutura & $\begin{array}{c}\lambda \\
{\left[\mathrm{W} . m^{-1} \mathrm{~K}^{-1}\right]}\end{array}$ & $\begin{array}{c}\rho \\
{\left[\mathrm{Kg} \cdot \mathrm{m}^{-3}\right]}\end{array}$ & $\begin{array}{c}C_{p} \\
{\left[\mathrm{KJ} \cdot \mathrm{Kg}^{-1} \mathrm{~K}^{-1}\right]}\end{array}$ & $\begin{array}{c}\rho_{b} \\
{\left[\mathrm{Kg} \cdot \mathrm{m}^{-3}\right]}\end{array}$ & $\begin{array}{c}C_{p b} \\
{\left[\mathrm{KJ} . \mathrm{Kg}^{-1} \mathrm{~K}^{-1}\right]}\end{array}$ & $\omega_{b}\left[s^{-1}\right]$ \\
\hline Eletrodo & 18 & 6540 & 840 & 0 & 0 & 0 \\
\hline $\begin{array}{c}\text { Parede do } \\
\text { átrio }\end{array}$ & 0,512 & 1060 & 3600 & 1000 & 4180 & 0,064 \\
\hline Esôfago & 0,512 & 1060 & 3600 & 1000 & 4180 & 0 \\
\hline Gordura & 0,512 & 1060 & 3600 & 0 & 0 & 0 \\
\hline
\end{tabular}

\subsection{EXPERIMENTO SIMPLIFICADO EM BANCADA}

O objetivo do experimento é obter a distribuição de temperatura entre o eletrodo do cateter de ablação e a parede do esôfago. O experimento é necessário para avaliarmos se, ao utilizar uma barreira térmica, nós conseguiríamos evitar o superaquecimento nos tecidos. E, dessa forma, minimizar as lesões causadas durante o procedimento de ACRF. Onde se lê barreira térmica pode-se considerar como condição de contorno favorável ao aquecimento excessivo.

O cateter escolhido, Figura 28, é o modelo SAFIRE TX, da empresa St. Jude Medical. A escolha do produto foi realizada de acordo com as características do cateter: deflexão bidirecional da ponta, bloqueio automático da direção que reduz a manipulação do cateter, a capacidade de monitorização da temperatura por meio de termistor e por ter formato ergonômico - facilitando o uso do equipamento. O SAFIRE TX foi adquirido pela equipe.

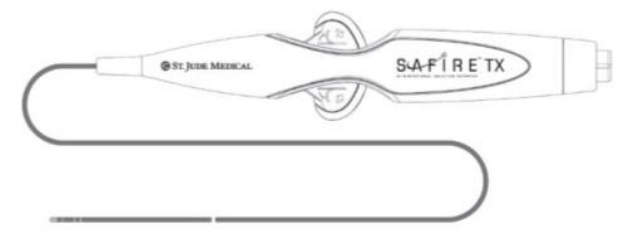

Figura 28 - Cateter de ablação, quadripolar, 7F, modelo SAFIRE TX, da empresa St. Jude Medical. [Imagem fornecida pela empresa St. Jude Medical]

Para fazer o controle do dispositivo Peltier será utilizado um controlador termoelétrico. O controlador escolhido foi o TC 48-20, da empresa TE Technology, Figura 29. O TC-48-20 é um controlador de temperatura PWM, possui um teclado e display e é capaz de controlar de 0 a 50 volts e até 20 amps de corrente. No trabalho usaremos a configuração de resfriamento. $\mathrm{O}$ controlador também pode ser conectado a um computador através de um cabo serial RS232 para controle da configuração. 
É necessário fazer a utilização de um termistor de referência, Figura 30 em contato com o Peltier para que seja obtida a temperatura desejada. O modelo escolhido foi o MP 31 93 da mesma empresa.

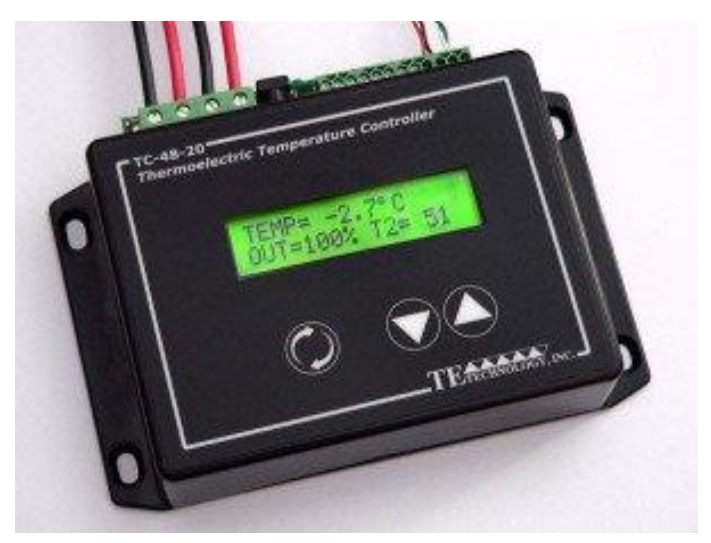

Figura 29 - Controlador TC 48-20, da empresa TE Technology. (Imagem comercial da empresa TE Technology)

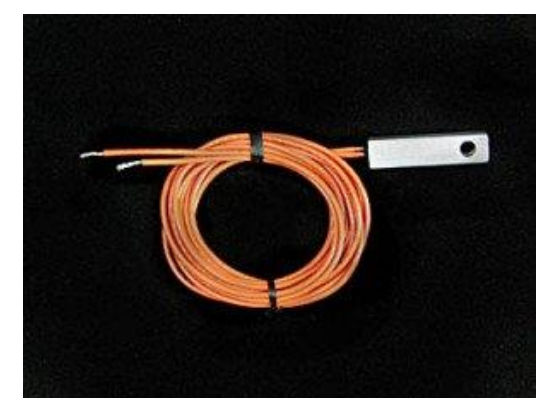

Figura 30 - Termistor de referência para o controlador TC 48-20. Modelo MP 31-93. (Imagem comercial da empresa TE Technology)

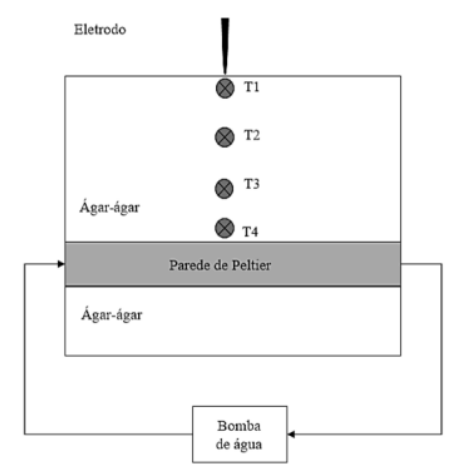

Figura 31 - Esquema com detalhamento do posicionamento dos elementos necessário para o experimento simplificado com barreira de térmica e simulação da ACRF. 
O presente trabalho tem como um dos objetivos criar uma barreira térmica, na Figura 31 denominada de parede de Peltier, para minimizar os efeitos da ablação. Para que a distribuição de temperatura seja obtida, quatro termistores estão alinhados na direção do eletrodo até a parede do esôfago. Onde se lê barreira térmica pode-se considerar como condição de contorno favorável ao aquecimento excessivo.

O experimento, inicialmente, não será realizado com o CETER. Neste primeiro momento, será feita uma simplificação. Mesmo assim os dados obtidos podem sustentar a hipótese de que com uma barreira térmica é possível mudar a distribuição de calor nos tecidos, criar uma melhor condição de contorno com o uso dos Peltiers e, assim, produzir dados pertinentes para serem analisados. Onde se lê barreira térmica pode-se considerar como condição de contorno favorável ao aquecimento excessivo.

A simulação da ablação é feita na bancada, em um ambiente controlado, com os elementos e instrumentos necessários para a realização do experimento. Esses instrumentos são o cateter para ablação, ágar-ágar, Peltier, a bomba de água, termistores e o computador para a aquisição dos dados.

A bomba de água serve para bombear água a $0^{\circ} \mathrm{C}$ na parede de Peltier, fazendo a dissipação de calor na face quente. Onde está escrito Parede de Peltier pode-se ter em mente que a face quente estará em contato com a água e a face fria está virada para a parede do esôfago que onde queremos resfriar. As faces são isoladas.

Para substituir os tecidos do átrio, do esôfago e da gordura, o experimento vai utilizar o gel ágar-ágar. Com relação a gordura, Berjano [13], em um estudo, provou que a camada de gordura não interfere na formação de lesões no esôfago durante a ACRF. Os termistores serão colocados em posições equidistantes para a observação das temperaturas nesses pontos. Esquemático na Figura 32.

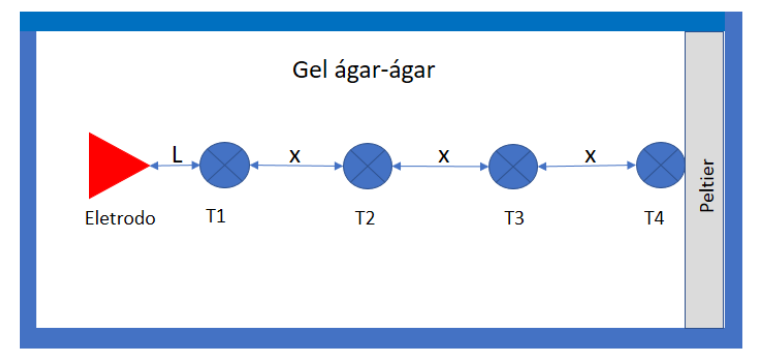

Figura 32 - Esquemático do experimento com distancias equidistantes entre os termistores e com o posicionamento da ponta do eletrodo.

Para facilitar a visualização do experimento, foi feita uma simulação 3D, no software CATIA, do que é esperado para o layout do experimento. A Figura 33 mostra como foi feita a distribuição dos elementos para a simulação. Na Figura 33-A é possível visualizar a 
disposição das duas caixas, a torre dos sensores, o Peltier e o termistor de referência. Na Figura 33-B tem-se a visão superior. Lembrando que a caixa de vidro estará cheia de ágarágar e a caixa de acrílico possui duas saídas, uma em cada extremidade, para que haja a troca água.

A caixa externa é de vidro, e a caixa interna é de acrílico. Na caixa de acrílico temos o dispositivo Peltier fixado e vedado com silicone. Há uma torre que coloca os termistores e o eletrodo diante do Peltier - as distancias serão discutidas na seção seguinte, Figura 34-A. Há também um termistor de referência que é utilizado pelo controlador para controlar a temperatura no Peltier - este está na base inferior do Peltier para não ter contato com o eletrodo e os demais termistores. A Figura 34-B mostra de forma mais próxima a disposição dos elementos.
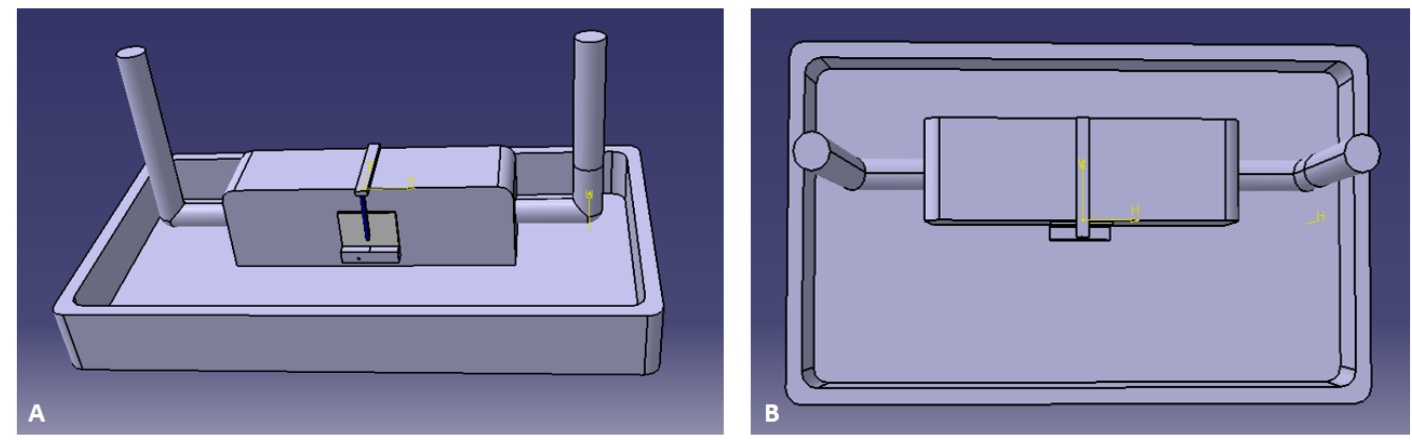

Figura 33 - Modelo 3D da disposição em bancada do experimento. A: visão completa do layout do experimento. B: vista superior.
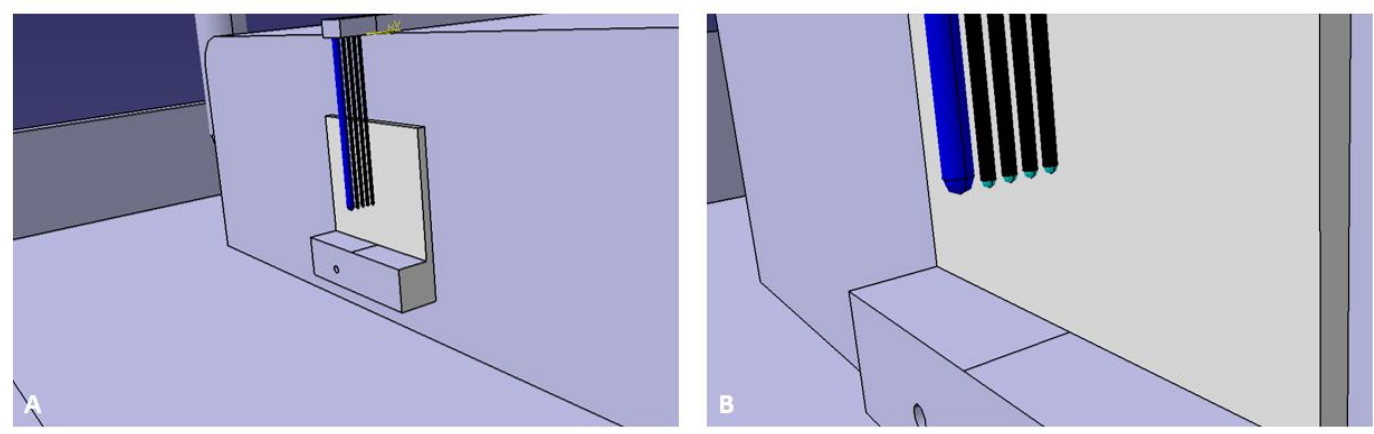

Figura 34 - Modelo 3D da disposição dos elementos para a simulação em bancada. A: vista lateral da caixa de acrílico. B: vista aproximada da disposição do eletrodo, termistores, Peltier e o termistor de referência do controlador.

A aquisição de dados é feita com a placa de circuito dos termistores implementada, o microcontrolador ATmega 2560, controlador TC-4820 e o computador. O processamento dos dados será feito no software MATLAB (Mathworks). 


\section{RESULTADOS}

Este capítulo apresenta os resultados obtidos na execução do projeto. Primeiramente, a fabricação da estrutura do CETER. Em seguida, os resultados para a simulação numérica simples do modelo proposto. Depois, são apresentados os circuitos implementados, a calibração dos termistores e o experimento em bancada são descritos nessa ordem. Por fim, têm-se as restrições que delimitaram o projeto.

\subsection{FABRICAÇÃO DA ESTRUTURA DO CETER}

Primeiramente, foi desenvolvido o molde para a construção do CETER. A Figura 35 mostra as duas peças desenvolvidas, o material de confecção foi o poliacetal - este foi modelado em torno mecânico por um parceiro do BioEngLab (Laboratório de Engenharia e Biomaterial, UnB). As cotas das peças estão na seção 3.3.2 da Metodologia. É possível perceber que a reprodução foi fiel ao modelo teórico e simulado. Por fim, foram adicionados dois cabos ao final de cada peça com o objetivo de facilitar o manuseio das peças e, então, fabricar uma estrutura com a menor intervenção possível.

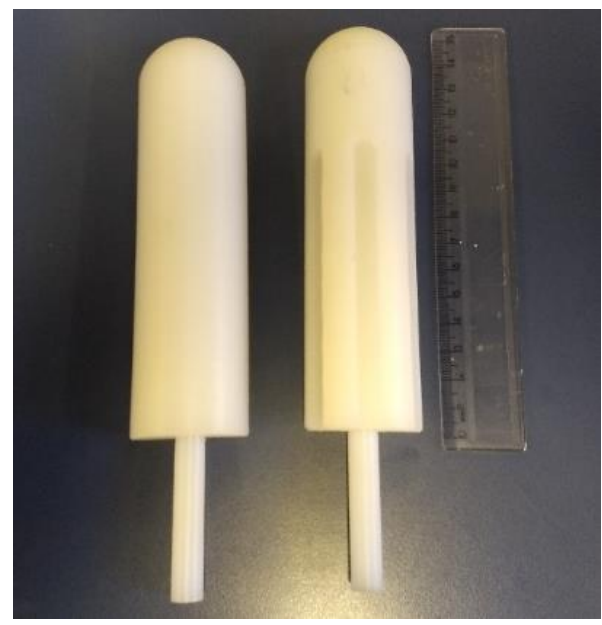

Figura 35 - Molde de poliacetal das peças 1 e 2, da esquerda para a direita, que formam a estrutura do CETER. Com cabos para o manuseio das peças.

Com o molde pronto, é necessário criar uma rotina de trabalho para a construção do cateter esofágico utilizando o látex puro. A Figura 36 apresenta um fluxograma para essa atividade. Primeiramente, o látex fica descansando para que não se formem bolhas e para que nata seja formada. Esse processo é necessário para garantir a homogeneidade do material. Para retirar a nata, foi utilizado uma espátula e a nata foi descartada. O látex utilizado é da empresa DU LÁTEX e já vem bicentrifugado e pré-vulcanizado. Esse processo está registrado na Figura 37. Foi utilizado luva em todo o processo de fabricação. 

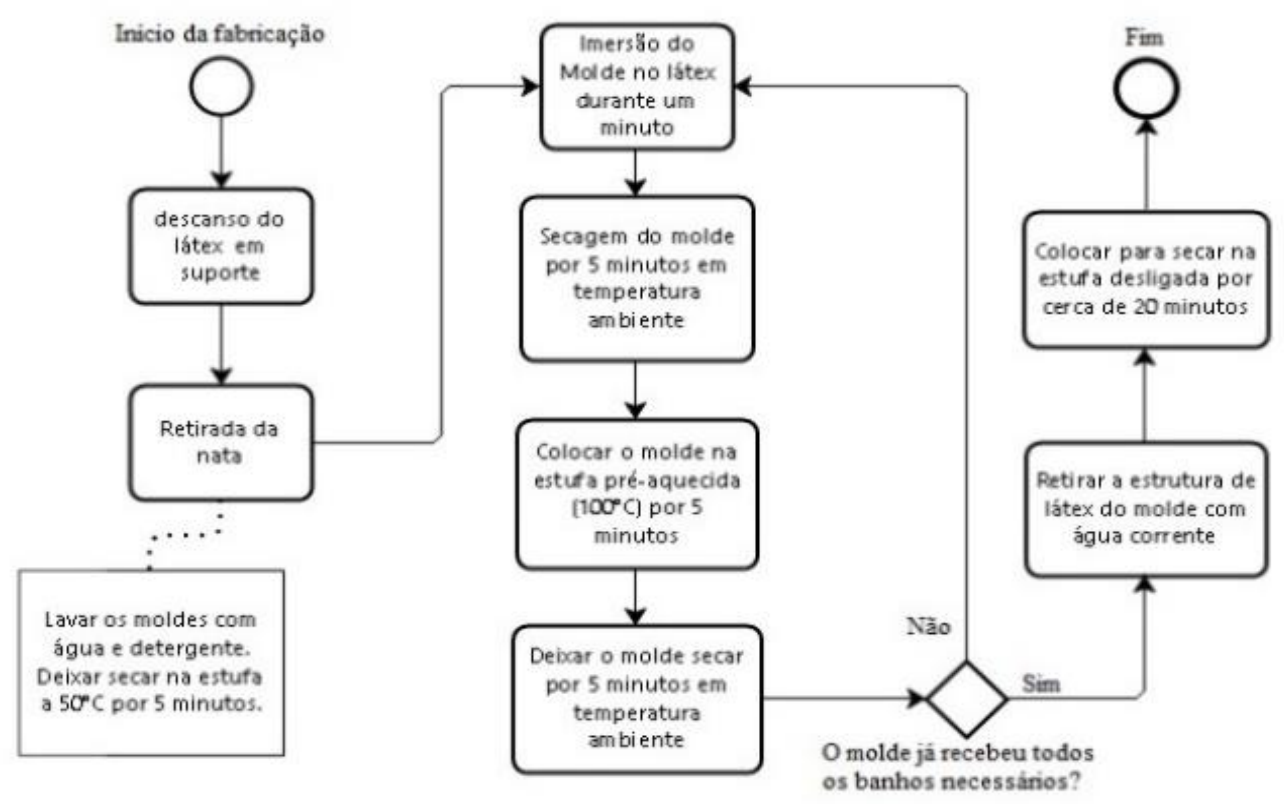

Figura 36 - Fluxograma para fabricação da estrutura do CETER com a descrição da rotina de desenvolvimento.
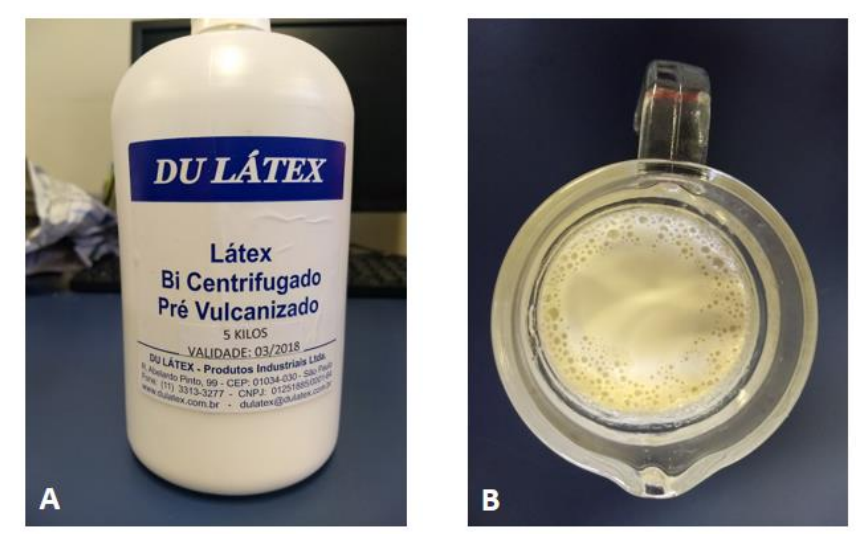

Figura 37 - Látex utilizado e a formação de nata durante o descanso do látex. A: látex bi centrifugado e pré-vulcanizado da marca DU LÁTEX. B: Nata de látex se formando e bolhas.

Em seguida, os moldes são lavados com detergente para que impurezas e gorduras sejam retiradas. Para a esterilização, os moldes secam por 5 minutos na estufa a $50^{\circ} \mathrm{C}$. O molde está pronto para fazer a imersão no recipiente, Figura 38. Essa etapa deve ser feita de forma lenta para não criar bolhas, tendo como meta a obtenção de uma parede resistente para o CETER, e levando em consideração que a espessura não pode ser muito grande. Isso porque a parede do CETER não pode ser muito rígida - pois vai ser introduzido no esôfago - e quanto maior o número de banhos em cima dos sensores, maior é a possibilidade deles apresentarem atenuação. Outra etapa importante é a secagem, pois garante a cura do látex. 

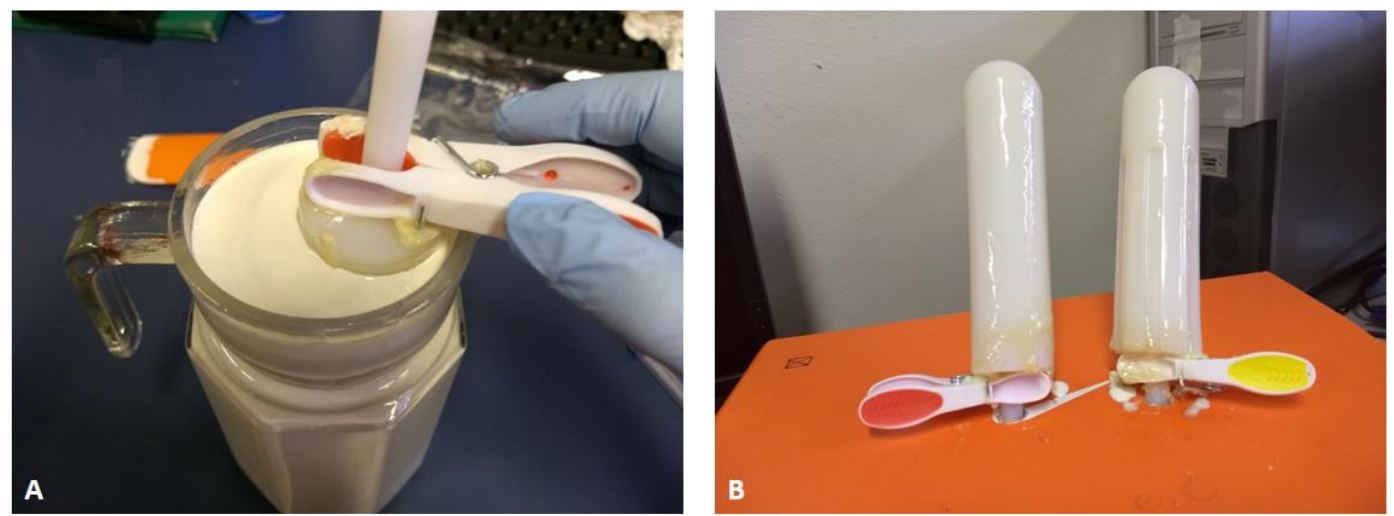

Figura 38 - A: banho de látex no molde. B: processo de secagem dos moldes após banho de látex.

O molde seca por 5 minutos depois do banho de látex em temperatura ambiente. Após esse ciclo, o molde é colocado na estufa pré-aquecida a $100{ }^{\circ} \mathrm{C}$ e permanece nela por mais 5 minutos. Na Figura 39 é possível identificar a estufa utilizada, bem como, visualizar a posição que o molde ficou dentro da estufa. É importante que o molde fique em uma posição que ele receba calor em todo o corpo. Se o calor for maior em alguma face, não haverá homogeneidade na estrutura e terá que ser descartado.
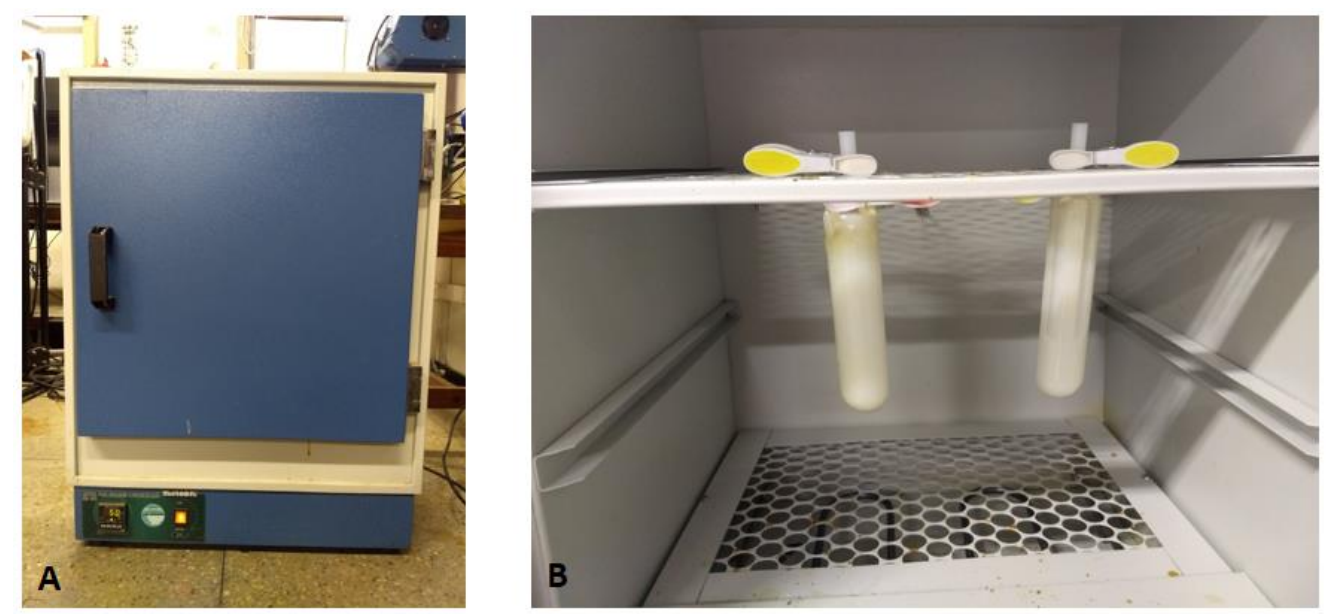

Figura 39 - A: estufa utilizada na fabricação da estrutura de látex. B: parte interna da estufa onde os moldes ficavam secando.

A ideia é que ocorra a menor quantidade de banhos possíveis. Isso, porque, uma parede com a espessura fina poderia criar uma acurácia maior na captação da temperatura e no resfriamento da parede do esôfago. A ideia é preencher os chanfros com os sensores de forma que o CETER fique com um aspecto homogêneo, porém respeitando a espessura da parede/melhor captação de dados. 
Com o fim da imersão, depois de adquirir $1 \mathrm{~mm}$ de espessura, o molde vai para a secagem final na estufa. Isso acontece porque o látex absorve água na hora em que é retirado do molde. Assim, tem-se a estrutura quase pronta do CETER. No modelo preliminar, foram realizados 25 banhos. Os moldes foram desenformados, secados, e besuntados com talco para que não grudassem.

O próximo passo foi cortar os moldes e deixá-los do tamanho desejado. Na Figura 40, as duas peças foram cortadas com $10 \mathrm{~mm}$ de comprimento. Para que as peças pudessem fazer a troca de água na parede interna, foram feitos furos próximos a parte abaulada da peça. $\mathrm{Na}$ Figura 37 está a estrutura final implementada e possui uma vista frontal com a peça $1 \mathrm{em}$ destaque, Figura 41-A, uma vista frontal com a peça 2 em destaque, Figura 41-B, e, por fim, a vista inferior do CETER na Figura 41-C. É possível observar que o cateter foi fechado com uma película de látex e os dois scalps de irrigação foram colocados e vedados com látex.
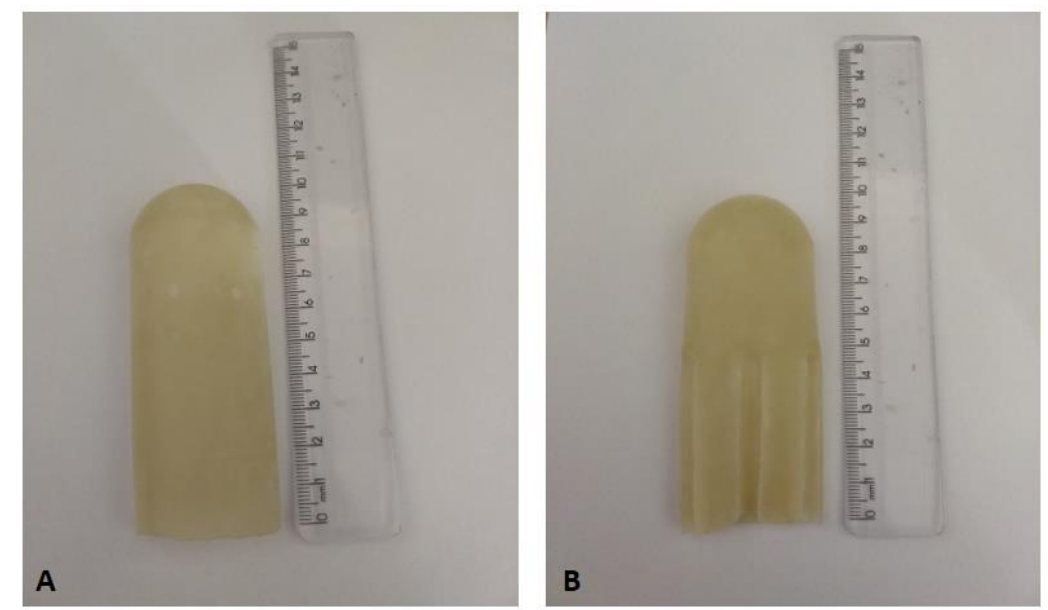

Figura 40 - Implementação das peças do molde do CETER em látex. A: peça 1. B: peça 2.
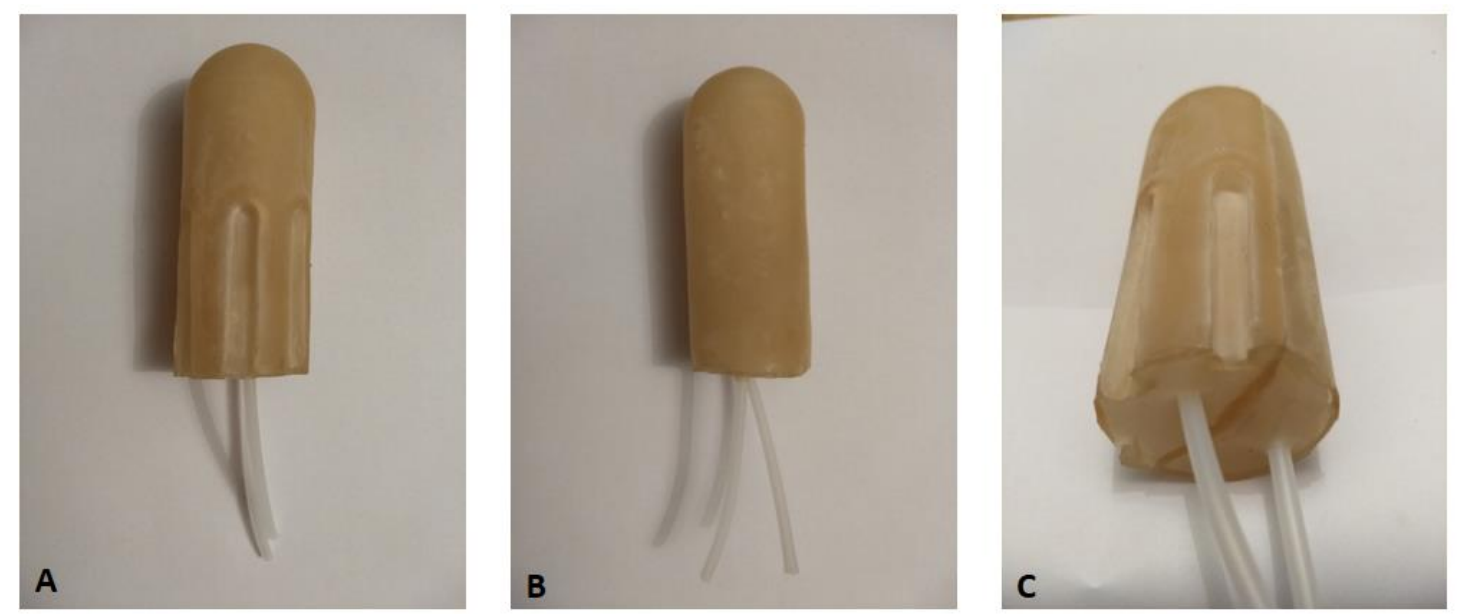

Figura 41 - Versão parcial da implementação do CETER com os scalps e sem os sensores. A: visualização da parede chanfrada. B: visualização da parede lisa. C: vista inferior. 


\subsection{SIMULAÇÃO NUMÉRICA}

O método utilizado para fazer a simulação foi o método de diferenças finitas. Este é um método que resolve equações diferenciais por meio de aproximações de derivadas por diferenças finitas. A partir das aproximações por diferença-quociente para derivadas de qualquer ordem, é possível transformar equações diferenciais em problemas lineares. Para isso, é necessário ignorar o termo de erro e tornar $h$ um número muito pequeno, mas grande o suficiente para que não cause instabilidades nas aproximações das derivadas.

A equação de bio-transferência de calor foi simulada com os seguintes parâmetros: as condições de contorno laterais são de $37{ }^{\circ} \mathrm{C}(310 \mathrm{~K})$, a condição inferior é de $0{ }^{\circ} \mathrm{C}(273$ $\mathrm{K})$ e $37{ }^{\circ} \mathrm{C}(310 \mathrm{~K})$; a corrente e a tensão são iguais a zero. A placa superior, que simula o eletrodo, está em $60{ }^{\circ} \mathrm{C}(333 \mathrm{~K})$ que é um valor médio para o eletrodo do ablador. Na Figura 42 pode-se observar uma representação da geometria da simulação. A temperatura de $37^{\circ} \mathrm{C}$ é a temperatura média do corpo humano, considerado nesse trabalho.

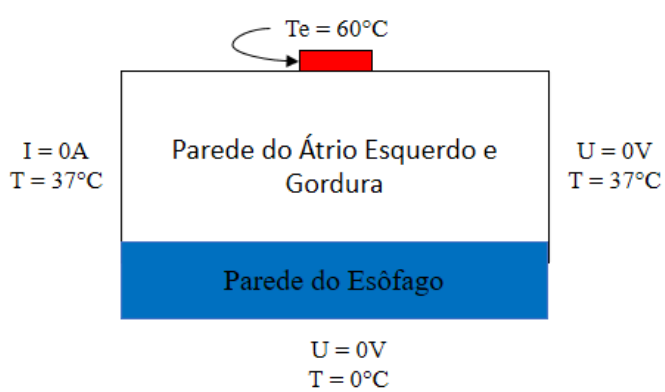

A

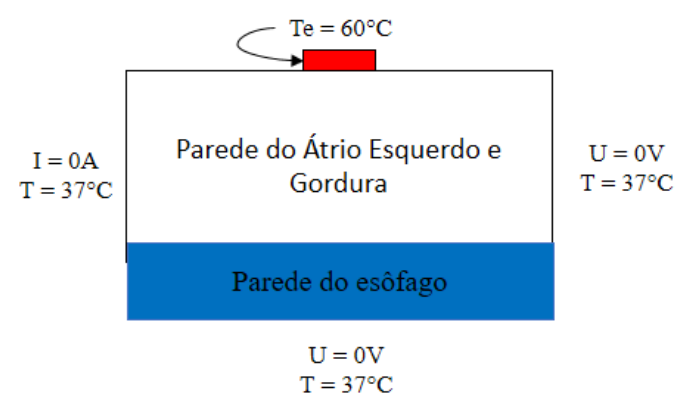

B

Figura 42 - Esquemático da simulação numérica. A: condição de contorno em $0^{\circ} \mathrm{C}$ na parede do esôfago. B: condição de contorno em $37^{\circ} \mathrm{C}$ na parede do esôfago.

As características físicas dos tecidos e dos materiais utilizados na simulação estão na Tabela 5. A ablação dura cerca de $900 \mathrm{~s}$. Na Figura 43 pode-se ver o gráfico gerado para a condição de contorno inferior de $0{ }^{\circ} \mathrm{C}$. Essa condição refere-se ao resfriamento gerado pelo dispositivo Peltier na parede do esôfago. A placa quente é a temperatura no átrio esquerdo. Podemos ver que o calor expande, porém, a barreira térmica cria um impedimento para esse calor chegar até o esôfago. Como o calor é difundido da maior temperatura para a menor temperatura, cria-se uma concentração de calor na região resfriada. Onde se lê barreira térmica pode-se considerar como condição de contorno favorável ao aquecimento excessivo.

Na Figura 44 tem-se o gráfico para a condição inferior de $37^{\circ} \mathrm{C}$. Neste caso, não temos a barreira térmica. É possível observar que, diferentemente da Figura 43, o calor está distribuído de uma forma diferente. A propagação do calor ocupa uma maior área até se 
aproximar da condição dos $37^{\circ} \mathrm{C}$. Isso significa que sem a barreira térmica o tecido seria queimado progressivamente e seriam geradas lesões profundas.

Os resultados dessas simulações parciais mostram que a barreira térmica criada na parede interna do esôfago pode evitar que o calor chegue em alta temperatura no órgão. Simulações mais refinadas podem prover resultados complementares e grau de certeza maior com relação à formação de fístulas. Os eixos X, Y, Z estão especificados nas legendas das Figuras 43 e 44.

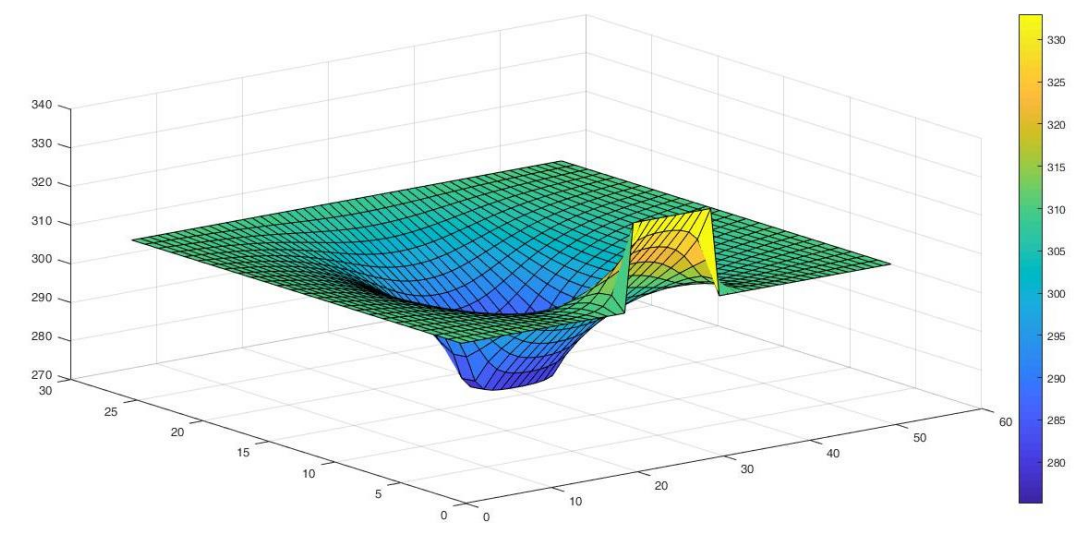

Figura 43 - Gráfico da simulação numérica 2D com a condição de contorno inferior em $0^{\circ} \mathrm{C}(273 \mathrm{~K})$. Eixo X: distância [mm]. Eixo Y: distância [mm]. Eixo Z: temperatura [K].

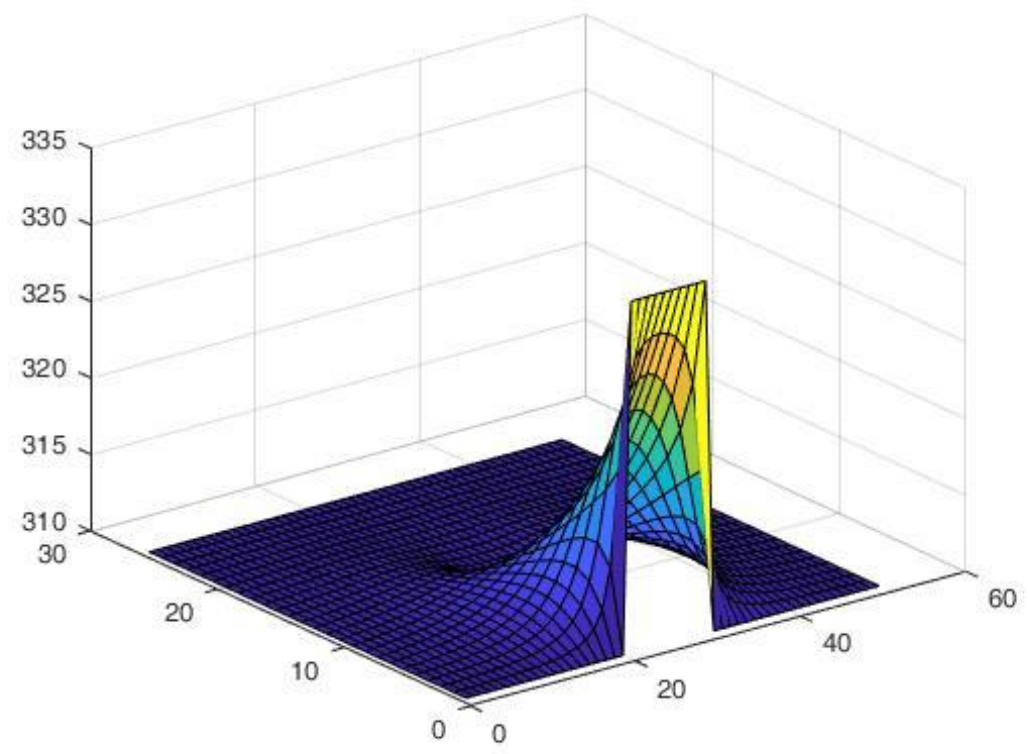

Figura 44 - Gráfico da simulação numérica 2D com a condição de contorno inferior em $37^{\circ} \mathrm{C}(310 \mathrm{~K})$. Eixo X: distância [mm]. Eixo Y: distância [mm]. Eixo Z: temperatura [K]. 


\subsection{IMPLEMENTAÇÃO DA PLACA DO CIRCUITO}

A placa final do circuito para a leitura das tensões do projeto, de acordo com o circuito (Figura 12) foi encomendado da empresa JLC PCB. É uma empresa coreana que imprime placas com baixo custo. Foram encomendadas dez placas por 25 dólares. A empresa disponibiliza um software online para o desenho do esquemático e implementação da PCB - o EasyEDA. O esquemático, já apresentado, bem como a PCB (Figura 45) foram implementados neste. A PCB possui duas faces.

O resultado final está na Figura 46 e apresentou um desing satisfatório e funcionamento adequado. Durante os testes da placa foi necessário retirar os trimpots que interferiam no ganho. No circuito revisado, e colocado na Metodologia do texto, a correção já está feita. Porém, como as placas já haviam sido encomendadas não foi possível retirar esse componente. No entanto, não houve perda para o projeto, pois o ganho dimensionado é um. Não há necessidade de colocar nenhum componente no INA - pinos 1 e 8 . O ganho é padronizado em um.

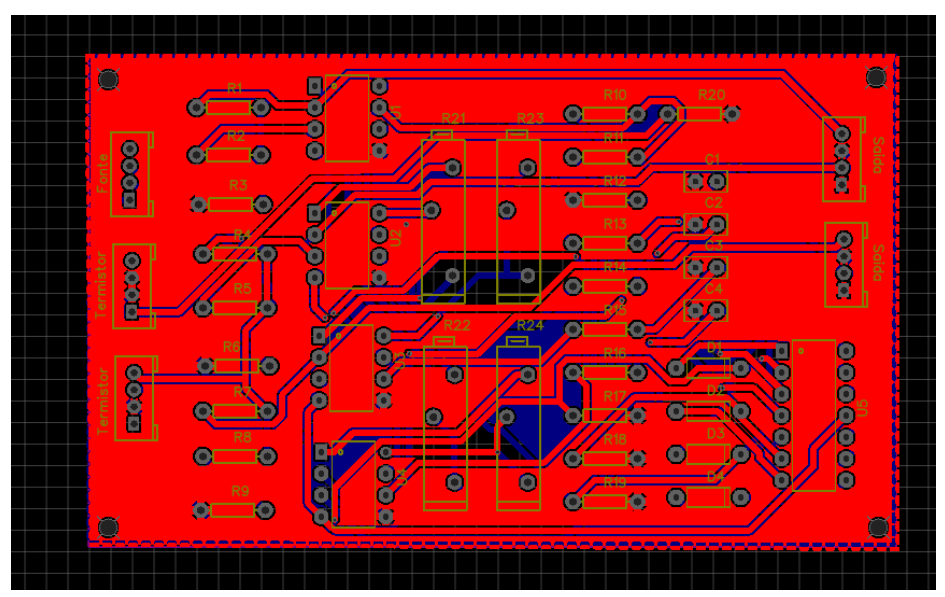

Figura 45 - Implementação da PCB do circuito para leitura das tensões nos termistores. Foi utilizado o software online EasyEDA.
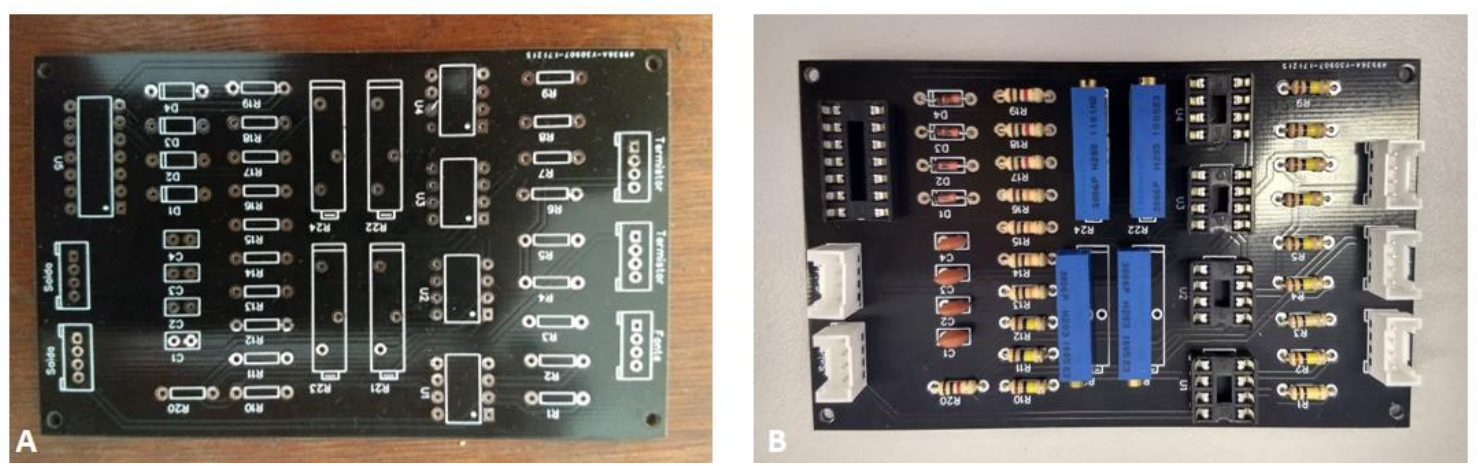

Figura 46- Placa final PCB do circuito para leitura das tensões nos termistores. 


\subsection{CALIBRAÇÃO DOS TERMISTORES}

Com a placa do circuito implementada, a calibração foi o passo seguinte. A calibração foi feita no banho maria e o método utilizado foi a comparação com o termômetro de referência externo ao circuito - equipamentos do LaB-UnB. O banho Maria utilizado foi o Banho Ultratermostatizado, MA 184, da empresa MARCONI (Figura 47-A). O termômetro é o Termômetro Digital, MV-362, da empresa Minipa (Figura 47-B e 47-C).

O processo consistiu em colocar os quatro termistores e o termômetro de referência em um tubo de ensaio alinhados (Figuras 1B e 1C). Esse tubo de ensaio foi colocado dentro do banho maria e a calibração começou. A temperaturas escolhidas para a calibração foram de $0{ }^{\circ} \mathrm{C}$ até $75^{\circ} \mathrm{C}$, de 5 em $5{ }^{\circ} \mathrm{C}$ - nos extremos a captação aconteceu com a diferença de $2^{\circ} \mathrm{C}$.
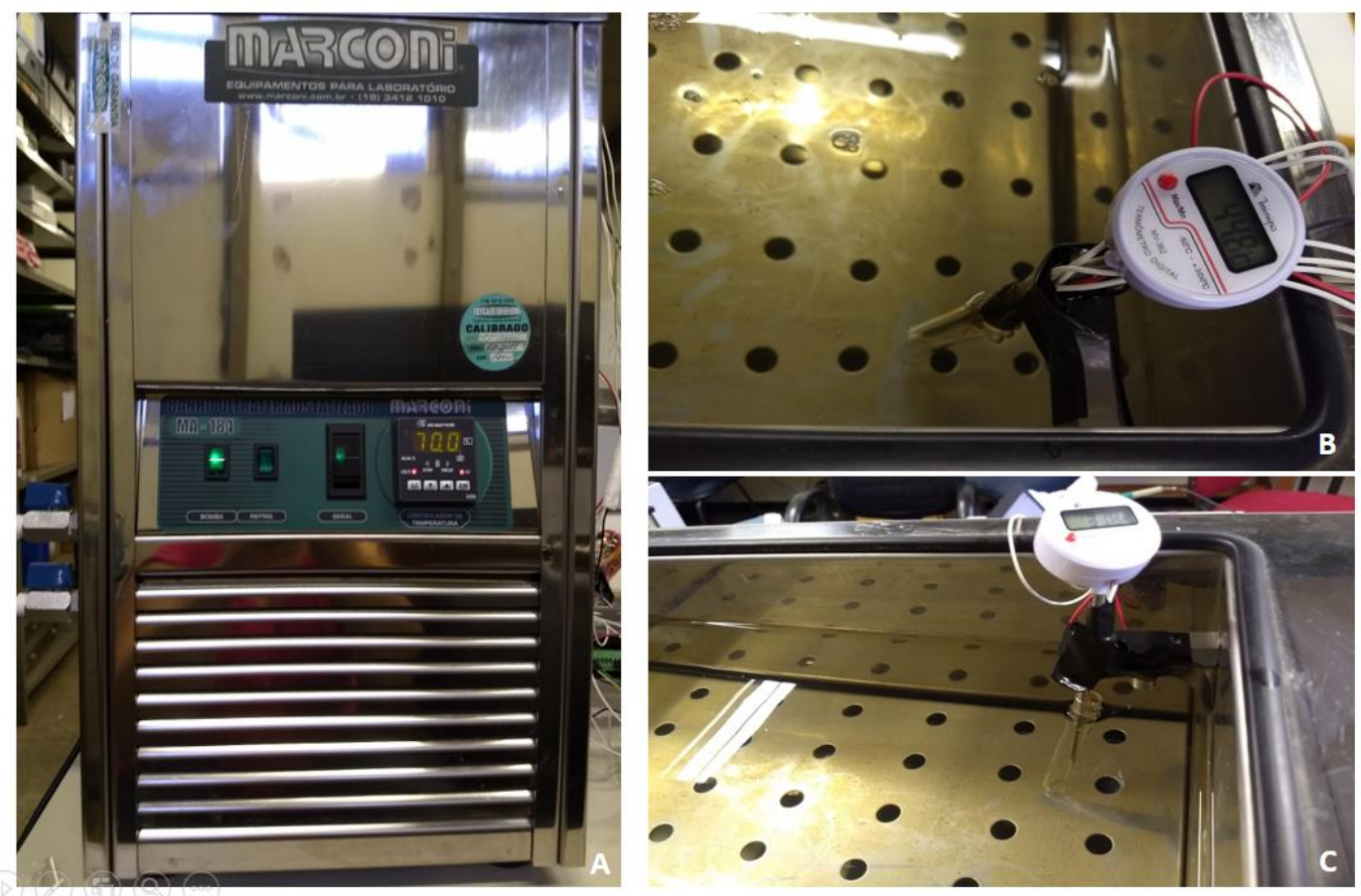

Figura 47- Calibração dos termistores. A: banho maria utilizado. B: vista superior do termômetro e dos termistores. C: vista lateral dos termistores e termômetro.

Cada temperatura foi associada a uma tensão e cada termistor teve a resposta para a variação de temperatura. Na Figura 48 está a base de operação para a calibração. A placa do circuito é alimentada pela fonte e ligada no Arduino. O Arduino é ligado no computador que obtém os dados. Na Tabela 6 estão os dados obtidos para cada termistor e temperatura. As temperaturas foram medidas em graus Celsius e as tensões foram obtidas em volts. Lembrando que a resolução do microcontrolador foi de 5/1023 V e cada amostra foi captada a cada 2 segundos. 
Com os dados obtidos, o passo seguinte foi a análise desses dados. O termistor é um componente não linear, por isso a necessidade da calibração, e as medidas obtidas deixam claro que cada um dos termistores, de acordo com os dados, vai ter uma equação correspondente.

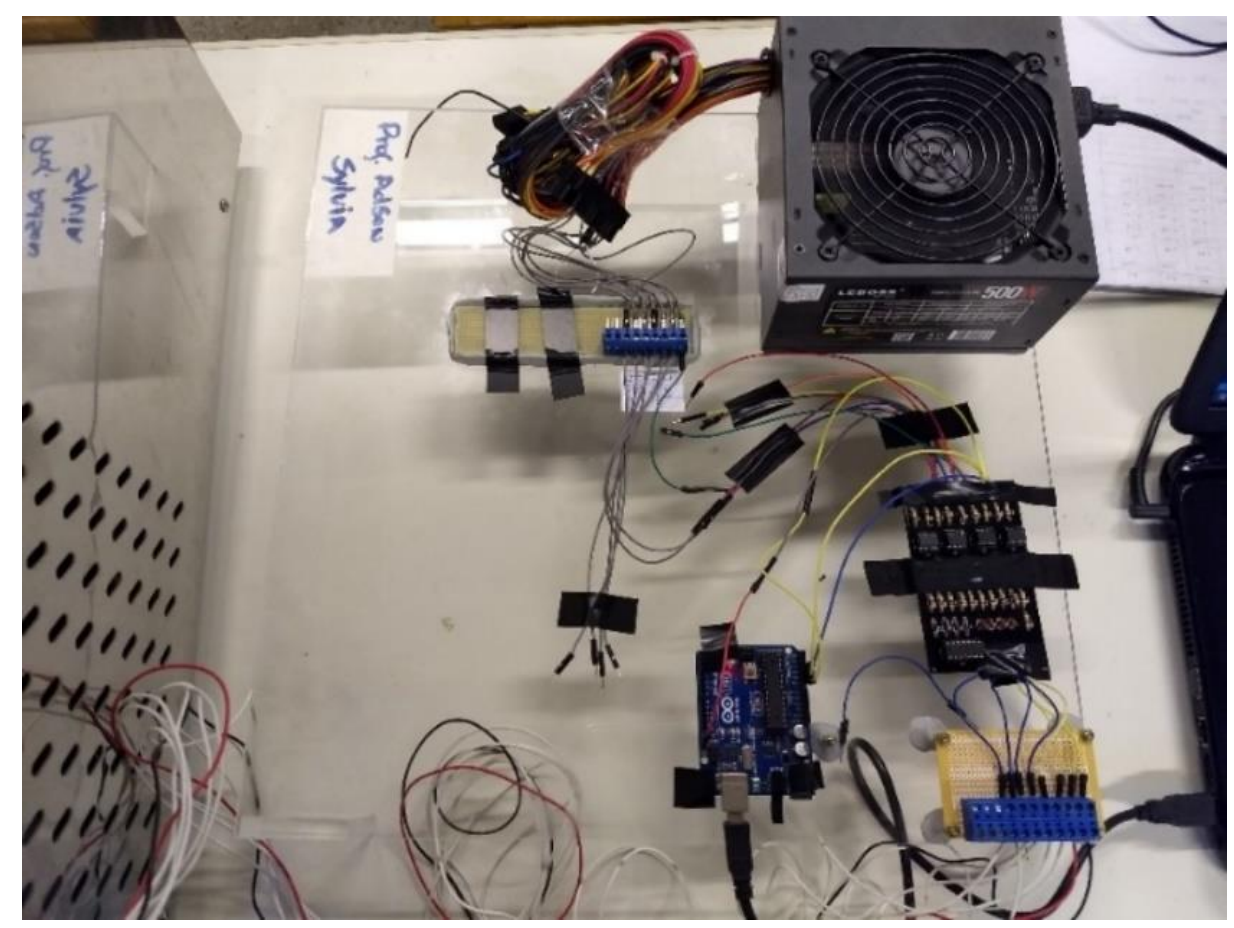

Figura 48- Layout para a calibração - fonte para alimentação da placa, a placa do circuito de leitura e o Arduino.

Tabela 6- Dados obtidos na calibração dos termistores. As temperaturas estão em ${ }^{\circ} \mathrm{C}$ e as tensões em volts.

\begin{tabular}{|c|c|c|c|c|}
\hline Temperatura $\left[{ }^{\circ} \mathrm{C}\right]$ & $\mathrm{T} 1[\mathrm{~V}]$ & $\mathrm{T} 2[\mathrm{~V}]$ & $\mathrm{T} 3[\mathrm{~V}]$ & $\mathrm{T} 4[\mathrm{~V}]$ \\
\hline 0 & 0,2 & 0,25 & 0,2 & 0,21 \\
\hline 0.5 & 0,21 & 0,25 & 0,21 & 0,22 \\
\hline 1 & 0,21 & 0,25 & 0,25 & 0,23 \\
\hline 2 & 0,22 & 0,28 & 0,28 & 0,26 \\
\hline 3 & 0,23 & 0,31 & 0,3 & 0,28 \\
\hline 5 & 0,35 & 0,32 & 0,38 & 0,35 \\
\hline 7 & 0,45 & 0,45 & 0,59 & 0,49 \\
\hline 10 & 0,7 & 0,64 & 0,7 & 0,68 \\
\hline 15 & 1,07 & 1,01 & 1,02 & 1,03 \\
\hline 20 & 1,31 & 1,38 & 1,4 & 1,36 \\
\hline 25 & 1,7 & 1,63 & 1,74 & 1,69 \\
\hline 30 & 1,99 & 1,96 & 1,96 & 1,97 \\
\hline 40 & 2,27 & 2,27 & 2,32 & 2,28 \\
\hline
\end{tabular}




\begin{tabular}{|c|c|c|c|c|}
45 & 2,4 & 2,51 & 2,58 & 2,49 \\
\hline 50 & 2,77 & 2,75 & 2,75 & 2,75 \\
\hline 55 & 2,93 & 2,97 & 2,95 & 2,95 \\
\hline 60 & 3,08 & 3,11 & 3,07 & 3,08 \\
\hline 63 & 3,15 & 3,15 & 3,18 & 3,16 \\
\hline 65 & 3,21 & 3,23 & 3,23 & 3,22 \\
\hline 67 & 3,26 & 3,26 & 3,29 & 3,27 \\
\hline 68 & 3,3 & 3,3 & 3,26 & 3,28 \\
\hline 69 & 3,31 & 3,3 & 3,3 & 3,3 \\
\hline 70 & 3,34 & 3,34 & 3,34 & 3,34 \\
\hline 72 & 3,39 & 3,38 & 3,39 & 3,38 \\
\hline 73 & 3,39 & 3,39 & 3,39 & 3,39 \\
\hline 75 & 3,39 & 3,39 & 3,39 & 3,39 \\
\hline
\end{tabular}

Os termistores, em conjunto com os circuitos de condicionamento, têm comportamento não linear, mostrado na Figura 49. Os pontos mostrados na Tabela 6 foram usados para se determinar quatro polinômios interpoladores de terceiro grau, na forma

$$
y=a x^{3}+b x^{2}+c x+d
$$

cujos coeficientes estão mostrados na Tabela 7. A forma dos polinômios de interpolação é mostrada na Figura 50.

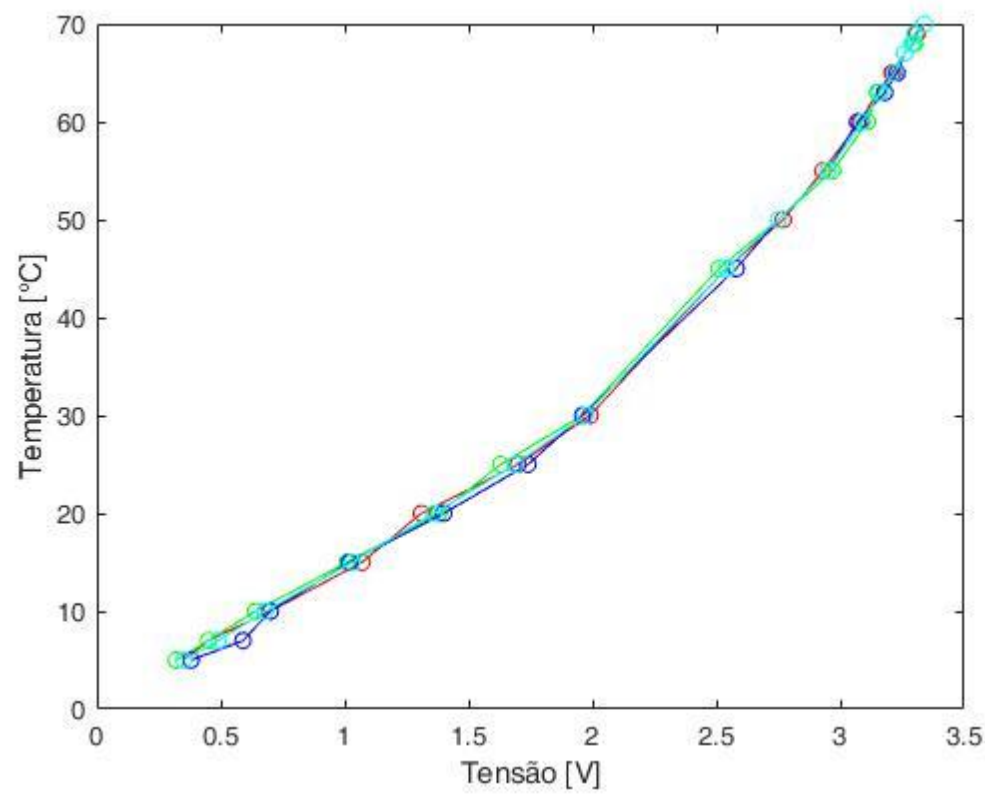

Figura 49 - Gráfico dos dados obtidos na calibração dos termistores. 
Tabela 7 - Coeficientes dos polinômios gerados para cada termistor com referência a equação 17.

\begin{tabular}{|c|c|c|c|c|}
\hline & $\mathrm{a}$ & $\mathrm{b}$ & $\mathrm{c}$ & $\mathrm{d}$ \\
\hline Termistor 1 & 1.1691 & -2.2045 & 15.2240 & 0.1525 \\
\hline Termistor 2 & 1.1809 & -2.4658 & 15.8445 & 0.2601 \\
\hline Termistor 3 & 1.3381 & -3.2111 & 17.1375 & -1.3252 \\
\hline Termistor 4 & 1.2520 & -2.7603 & 16.2944 & -0.3997 \\
\hline
\end{tabular}

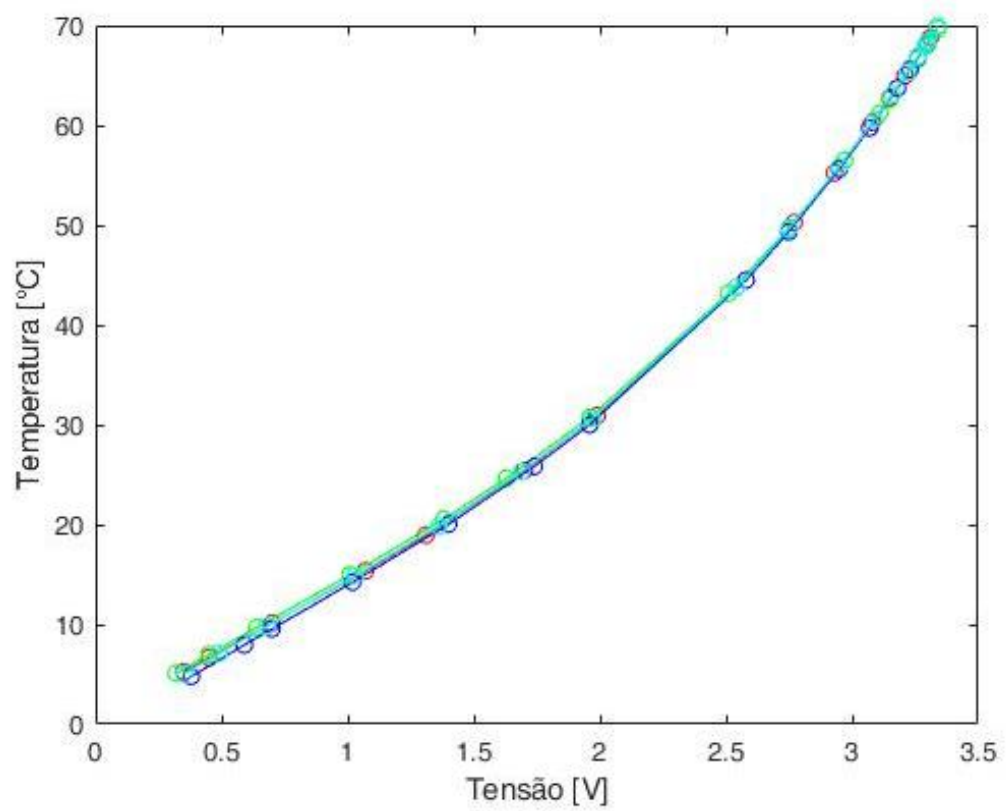

Figura 50 - Gráfico dos polinômios de interpolação obtidos para cada termistor.

O valor do erro RMS (do inglês, root mean square), entre as medidas das temperaturas feitas na calibração e das medidas obtidas através do polinômio de interpolação, está na Tabela 08 - para cada termistor.

Tabela 08 - Erro RMS obtido por meio das medidas da calibração e do polinômio gerado na interpolação.

\begin{tabular}{|c|c|}
\hline & Erro RMS $\left[{ }^{\circ} \mathrm{C}\right]$ \\
\hline Termistor 1 & 0.5146 \\
\hline
\end{tabular}




\begin{tabular}{|c|c|}
\hline Termistor 2 & 0.7523 \\
\hline Termistor 3 & 0.5392 \\
\hline Termistor 4 & 0.4776 \\
\hline
\end{tabular}

\subsection{EXPERIMENTO EM BANCADA}

O experimento em bancada foi construído em partes e cada parte foi testada para que fosse obtido um melhor resultado. O primeiro passo foi construir uma caixa, de acrílico, onde o Peltier pudesse ser fixado e que proporcionasse a convecção no lado quente deste. Por isso, essa peça foi montada com canos que pudessem ser fixados na bomba de água. A ideia é fazer com que a caixa simule o cateter. Foi utilizado somente um Peltier (modelo TEC1-12706).

O Peltier foi fixado com silicone, os lados quente e frio estão isolados, de modo que o lado quente está virado para dentro e o lado frio para fora. A caixa é oca e só recebe o fluxo de água - como dissipador do calor do lado quente. A bomba escolhida possui vazão de 1000 L/h, modelo SB1000C, da marca SarloBetter. A Figura 51-A mostra a caixa com o Peltier e duas ligas que prendem a tampa. A Figura 51-B mostra o encanamento desenvolvido - de um lado entra a água e do outro sai. Tanto a tampa, como o encanamento, foi vedada com silicone para que não houvessem vazamentos.
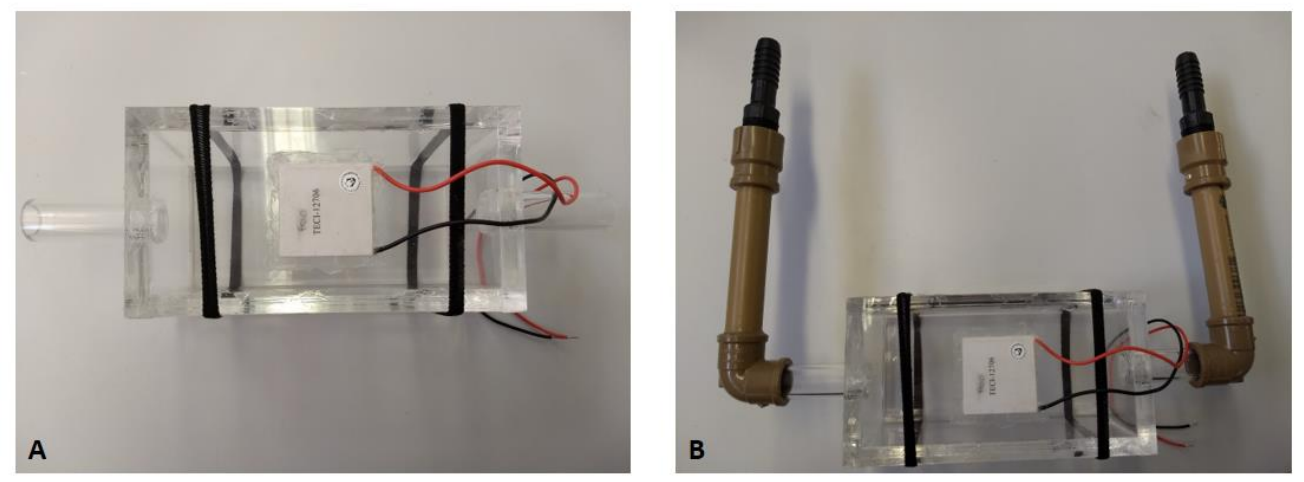

Figura 51 - Caixa para o Peltier. A: caixa com o Peltier inserido e vedado. B: caixa com o encanamento implementado.

Com a caixa montada, o próximo passo foi colocar o termistor de referência e o controlador para controlar a temperatura de saída do Peltier. O experimento tem como objetivo chegar a $0^{\circ} \mathrm{C}$ - para simular este resfriamento durante a ablação cardíaca por RF. Na Figura 52 pode ser observado como foi o teste. Na panela tinha água e a bomba, e fora 
dela estava a caixa do Peltier. Esse teste serviu para fazer reparos na vedação e para observar o funcionamento do controlador e do Peltier.

O layout implementado da caixa dos sensores foi simulado em 3D na metodologia. $\mathrm{Na}$ simulação, Figuras 33 e 34, é possível visualizar o posicionamento dos sensores. Lembrando que são informações que se complementam. Nesta seção há a construção física da simulação apresentada.

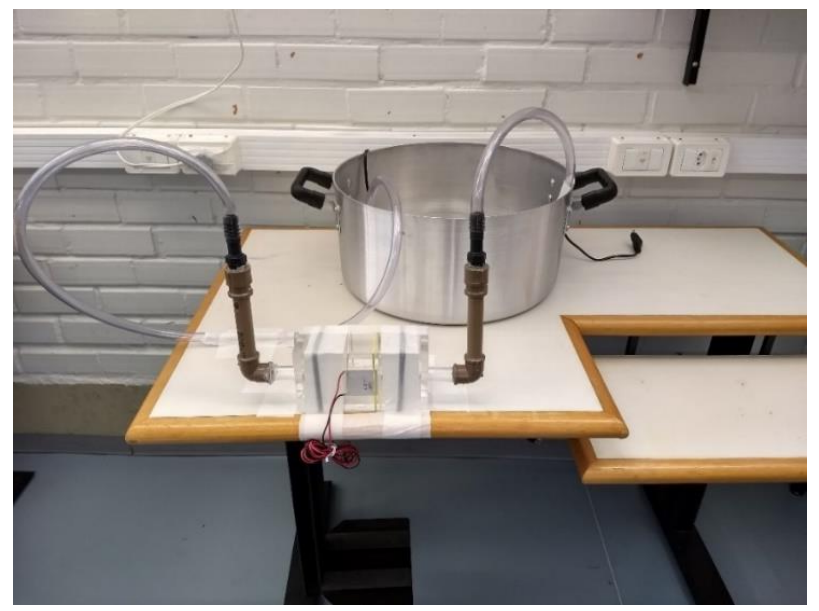

Figura 52 - Primeiro teste (verificar vazamentos) com a caixa do Peltier, a bomba de água e o controlador.

Após todos os reparos necessários serem feitos, o segundo teste de desempenho da estrutura montada foi com a imersão desta em água. Para fixar adequadamente o termistor de referência foi utilizado pasta térmica no contato com o Peltier e silicone para vedar e colar na posição que ele está - na parte inferior do Peltier. A Figura 53 mostra o momento em que esse teste estava em andamento.

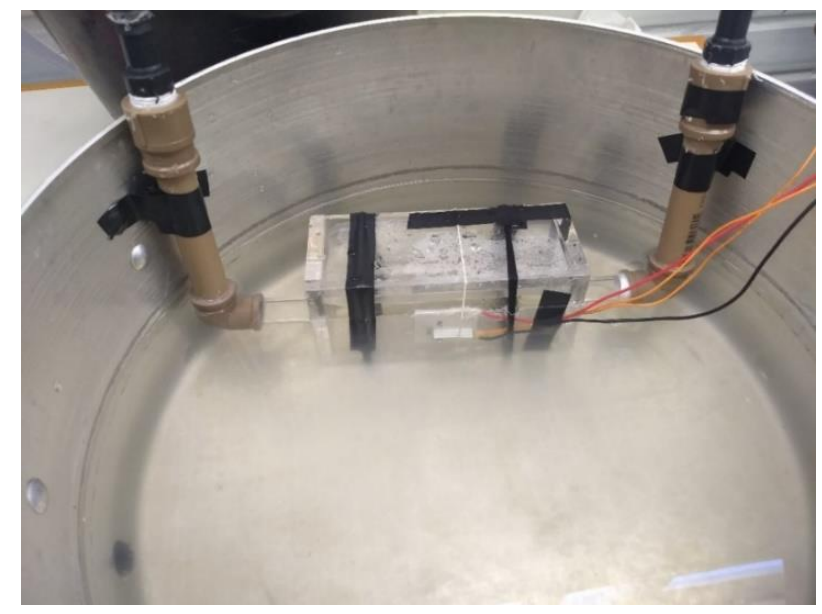

Figura 53 - Segundo teste com a caixa do Peltier imersa em água, a bomba de água e o controlador. 
O experimento consiste em simular a ablação cardíaca, com um eletrodo que emite RF, e obter a distribuição de temperatura ao longo da distância entre o eletrodo e o peltier (que proporciona o resfriamento). A princípio, foi considerado o pior cenário da distância possível entre o átrio esquerdo, tecido conjuntivo e a parede do esôfago. Isso porque a menor distancia possível deveria ser esta.

Berjano, nos trabalhos [13] e [44], afirma que a parede do átrio mede de 1.3 a $3.1 \mathrm{~mm}$ e o tecido conjuntivo cerca de $2.4 \mathrm{~mm}$. Os trabalhos [1], [13] e [45] colocam que a parede do esôfago tem cerca de 1.9 a $5.3 \mathrm{~mm}$. Assim, o pior cenário possível seria com a parede atrial medindo $1.3 \mathrm{~mm}$, o tecido conjuntivo $2.4 \mathrm{~mm}$ e a parede do esôfago com $1.9 \mathrm{~mm}$.

Para simular essa distância, os quatro termistores foram alinhados e com a distância total de $6 \mathrm{~mm}$ (Figura 54), aproximadamente. A distância entre eles foi cerca de $0.5 \mathrm{~mm}$, já que o próprio sensor mede cerca de $1 \mathrm{~mm}$. Eles foram fixados e isolados com fita isolante de forma que um deles estivesse encostado no Peltier e os outros estivessem distribuídos até chegar no ablador. Como foi explicado na metodologia, a parede de resfriamento está em contato com a parede do esôfago. Dessa forma, os quatro termistores pegam a distribuição da temperatura até o ablador. Para simular os tecidos foi utilizado gel ágar-ágar. Isso porque este possui características físicas e térmicas próximas as dos tecidos.

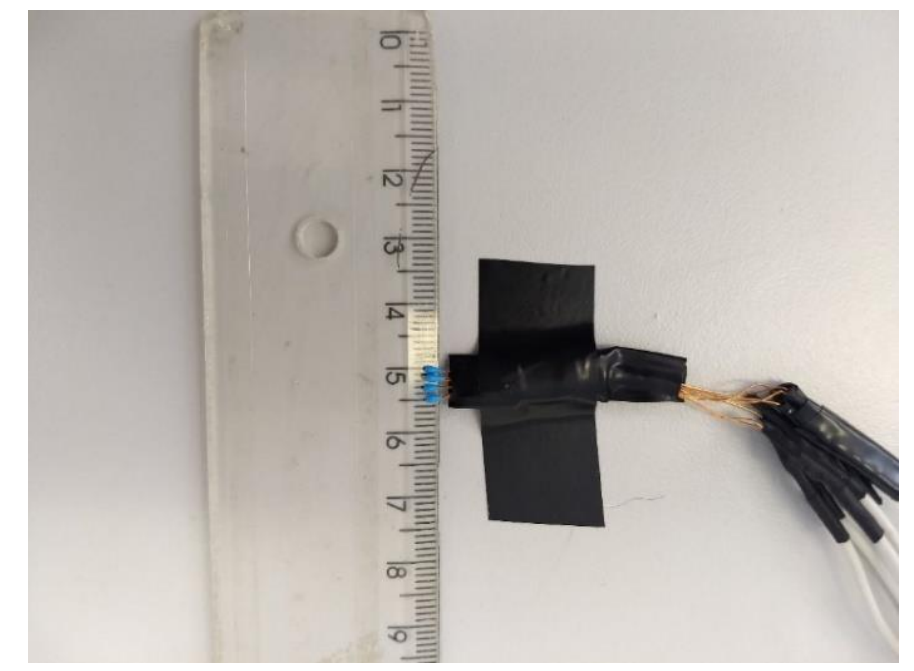

Figura 54 - Fixação dos termistores com distancia total de $6 \mathrm{~mm}$.

Para a conclusão da montagem dos equipamentos, todos os sensores foram fixados. Os quatro termistores e o eletrodo de ablação. A distância final entre o Peltier e o ablador foi de $15 \mathrm{~mm}$. Sendo que a distância total dos termistores foi de $6 \mathrm{~mm}$. A distância entre o primeiro termistor e o Peltier foi de $3 \mathrm{~mm}$ e a distância entre o ablador e o último termistor foi de $6 \mathrm{~mm}$. Na Figura 55 é possível visualizar como ficou a implementação completa. É importante observar que o termistor de referência foi isolado, com fita isolante, do ablador e demais termistores. A Figura 56 mostra a distância final, já citada, os componentes. 

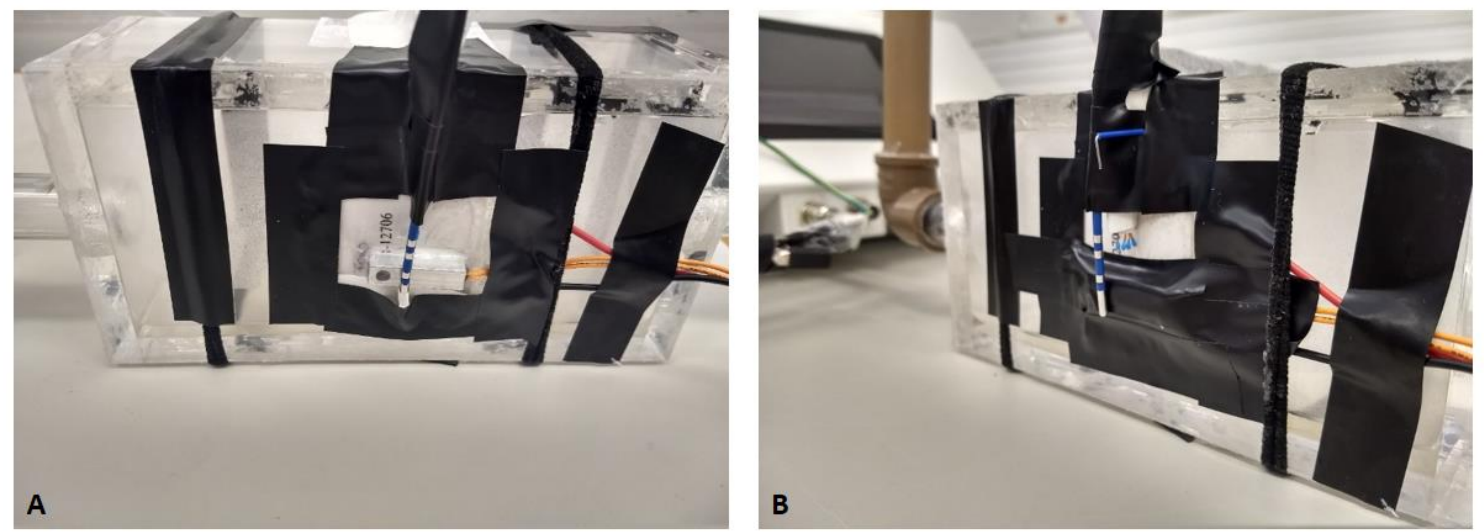

Figura 55 - Implementação dos termistores com o eletrodo de ablação e a caixa do Peltier. A: primeira parte concluída com a fixação de todos os sensores. B: isolamento entre o eletrodo de ablação e o termistor de referência do controlador.

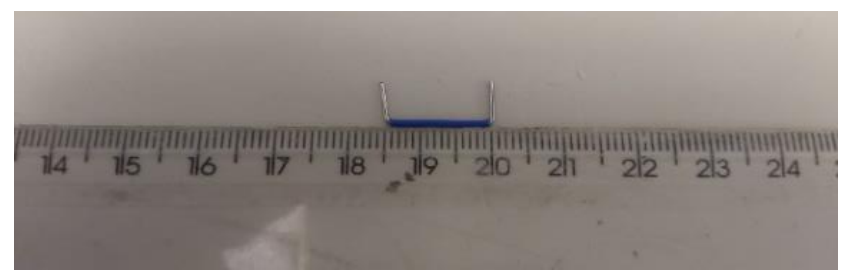

Figura 56 - Medida da distância total entre o Peltier e o eletrodo. A distância obtida foi de $1.5 \mathrm{~cm}$.

Neste ponto, toda a implementação de layout para que o experimento fosse realizado foi concluída. A água foi resfriada, $-4.3{ }^{\circ} \mathrm{C}$, Figura 57 , e as mangueira para a bomba de água foram conectadas na caixa de acrílico. O passo seguinte foi colocá-la dentro do agar-agar, Figura 58. E fixa-la em posição para que ela, a caixa, não se mexesse durante o experimento.

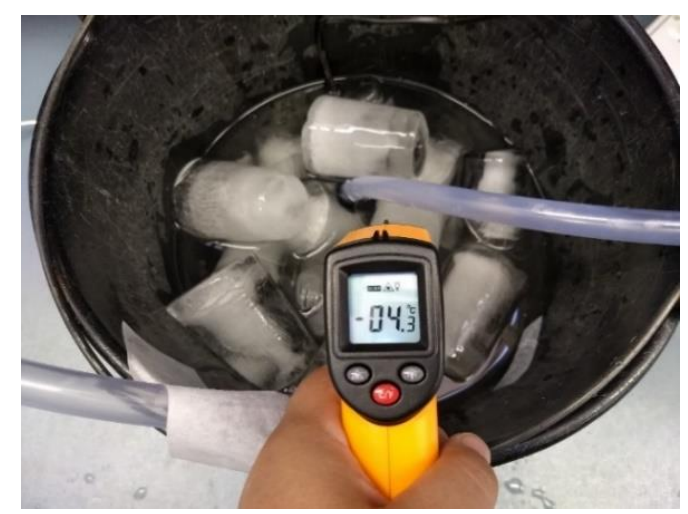

Figura 57 - Temperatura da água circulante dentro da caixa dos sensores. A temperatura medida foi de $-4.3^{\circ} \mathrm{C}$. A circulação de água é necessária para que seja realizada a convecção da parte quente do Peltier. 


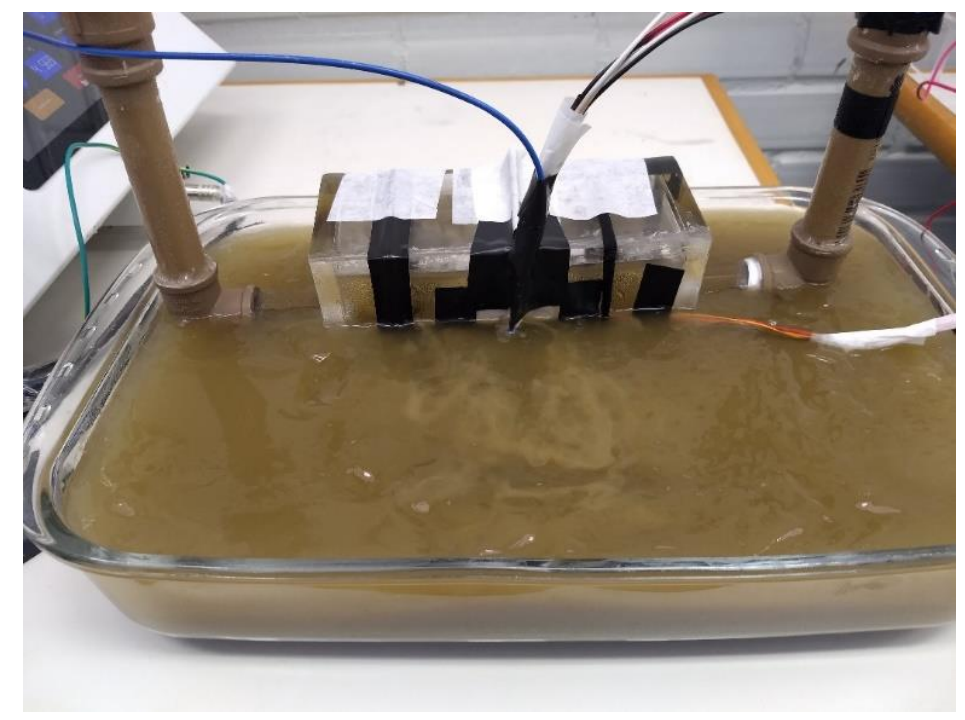

Figura 58 - Imersão da caixa com os sensores no gel agar-agar.

O eletrodo do ablador foi ligado em um gerador de radiofrequência, o SOFIA, desenvolvido na UnB e emprestado pelo $\mathrm{LaB}$ para que o experimento fosse realizado. Configuração utilizada no SOFIA: potência em 26.41W, impedância em $190.90 \Omega$ e referência em 60 . O controlador termoelétrico manteve a temperatura do Peltier em $0^{\circ} \mathrm{C}$.

As Figuras 59 e 60 mostram o layout final para a realização do experimento. A Figura 59 mostra o SOFIA e o recipiente com agar-agar e os sensores. A Figura 60 mostra a parte que fazia o controle da temperatura no peltier e a aquisição de dados. A Figura 61 mostra uma visão geral do que foi montado para a execução do experimento.

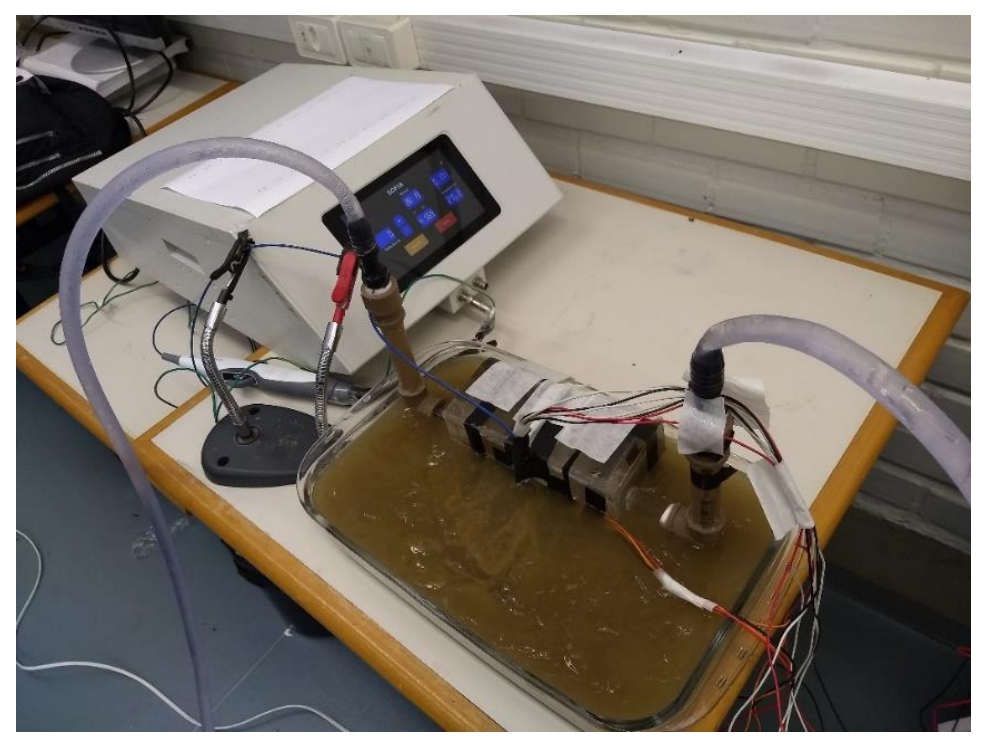

Figura 59 - Parte do layout do experimento com o SOFIA, gel agar-agar e a caixa com os sensores e o eletrodo. 


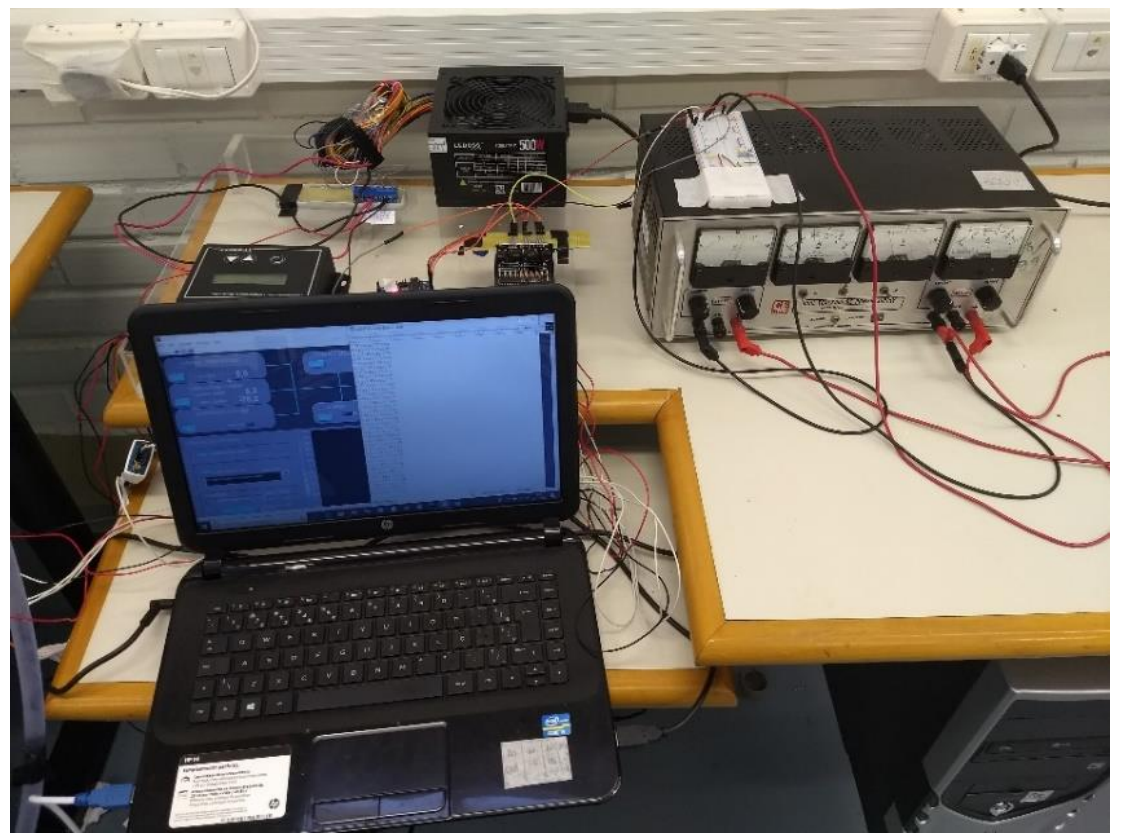

Figura 60 - Parte do layout com o computador, fonte, controlador, Arduino e placa.

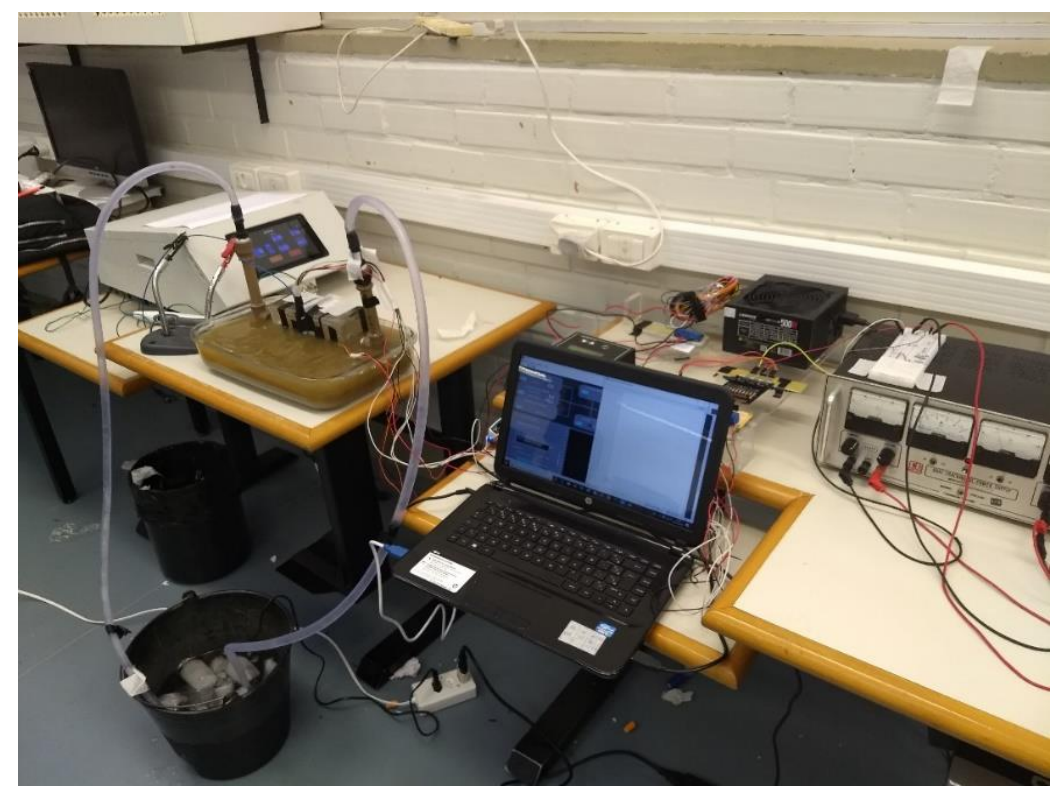

Figura 61 - Layout completo do experimento em andamento.

Assim, foi obtida a distribuição de temperaturas entre o ablador e o Peltier, Figura 62. O termistor mais próximo do ablador (term4, no gráfico) teve um pico de temperatura com o aquecimento chegando a quase $70^{\circ} \mathrm{C}$, os dois termistores seguintes (term 2 e term 3 ) obtiveram uma resposta semelhante - inicialmente esquentaram em temperaturas de cerca de $23^{\circ} \mathrm{C}$ e $34 / \mathrm{C}$, respectivamente. O termistor a maior proximidade do Peltier apresentou uma constância na temperatura de $7^{\circ} \mathrm{C}$. 


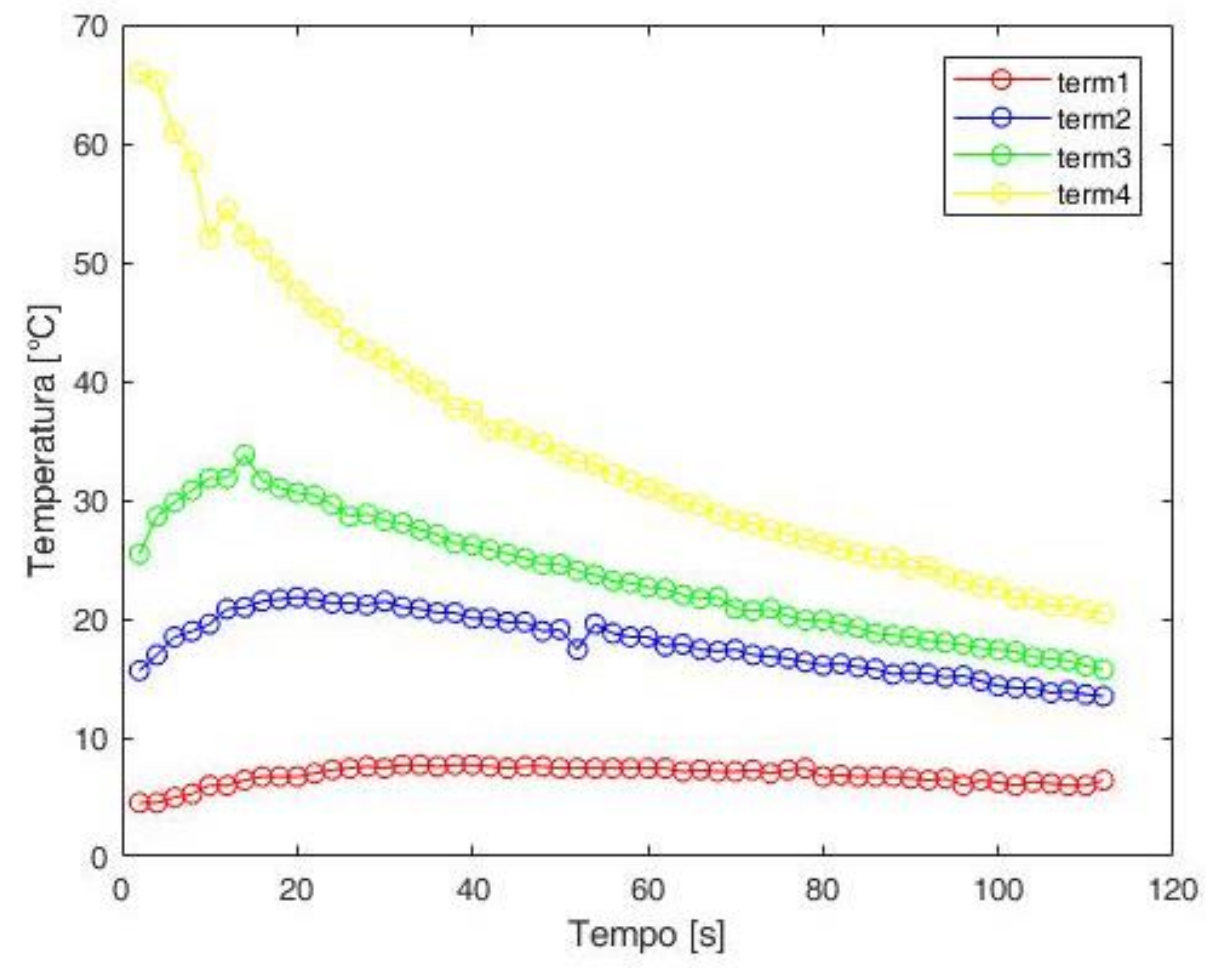

Figura 62 - Gráfico do resultado do experimento em bancada. Term1 é o termistor mais próximo do Peltier e term4 o mais próximo do ablador.

Dessa forma, o resultado do experimento mostra que com o resfriamento é possível criar uma barreira térmica e não superaquecer as regiões próximas a ele. Como as medidas ficaram um pouco irregulares, não há como definir exatamente a temperatura nos tecidos, porém, o que fica claro é, que no momento que o eletrodo está com a temperatura mais elevada, a barreira térmica se manteve abaixo de $10^{\circ} \mathrm{C}$. Lembrando que a desnaturação das células ocorre a partir de $50^{\circ} \mathrm{C}$. Onde se lê barreira térmica pode-se considerar como condição de contorno favorável ao aquecimento excessivo.

\subsection{RESTRIÇÕES}

O modelo matemático será desenvolvido em duas dimensões. Não serão usados modelos probabilísticos para estimar a área efetiva da ablação, levando em consideração a média e a variância das características de cada estrutura e indivíduo. Outra restrição é a não validação do cateter in vitro ou in vivo. Os experimentos se estenderão à simulação simplificada, em bancada, da ablação cardíaca para obtenção de dados relevantes à pesquisa. Além disso, os valores de relaxamento tecidual do coração e do esôfago não serão determinados, pois a complexidade do modelo biológico mais realístico não está dentro do escopo da dissertação. 


\section{CONCLUSÃO}

Nesta pesquisa, investiguei o uso de um sistema proposto para o controle da temperatura no esôfago durante o procedimento de ablação cardíaca por radiofrequência. Por meio de simulação numérica, testes com modelo físico e modelamento de um módulo esofágico obtive dados que comprovam que com uma condição de contorno favorável é possível gerar uma melhor distribuição de temperatura entre o átrio esquerdo e o esôfago, pois a temperatura propagada não ultrapassa os valores que proporcionam a necrose celular.

Primeiramente, construí a estrutura do CETER em látex e o resultado foi um produto ergonômico e homogêneo. Os chanfros para acoplar os sensores - termistor e Peltier - foram modelados. A rotina de trabalho foi definida e representa um protocolo padrão para a fabricação do módulo. Na dissertação também foi realizado o modelamento em 3D e construção de um protótipo. No entanto, somente em trabalhos futuros serão realizados a implementação dos sensores, bem como testes in vitro e in vivo, para validação do CETER.

A implementação da simulação numérica, pelo método de diferenças finitas em 2D, utilizando a equação bidimensional de Pennes, mostrou que, ao refrigerar a parede do esôfago é possível criar uma melhor distribuição de temperaturas para que haja uma proteção térmica. Futuramente, algumas implementações podem ser feitas, como: colocar a escala de acordo com a limitação dos órgãos estudados, utilizar o método de elementos finitos, gerar as simulações em 3D e levantar dados estatísticos dos cenários simulados.

Por fim, com o intuito de responder à pergunta de pesquisa, foi realizado um experimento em bancada que simulava a ablação cardíaca com RF no meio de agar-agar. Alguns testes foram realizados, o primeiro teste foi uma verificação da vedação do sistema e o segundo teste possibilitou o uso do controlador termoelétrico e da usabilidade do layout proposto. O experimento possibilitou a validação do modelo numérico. Foi criado uma condição de contorno favorável ao resfriamento de onde estaria o esôfago e foi possível obter dados que comprovam que há uma distribuição de temperatura ao longo da área em que é feita a ablação. As temperaturas nos termistores foram menores do que as temperaturas de desnaturação celular (cerca de $50^{\circ} \mathrm{C}$ ). E o erro RMS médio dos termistores foi de $0.5709^{\circ} \mathrm{C}$.

Assim, é possível concluir - por meio da simulação e do experimento em bancada que a construção de uma barreira térmica (condição de contorno favorável) pode evitar o superaquecimento dos tecidos, pois mantem a temperatura abaixo da temperatura de desnaturação celular. Pretende-se, em trabalhos futuros, realizar experimentos mais precisos que mostrem a distribuição da temperatura em cada tecido e que possam modificar de forma positiva o procedimento da ACRF para que fistulas átrio-esofágica sejam evitadas.

O próximo passo para o desenvolvimento é a validação do CETER em testes clínicos com cobaias animais e humanas, simulações numéricas com modelo matemático que simule com fidelidade o processo da ACRF e testes em bancadas para obtenção de dados pertinentes ao procedimento. Estes serão realizados em trabalhos futuros. 


\section{REFERÊNCIAS BIBLIOGRÁFICAS}

[1] D. B. de Oliveira, "Estudo sobre o efeito de técnicas preventivas na incidência de lesões esofageanas após ablação do átrio esquerdo para tratamento de fibrilação atrial," Universidade de São Paulo, 2015.

[2] J. E. Hall and A. C. Guyton, Tratado de Fisiologia Médica, 12th ed. Rio de Janeiro: Elservier Editora Ltda., 2011.

[3] J. Tarcísio et al., "Tratamento Cirúrgico da Fibrilação Atrial por Isolamento da Parede Posterior do Átrio Esquerdo em Doentes com Valvopatia Mitral Reumática Crônica," Arq. Bras. Cardiol., vol. 83, pp. 32-35, 2004.

[4] E. J. Benjamin, P. A. Wolf, R. B. D. Agostino, H. Silbershatz, W. B. Kannel, and D. Levy, "Clinical Investigation and Reports Impact of Atrial Fibrillation on the Risk of Death The Framingham Heart Study,” Am. Hear. Assoc., pp. 946-953, 1998.

[5] F. A. Justo et al., "Aspectos epidemiológicos da fibrilação atrial,” Rev. Médica São Paulo, vol. 93, no. 1, pp. 1-13, 2014.

[6] A. C. Guyton, Fisiologia Humana, 6th ed. Mississippi: Editora Guanabara, 1988.

[7] A. V. Brick, T. Seixas, C. Portilho, and A. K. Peres, "Tratamento intra-operatório da fibrilação atrial crônica com ultra-som," $28^{\circ}$ Congr. Nac. Cir. Cardíaca, vol. 16, no. 4, pp. 337-349, 2001.

[8] A. C. Guyton and J. E. Hall, Fisiologia Humana e Mecanismos das Doenças, 6th ed. Rio de Janeiro: Guanabara Koogan, 1988.

[9] R. A. de Sousa, "Cateter esofágico para medição de temperatura durante procedimento de ablação cardíaca por rádiofrequência," Universidade de Brasília, 2009.

[10] A. C. Azevedo, I. F. de Lima, V. Brito, M. J. Centeno, and A. Fernandes, "Tamponamento cardíaco : uma complicação rara da caracterização venosa central relato de um caso clínico," Rev. Bras. Anestesiol., p. 5, 2016.

[11] N. Katz-Agranov and M. I. Nevah Rubin, "Severe esophageal injury after radiofrequency ablation - a deadly complication.," World J. Gastroenterol., vol. 23, no. 18, pp. 3374-3378, 2017.

[12] C. Alberto et al., "Resultados da ablação cirúrgica por radiofreqüência da fibrilação atrial crônica," Rev. da Soc. Bras. Cardiol., vol. 19, no. 3, pp. 301-308, 2014.

[13] E. J. Berjano and F. Hornero, "A cooled intraesophageal balloon to prevent thermal injury during endocardial surgical radiofrequency ablation of the left atrium: A finite element study," Phys. Med. Biol., vol. 50, no. 20, 2005.

[14] M. Y. Khan, W. J. Siddiqui, P. Iyer, A. Dirweesh, and N. Karabulut, "Left Atrial to Esophageal Fistula : A Case Report and Literature Review," Am. J. Case Rep., vol. 17, pp. 814-818, 2016.

[15] T. D. Bahnson, "Strategies to Minimize the Risk of Esophageal Injury durings Catheter Ablation for Atrial Fibrillation," Pacing Clin. Electrophysiol., vol. 32, no. 2, pp. 248-260, 2009. 
[16] H. A. E. W. Lim, G. A. Cogert, C. S. Cameron, V. Y. Cheng, and D. A. Sandler, "Atrioesophageal Fistula During Cryoballoon Ablation for Atrial Fibrillation," J. Cardiovasc. Electrophysiol., vol. 25, no. 2, pp. 208-213, 2014.

[17] S. P. M. Camilleri and D. P. K. Monahan, "Upper gastrointestinal complications following ablation therapy for atrial fibrillation," Neurogastroenlogy Motil., no. March, pp. 1-11, 2017.

[18] J. E. Cummings et al., "Esophageal Luminal Temperature Measurement Underestimates Esophageal Tissue Temperature During Radiofrequency Ablation Within the Canine Left Atrium : Comparison Between $8 \mathrm{~mm}$ Tip and Open Irrigation Catheters," J. Cardiovasc. Electrophysiol., vol. 19, no. 6, pp. 641-644, 2008.

[19] S. de S. Rodrigues, "Desenvolvimento de um sistema de controle de fluxo esofagiano para o tratamento da obesidade," Universidade de Brasília, 2008.

[20] P. M. C. de Paula, "Proposta de aplicabilidade do módulo CFE ® e sua instrumentação para análise fisiológica do esôfago," Universidade de Brasília, 2010.

[21] V. B. Richter, "Evidências na prática de cicatrização tecidual com biomembrana de látex," Universidade de Brasília, 2016.

[22] K. E. Barret, S. M. Barman, S. Boitano, and H. L. Brooks, Fisiología Médica de Ganong, 23rd ed. México: Mc Graw Hill, 2010.

[23] S. G. Quallich, K. E. Kriege, and P. A. Iaizzo, "The Effects of Radiofrequency or Cryothermal Ablation on Biomechanical Properties of Isolated Human or Swine Cardiac Tissues," IEEE J. Transl. Eng. Heal. Med., vol. 4, 2016.

[24] M. Q. Rossignolli, “Radiofrequência: Revisão,” 2013.

[25] M. C. D. Rambo, "Modelagem matemática da distribuição de temperatura na ablação por radiofrequência devido a um ponto com uma fonte de corrente elétrica," Universidade Regional do Noroeste do Estado do Rio Grande do Sul, 2008.

[26] L. Magalhães et al., "Diretrizes Brasileiras de Fibrilação Atrial," Rev. da Soc. Bras. Cardiol., vol. 106, no. 2, pp. 1-15, 2016.

[27] K. Lemola et al., "Computed Tomographic Analysis of the Anatomy of the Left Atrium and the Esophagus Implications for Left Atrial Catheter Ablation," Am. Hear. Assoc., vol. 110, no. 24, pp. 3655-3660, 2004.

[28] R. M. John, S. Kapur, K. A. Ellenbogen, and J. N. Koneru, "Atrioesophageal fistula formation with cryoballoon ablation is most commonly related to the left inferior pulmonary vein," Hear. Rhythm, vol. 14, no. 2, pp. 184-189, 2016.

[29] D. P. Redfearn et al., "Esophageal Temperature Monitoring During Radiofrequency Ablation of Atrial Fibrillation," J. Cardiovasc. Electrophysiol., vol. 16, no. 6, pp. 589-593, 2015.

[30] G. A. Smith and A. M. Kleiman, "Case Report of a Rare Iatrogenic Atrialesophageal Fistula and Anesthetic Considerations for Primary Surgical Repair," J. Cardiothorac. Vasc. Anesth., vol. 31, pp. 1-14, 2017.

[31] J. B. Velotta, C. R. Vasquez, R. M. Bolman, and M. C. Dasilva, "Left AtrialEsophageal Fistula Repair after Radiofrequency Catheter Ablation for Atrial 
Fibrillation,” Thorac. Cardiovasc. Surg. reports, vol. 2, no. 1, pp. 13-15, 2013.

[32] P. Liu, J. Liu, and H. Duan, "Thermal modelling for endocardiac radiofrequency ablation : comparison of hyperbolic bioheat equation and Pennes bioheat equation with finite element method," Cornell University, 2012.

[33] D. INCROPERA, F.; DEWITT, Fundamentos de Transferência de Calor e Massa, 6th ed. 2008.

[34] F. Strazza and R. M. Riberi, "Projeto de micro-adega climatizada de baixo custo," Escola Politécnica da Universidade de São Paulo, 2015.

[35] L. F. Patsko, “Aplicações, Funcionamento e Utilização de Sensores," Universidade de São Carlos, 2006.

[36] J. Conrradi, “Termistor,” Controle e automação industrial, 2016. [Online]. Available: http://www.corradi.junior.nom.br.

[37] H. E. Silva, “Análise microclimática de um edifício histórico em clima temperado: limites sustentáveis para a correta conservação dos materiais," Assoc. Nac. Tecnol. do Ambient. Construído, vol. 15, no. 2, pp. 65-77, 2015.

[38] M. H. Shimabukuro, A. F. C. Do Carmo, and E. H. Alcântara, "Using Visual Analytics techniques to evaluate the Data Quality in environmental datasets," Bol. Ciencias Geodésicas, vol. 22, no. 3, pp. 542-556, 2016.

[39] V. Stornelli, G. Ferri, A. Leoni, and L. Pantoli, "Sensors and Actuators A : Physical The assessment of wind conditions by means of hot wire sensors and a modifed Wheatstone bridge architecture," Sensors Actuators A Phys., vol. 262, pp. 130-139, 2017.

[40] J. A. Moura, “Aplicações térmicas e tecnológicas do efeito Peltier," UNIVASf, 2016.

[41] C. F. De Matos, F. Galembeck, and J. G. Zarbin, "Nanocompósitos Multifuncionais de Látex de Borracha Natural e Nanoestruturas de Carbono," Rev. Virtual Química, vol. 9, no. 1, pp. 73-96, 2017.

[42] T. M. Torquato, S. R. F. Rosa, M. F. F. Rosa, and R. Tahmassebi, "Úlceras por pressão: proposta de um colchão inteligente derivado do látex natural (Hevea brasiliensis)," Sci. Eng. J., vol. 24, no. 2, pp. 47-57, 2015.

[43] M. do C. dos Reis, "Sistema indutor de neoformação tecidual para pé diabético com circuito emissor de luz de LEDs e utilização do látex natural," Universidade de Brasília, 2013.

[44] R. M. Irastorza, A. D'avila, and E. Berjano, "Thermal latency adds to lesion depth after application of high-power short-duration radiofrequency energy: Results of a computer-modeling study," J. Cardiovasc. Electrophysiol., vol. 1, no. 1, pp. 1-6, 2017.

[45] J. J. P. Erez, A. D'avila, and E. Berjano, "Electrical and Thermal Effects of Esophageal Temperature Probes on Radiofrequency Catheter Ablation of Atrial Fibrillation : Results from a Computational Modeling Study," J. Cardiovasc. Electrophysiol., vol. 26, no. 5, pp. 556-564, 2015.

[46] G. Deshazer, D. Merck, M. Hagmann, and D. E. Dupuy, "Physical modeling of 
microwave ablation zone clinical margin variance," Med. Phys., vol. 43, no. April, pp. 1764-1776, 2016. 
ANEXO 


\section{ANEXO 1: CIRCUITO PARA AQUISIÇÃO DE DADOS DA TEMPERATURA}

Segue em anexo o circuito implementado para a leitura dos termistores.

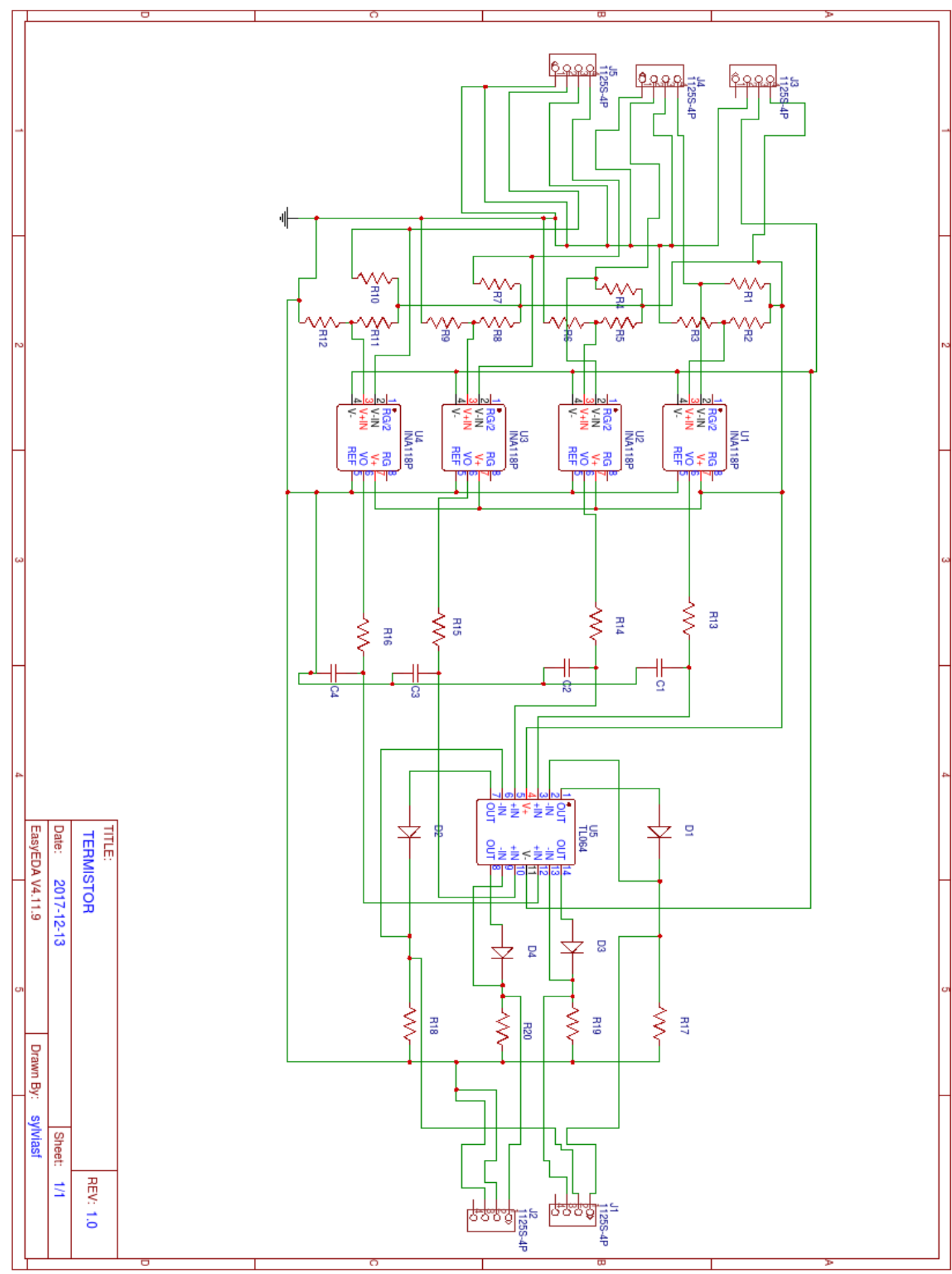

